\title{
RESEARCH-LED TEACHING IN HIGHER EDUCATION: PERSPECTIVES OF CAMBODIAN AND NEW ZEALAND ACADEMICS
}

BY

SOVANNDEN MOEUNG

\begin{abstract}
A thesis
submitted to the Victoria University of Wellington in partial fulfilment of the requirements for the degree of

Master of Education
\end{abstract}

Victoria University of Wellington 2013 


\begin{abstract}
Research and teaching are the core mission of most universities in the 'knowledge society' during the $21^{\text {st }}$ century. However, the exact nature of the connection between research and teaching is not obvious. The purpose of this study was, therefore, to contribute to the debate by investigating how research was used to inform teaching and to benefit student learning. The study also intended to identify the benefits and drawbacks of Research-Led Teaching (RLT) for academics as well as to examine what scholars considered to be the main supports and challenges academics experienced while practicing RLT.
\end{abstract}

A qualitative single-case study was employed for this study. The perceptions and experiences from twelve academics from a university in Cambodia and another in New Zealand (NZ) were collected using semi-structure interviews. Official documents such as university policy, position descriptions from each university and course outlines or syllabi from each participant were collected for the purpose of document analysis. This study provided an understanding of RLT and the current practices of academics. Four conceptualizations of RLT emerged: teaching informed by academics' own research; teaching informed by other people's recent research; teaching that promoted student engagement in research; and teaching informed by academics' performance research. The findings indicated that the benefits of RLT outweigh the drawbacks. The lack of support was the main challenge for Cambodian participants. However, some participants suggested personal commitment, and institution accountability were important factors that support RLT. Perceptions and experiences that academics in Cambodian and NZ tertiary education have about the practices of RLT provide a useful basis for consideration of possible changes and how to implement such changes.

Recommendations to enhance the practice of RLT include the emphasis of RLT in position descriptions and strategies to promote the implementation of RLT in institutions to ensure the improvement of student learning. Academic professional development and university supports are also needed for enhancing RLT practices. 


\section{ACKNOWLEDGEMENTS}

I acknowledged that this thesis would not have been possible and completed without guidance, support, encouragement and love of a number of individuals who I wish to show my sincere appreciation here.

My deepest gratitude goes to my primary supervisor, Mike Taylor and equally, no less important in any means, my secondary supervisor, Dr. Liz Jones. Their insightful supervision of this study, broad base of knowledge and professional perceptiveness has contributed to my development as a researcher. I will be forever thankful to their limitless guidance, critical and constructive comments, and timely feedback, which have given me the motivation and strength along the way of this thesis. Also, their patience, understanding and sympathy of my academic and personal situations have created the best conditions for me to complete my thesis.

My special thanks to all the enthusiastic Cambodian and NZ lecturers for their willingness to participate and contribute to this study. I appreciated the time they made in their busy day to share their valuable thoughts, knowledge and experiences with me which has made the research findings all the more interesting and this study possible.

My sincere appreciation goes to Dr. Xiaodan Gao from the Student Learning Support Service for her inspirational conversation with me when things did not go smoothly, great patience to read the bits and pieces of my writing, and constructive academic writing advice. A special thank also goes to my proof reader, Oliver, for his wonderful professional work in putting together my final draft within a very limited time frame. I wish to extend my great thanks to the faculty administrators, Sheila and Alex, for their assistance with many of the important issues, as well as the librarians who were always ready to help. I will never forget my friends for their positive encouragement and frank on-going conversations when needed.

My sincere acknowledgement goes to NZAID for sponsoring my Master of Education in Aotearoa, New Zealand and unconditionally supporting me through conducting this research. My humble thanks also goes to the Victoria University of Wellington Faculty of Education for sponsoring my data collection in Cambodia and New Zealand. I would like to also thank the Victoria University of Wellington for handy support and resources made available that contributed to this exciting, satisfying and challenging undertaking. 
I am greatly indebted to my beloved family who meant so much to me. To my loving mum, I owe you a lot of care as I had to leave you behind during my study here. You gave me endless love and encouragement to accomplish my ambition. To my husband who has stood by me all the way through my research journey in New Zealand without any complaints and shared his eternal love, unconditional support, and special care, thank you so much. You have given me the strength to keep on being motivated and persistent. To my dearest sisters, brother and extended family members, I profoundly thank for your on-going support, prayer for success of my study and your faith in my ability to achieve my goal. Finally, I dedicate this thesis to all of you, especially my loving late father. Without your brilliant advice, I would not have reached this far. May you rest in peace. 


\section{TABLE OF CONTENTS}

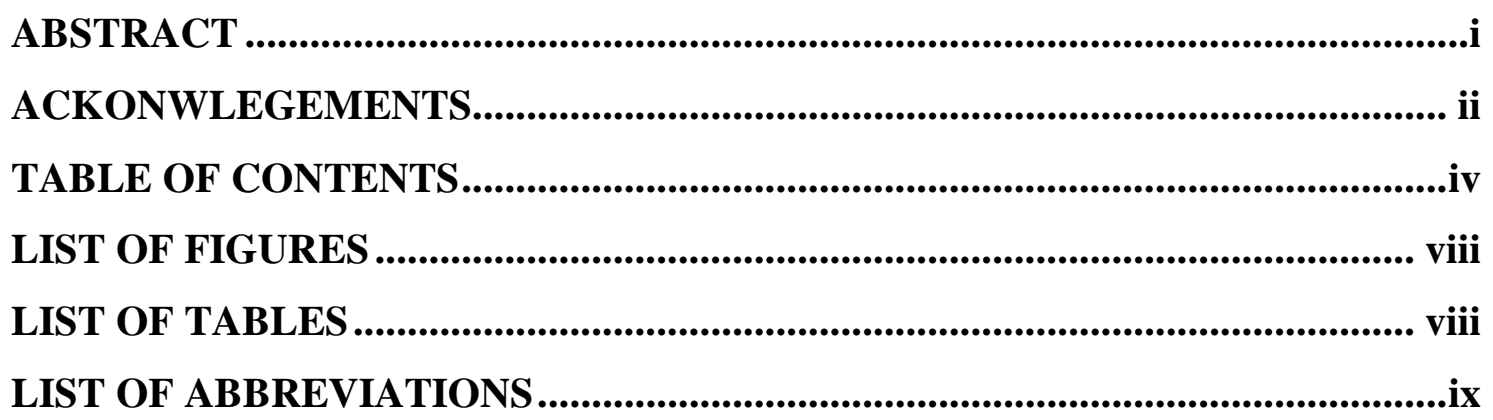

\section{CHAPTER 1: INTRODUCTION}

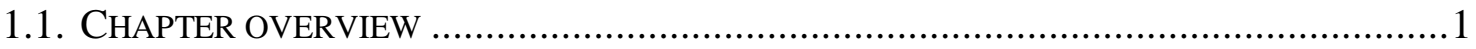

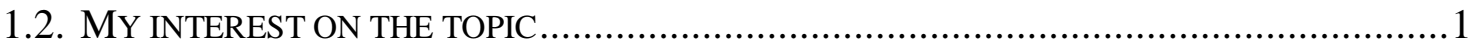

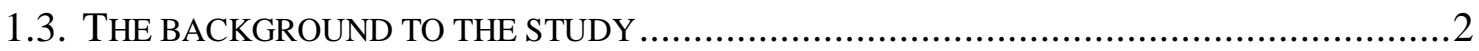

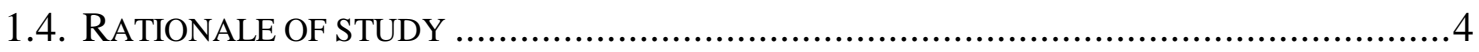

1.5. RLT IN CAMBODIAN AND NEW ZEALAND HIGHER EDUCATION..............................4

1.6. RESEARCH OBJECTIVES \& QUESTIONS..............................................................

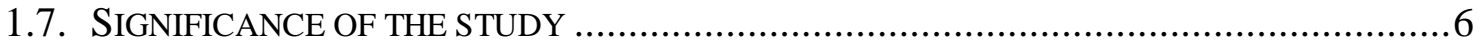

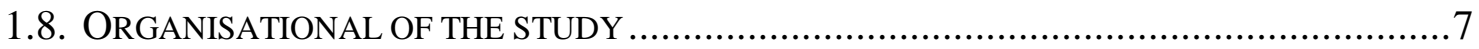

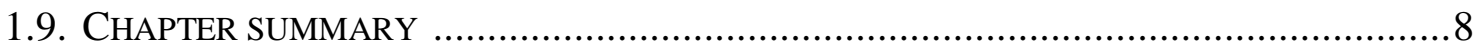

\section{CHAPTER 2: CONTEXT OF STUDY}

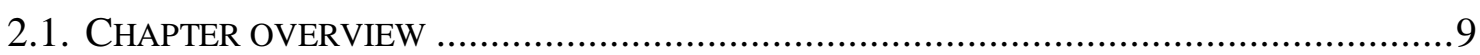

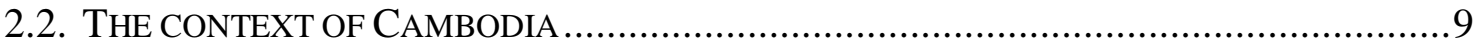

2.2.1. Geographical and physical features......................................................... 9

2.2.2. The history and development of higher education .................................. 10

2.2.3. The current higher educational system .................................................... 11

2.2.4. The status of research in higher education ............................................. 12

2.3. ThE CONTEXT OF NEW ZEALAND ................................................................. 14

2.3.1. Geographical and physical features....................................................... 14

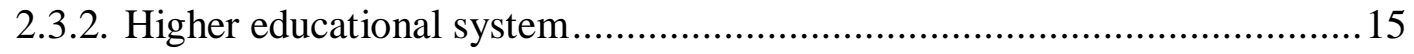

2.3.3. The emphasis of research in higher education ....................................... 16

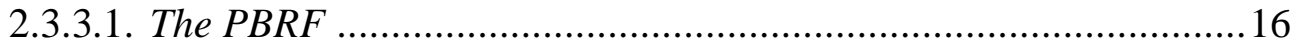

2.3.3.2. The PBRF funding formula .................................................. 17

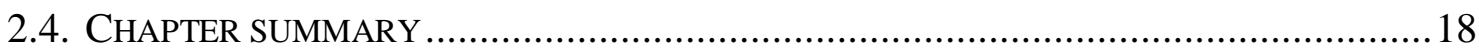




\section{CHAPTER 3: LITERATURE REVIEW}

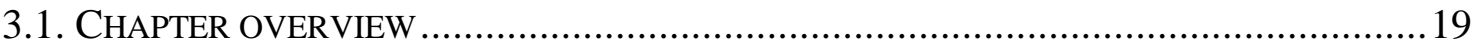

3.2. CONCEPTIONS OF RESEARCH, TEACHING AND STUDENT LEARNING ......................... 19

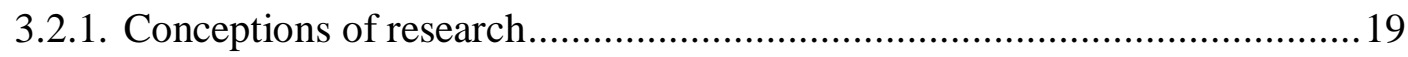

3.2.2. Conceptions of teaching and student learning ...................................... 21

3.3. CONCEPTIONS OF THE LINK BETWEEN RESEARCH AND TEACHING ..........................22

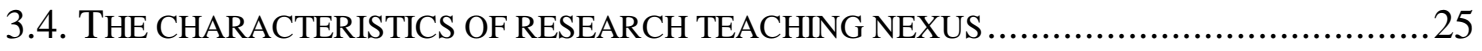

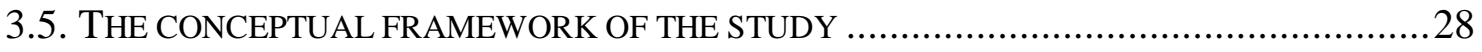

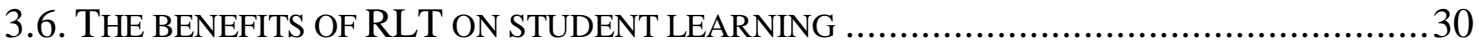

3.7. THE DRAWBACKS OF RLT ON TEACHING AND LEARNING ....................................... 31

3.8. THE OPPORTUNITIES AND CHALLENGES OF RLT IMPLEMENTATION .........................32

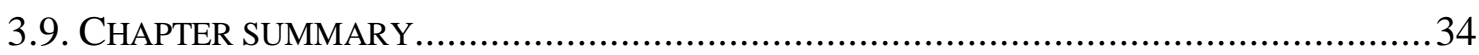

\section{CHAPTER 4: RESEARCH METHODOLOGY}

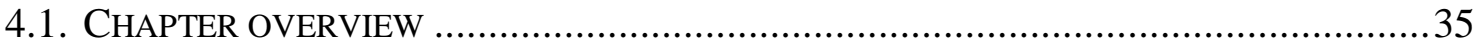

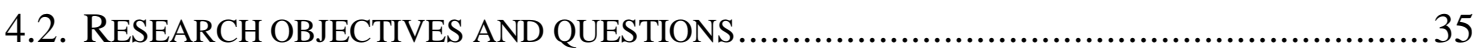

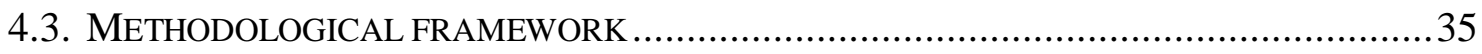

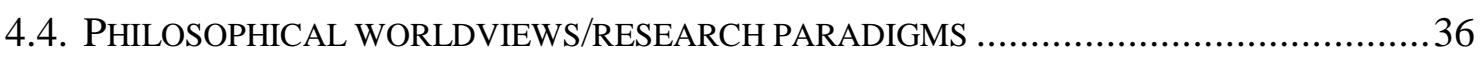

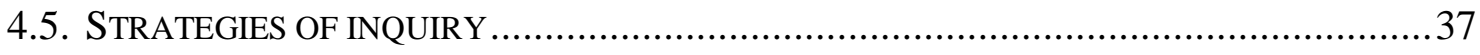

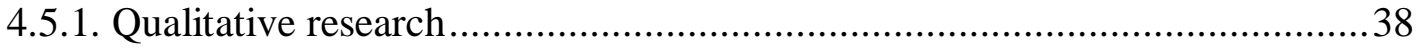

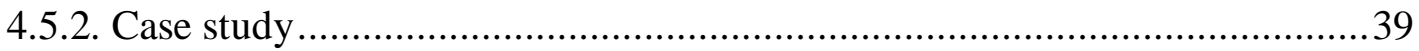

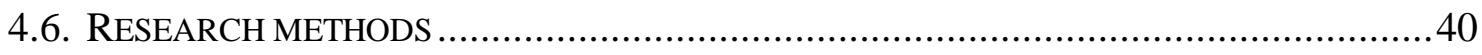

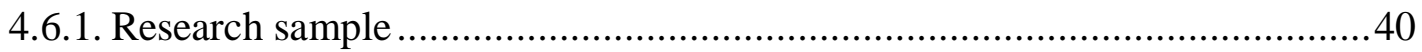

4.6.2. Research participants and recruitment procedures................................... 41

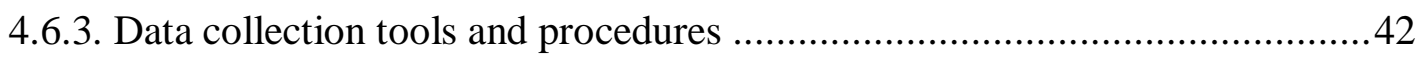

4.6.4. Data analysis process and methods ........................................................ 45

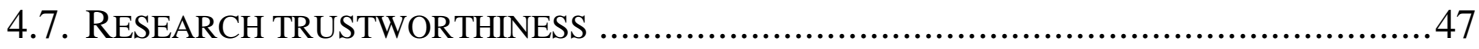

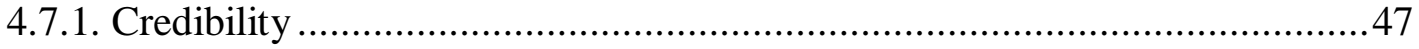

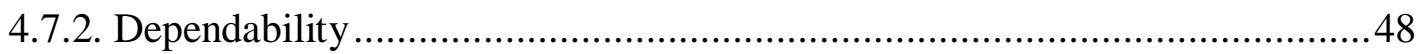

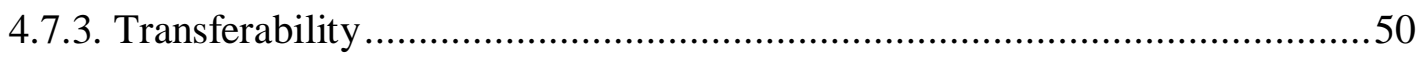

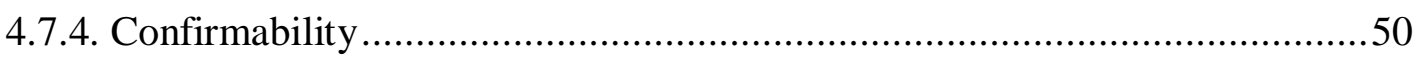

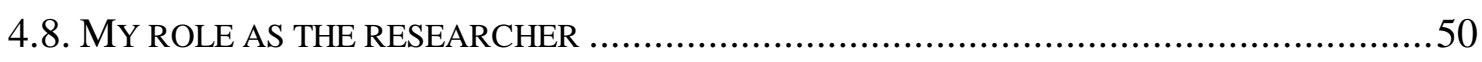

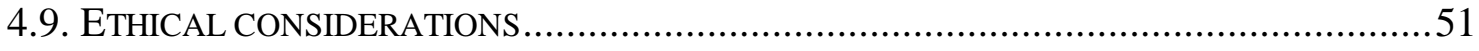

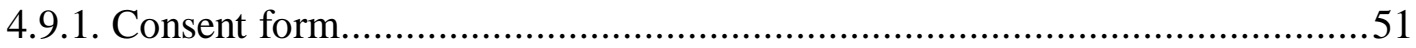




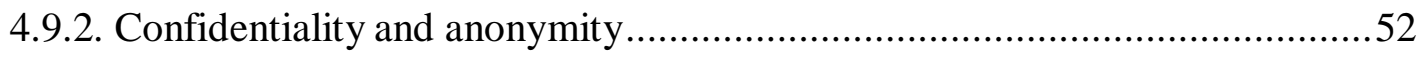

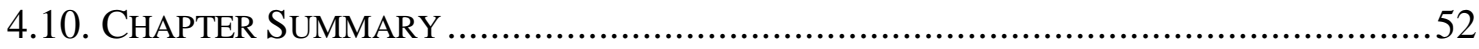

\section{CHAPTER 5: RESEARCH FINDINGS}

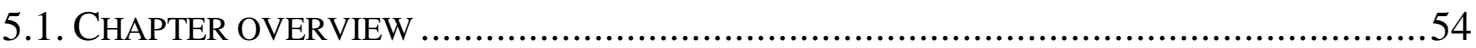

5.2. ACADEMICS' PERCEPTIONS, ATTITUDES, AND PRACTICES OF RLT ….......................54

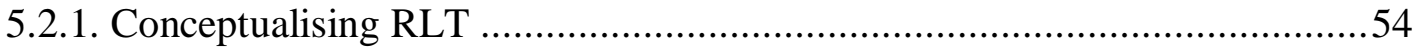

5.2.2. Academic' practices of RLT and attitudes towards RLT ............................57

5.2.2.1. The practices of RLT at institutional level...................................57

5.2.2.2. The practices of RLT at personal level ..........................................59

5.3. PERCEIVED IMPACT OF RLT ON ACADEMICS AND STUDENTS .................................6 63

5.4. THE SUPPORTS AND CHALLENGES IN CONDUCTING RLT …..................................6

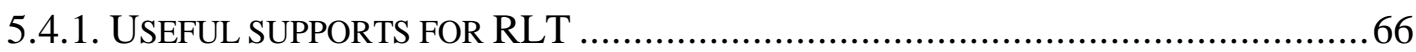

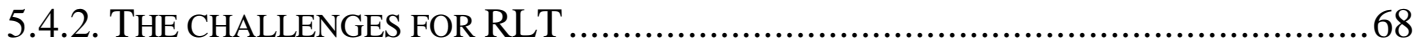

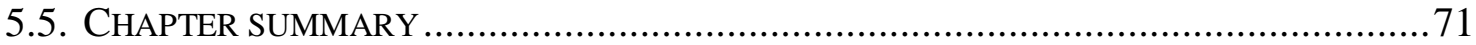

\section{CHAPTER 6: DISCUSSION AND CONCLUSION}

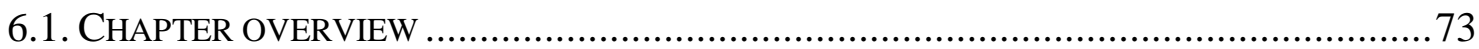

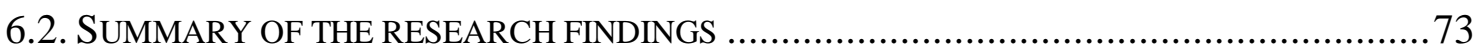

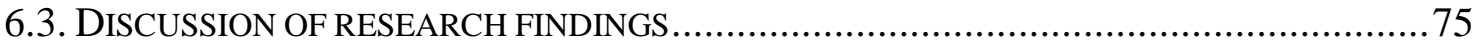

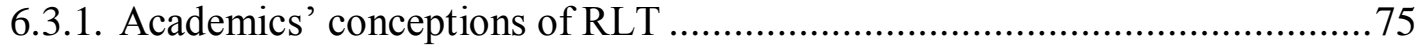

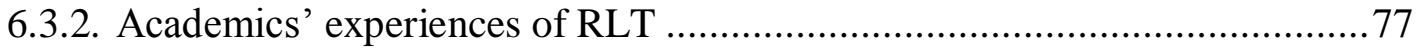

6.3.3. Academics' attitudes towards RLT........................................................... 78

6.3.4. The impacts of RLT on academics and students ....................................... 78

6.3.5. The supports and challenges of RLT on academics ................................. 79

6.4. IMPLICATIONS FOR POLICY AND PRACTICES ….............................................. 79

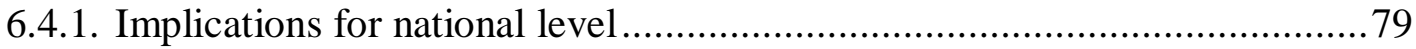

6.4.2. Implications for institutional level.............................................................. 80

6.4.3. Implications for individual level........................................................... 80

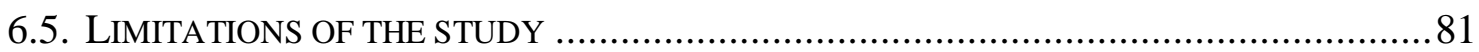

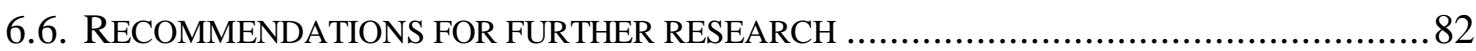

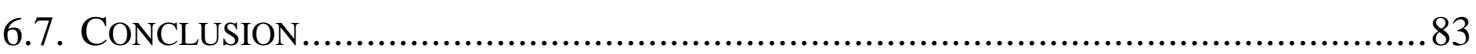

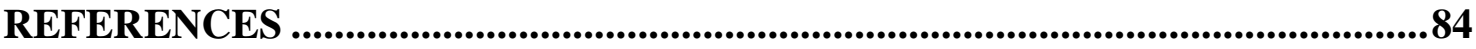


Appendix A: Invitation email to participate in research ...................................... 91

Appendix B: Research information sheet for Cambodia ............................................92

Appendix C: Research information sheet for New Zealand .....................................94

Appendix D: Consent form for Cambodian participants ......................................... 96

Appendix E: Consent form for New Zealand participants...................................... 97

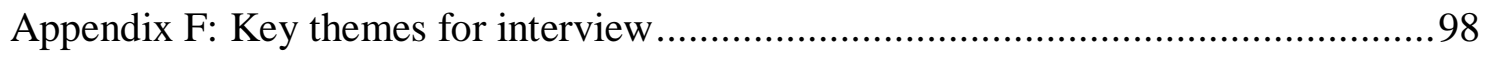

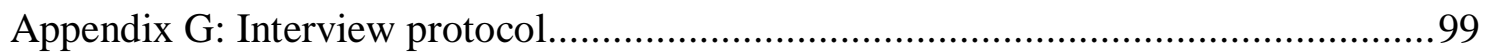

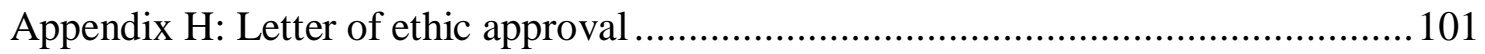

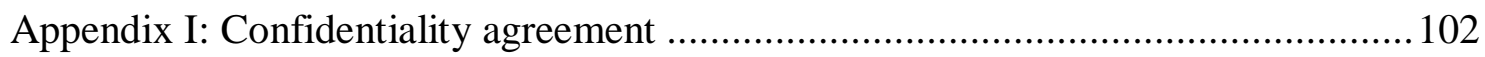




\section{LIST OF FIGURES}

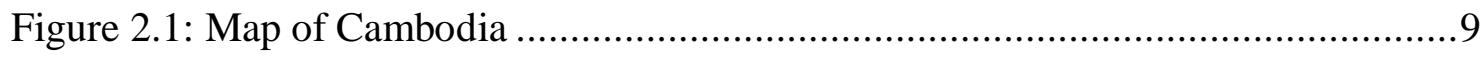

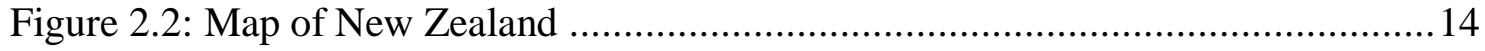

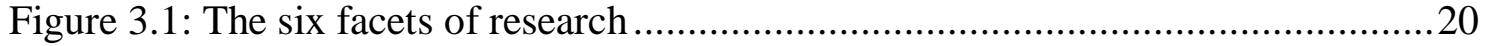

Figure 3.2: Conceptions of teaching and student learning .................................. 21

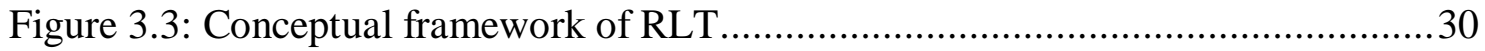

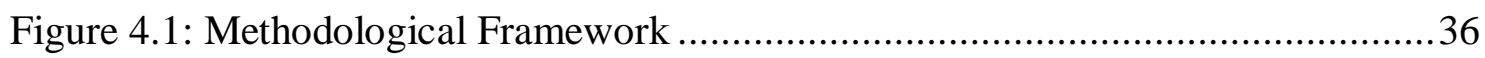

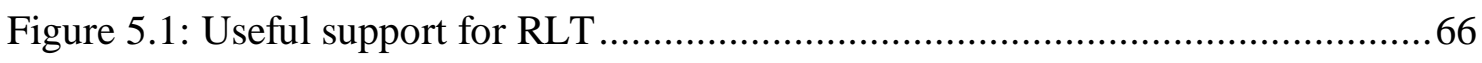

Figure 5.2: Useful components in promoting RLT across the institution .................... 71

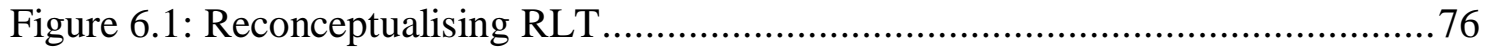

\section{LIST OF TABLES}

Table 3.1: International literature scope for literature review.................................23

Table 3.2: Principles to guide implementation of RLT ….......................................... 33

Table 4.1: The summary of the characteristics of the participants .............................42

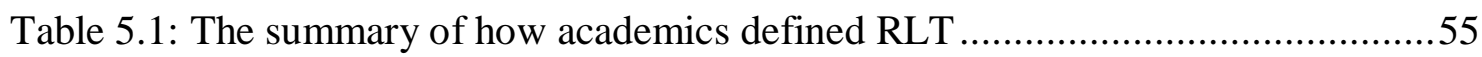

Table 5.2: The summary of academics' practices of RLT .......................................59 


\section{LIST OF ABREVIATIONS}

$\begin{array}{ll}\text { CL } & \text { Cambodian Lecturer } \\ \text { HE } & \text { Higher Education } \\ \text { HEI(s) } & \text { Higher Education Institution(s) } \\ \text { MoE } & \text { Ministry of Education (New Zealand) } \\ \text { MoEYS } & \text { Ministry of Education, Youth and Sports (Cambodia) } \\ \text { NHEAP } & \text { National Higher Education Action Plan } \\ \text { NZ } & \text { New Zealand } \\ \text { NZL } & \text { New Zealand Lecturer } \\ \text { PBRF } & \text { Performance-Based Research Fund } \\ \text { R\&D } & \text { Research and Development } \\ \text { RGC } & \text { Royal Government of Cambodia } \\ \text { RLT } & \text { Research-Led Teaching } \\ \text { RTN } & \text { Research-Teaching Nexus } \\ \text { TEC } & \text { Tertiary Education Commission } \\ \text { TEO } & \text { Tertiary Education Organisations }\end{array}$




\section{CHAPTER 1: INTRODUCTION}

\subsection{Chapter overview}

In a 'knowledge society', universities are expected to be places for teaching knowledge dissemination or transmission - and also places for researching - knowledge creation (Scott, 2002). Within this notion, there is an increasing debate over the link between teaching and research, especially the benefits of this link. The terms used to talk about this link included Research-Led Teaching (RLT), Research-Teaching Nexus (RTN), and Research-based teaching. Although, the benefits are unclear, it is, nevertheless a strong discourse in Higher Education (HE). Also, many Higher Education Institutions (HEIs) in the $21^{\text {st }}$ century have included RLT as one of the core missions.

This single-case study design was conducted to investigate how RLT is perceived and practiced by two groups of academics in Cambodia and New Zealand (NZ) and to discover how the concept of RLT has been operationalized in the university teaching practices of the two academic groups. It also examined the extent to which RLT has been supported by the institution and the extent to which RLT has contributed to and impacted on academics and students. The study finally identified the challenges for academics to practice RLT.

This chapter, therefore, describes how I become interested in the topic and provides background information about the conception of RLT in recent times. It then addresses RLT in NZ and Cambodian HE contexts. The rationale for conducting this study is also explained before the presentation of research objectives and research questions. The chapter discusses the significance and the structure of the study.

\subsection{My interest on the topic}

The passion for conducting this research grew from my personal observation, reflection and experiences as an international post-graduate student in NZ and was also inspired by my belief in the benefits of RLT.

Being a student in Cambodia, I had a very limited understanding about research as there was very little emphasis on research during my time of study. Also, the term 'research' 
was not heard frequently in the teaching and learning environment. I thought that research or researcher was not related to teaching or learning. Therefore, when I became a teacher I did not really see the importance of the link between research and my teaching or my students' learning. Other than reading to broaden my general knowledge, I did not involve myself or my students in conducting any research or draw on research to inform my teaching. I relied on textbooks and my knowledge from reading books or general articles for my class.

Upon undertaking post-graduate studies in NZ, I experienced different ways of teaching and learning. From my observation, academic staff and students in NZ were encouraged to conduct, read and use research in relation to their teaching and learning in postgraduate study. For instance, as a student I was expected to read a lot of research, not only textbooks, for my class assignments to enhance my understanding of the course. The term 'research' was frequented and my awareness about research improved.

Through my own experiences with different ways of learning and teaching, I became interested in the relationship between research and teaching/learning and wished to investigate this relation. In particular, how research can be used to inform teaching and students learning from the perspectives of Cambodian and NZ academics. With this inquiry in mind, I began the journey of the present study. I strongly feel that this study can broaden my understanding about RLT which is very useful for my teaching profession in Cambodia.

\subsection{The background to the study}

In a 'knowledge society' all students - certainly all graduates - have to be researchers. Not only are they engaged in the production of knowledge; they must also be educated to cope with the risks and uncertainties generated by the advance of science" (Scott, 2002, p.13). In this sense, in order for education at the university level to fulfill its educational role in a 'knowledge society', it must be embedded in research. Universities are asked to position themselves within a knowledge society. A knowledge society is one created for the need to develop further through their research, service and education.

Due to this conception of the role of a modern university, the study on the linkage between teaching and research has been very popular for debate in HE research. There 
are a number of theoretical studies (Badley, 2002; Brew, 2003; Clark, 1997; Coate, Barnett \& Williams, 2001; Griffiths, 2004; Hattie \& Marsh, 1996; Healy, 2005; Schapper \& Mayson, 2010) and empirical studies (Deakin, 2006; Neumann, 1992; Ramsden \& Moses, 1992; Robertson, 2007; Robertson \& Bond, 2001, 2005; Trowler \& Wareham, 2008; Zamorski, 2002) conducted to understand this relationship. In these studies, several terms were used to investigate this link: teaching-research nexus (Neumann, 1992), research-based teaching (Clark, 1997), RLT (Brew, 2003; Deakin, 2006; Schapper \& Mayson, 2010; Zamorski, 2002); or RTN (Griffiths, 2004; Robertson, 2007).

In the last few decades, a quantitative approach has been used to investigate the relationship between research and teaching. For example, a study by Ramsden and Moses (1992) saw little or no foundation for a belief in the existence of a positive causal relationship between high levels of research activities and effective undergraduate teaching. Similarly, Hattie and Marsh (1996) in their meta-analysis of 58 studies found no significant relationship between research productivity and teaching effectiveness. However, until recently the nature of this link has been poorly understood (Robertson, 2007).

In recent times, a qualitative approach using in-depth interviews to explore the perceptions of administrators, academics, and/or students has been employed to examine the relationships. Academics often assert that there is a positive relationship between teaching and research (Brew, 2003; Brew \& Boud, 1995). Other literature indicates that research and teaching should be linked for better quality of teaching and student learning. Hattie and Marsh (1996) suggest that marrying teaching and research by enhancing their relationship is a desirable aim of universities. As stated in Zetter (2002), this is because in a research-led institution the linkage between teaching and research can provide benefits for teaching practice and research as well as the enhancement of the student experiences. Moreover, the link between teaching and research has been seen and viewed as valuable in terms of the connection that RLT has to knowledge and understanding at advanced levels of learning (Deakin, 2006). Healey (2005) also recognizes that students are most likely to benefit from research with reference to understanding and depth of learning when they are involved with research themselves through, for example enquiry-based learning. 
In this study, I used the term 'RLT' as a key term of the investigation. For the purpose of my study, the term 'RLT' is not used to investigate the nexus between teaching/learning and research itself, but is mainly used to focus on how research is used to inform teaching and benefit student learning. This will be elaborated in detail in the conceptual framework of the study in Chapter 3.

\subsection{Rationale of the study}

Since the relationship between teaching and research has been seen and viewed as valuable in terms of the connection that RLT has to knowledge and understanding at advanced levels of learning (Deakin, 2006), the rationale for this study was to increase the understanding that we have about this increasingly recent important idea in HE.

Moreover, although the benefits of RLT are unclear, it is nevertheless a strong discourse in HE. This study, makes no attempt to address the merits (or otherwise) of RLT. Rather, it seeks to explore the meanings given by academics to this term and their experiences of the phenomena as part of their professional working lives.

\subsection{RLT in the context of Cambodia and NZ}

Similarly to some other South-East Asian countries, Cambodia is facing a missing generation of academics in the immediate post-conflict era and there is a lack of welltrained researchers in the countries as seen in the low numbers of lecturers with $\mathrm{PhDs}$ across all universities both, public and private (Kwok, Chan, Heng, Kim, Neth \& Thon, 2010). This has meant Cambodian HE is far behind other western universities in term of knowledge creation through research.

The lack of research capacity can be one of the reasons for the lack of well-trained researchers. Overall, this may stem from deeper cultural traditions in Cambodia (Pit \& Ford, 2004). Education in Cambodia could be described as "Banking Education" in which students are regarded as knowledge receivers, while educators are considered as knowledge providers through the transmission model (Freire, 1972). Although research has been put in national policy, the emphasis on RLT is very low due to the lack of support to produce it. There is no specific allocation of budget to research activities compared with institutional support and operation in HE (Kwok et al., 2010). Governmental funding for the HE sector is low compared to other sub-sectors of education over the past years, leaving the growth of the sector reliant on privatization 
(Clayton \&Yuok, 1997). A recent study by Kwok et al. (2010) emphasizes that there is nearly a complete absence of government-initiated or government-commissioned research in public universities. In short, the lack of national support and institutional emphasis on research drives Cambodian universities toward teaching and degreegranting institutions. Furthermore, the universities have largely continued to use traditional didactic teaching styles - the opposite approach to learning through inquiry in knowledge society (Pit \& Ford, 2004).

Different from Cambodia, HE in NZ has moved towards the concept of RLT in all universities. Those universities or institutions stress or incorporate strategies for enhancement of the nexus of teaching/learning and research in their missions and much attention and support were provided for research-led activities.

Regarding the enhancement of the linkage of teaching/learning and research, Jenkins and Healey (2005) suggested that the attention and action should firstly begin with institutional policies and if supported by national policies would become more viable. These researchers also stressed that the key factor to generating more efforts from institutions is increasing the national and international competition.

In NZ, government's policies appear to support the enhancement of the teachingresearch relationship at its HEIs. The Education Act 1989 stated that in universities, research and teaching are closely interdependent and most of their teaching is done by people who are active in advancing knowledge.

Moreover, NZ government has paid a great deal of attention and established Performance-Based Research Fund (PBRF) aiming at enhancing the quality of research produced in HEIs (Smart, 2009). The PBRF is a research-funding model that is based on an assessment of the quality and productivity of research at all universities and participating tertiary education institutions. This program provides an incentive to research-active institutions to gain the best rating in the assessment. However, it does not recognize the teaching of academic staff (see more detail in Chapter 2).

\subsection{Research Objectives and Questions}

The study has three main objectives: (1) to explore the perceptions, attitudes and experiences of the Cambodian and NZ academics on RLT; (2) to explore academics' perceptions on the contributions and impacts of RLT on teaching and student learning; 
(3) to explore academics' perceptions on the opportunities and barriers for the implementation of RLT.

To achieve these objectives, the following research questions were formulated:

1. What understanding do academics in Cambodia and NZ have of the term 'RLT'?

2. To what extent do the academics engage in RLT? Why or why not?

3. What are the academics' attitudes towards RLT?

4. How do the academics perceive RLT impacts on their teaching and student learning? Why?

5. What are the supports and challenges for RLT?

To answer the research questions I adopted a qualitative approach and a single-case study design. Six academics from universities in Phnom Penh and Wellington were recruited using purposeful and convenient sampling techniques. They serve as the key participants and units of analysis in this study. Semi-structured interviews of 12 academics was used to synthesize (with data from document analysis) university policy, position description, employment contracts, and course syllabi.

\subsection{Significance of the study}

This study is worthwhile to investigate for four main reasons. Firstly, although various studies on the relationship between research and teaching have been well published, there seems to be a lack of empirical research on the practice of RLT in Cambodia and NZ. Most studies are theoretical rather than empirical. Perhaps this is due to the fact that it is generally assumed that there is little or no relationship between research and teaching performance (Hattie \& Marsh, 1996; Ramsden \& Moses, 1992). Therefore, this study would hopefully provide some valuable insights into the roles of research in informing teaching and student learning.

Secondly, this study contributes to the literature on RLT in HE in Cambodia and NZ and thus will provide an important reference for future studies about RLT.

Thirdly, this study draws on two groups of academics who are relatively at early stages of RLT. One group of academics is based in a NZ university. These academics were selected for this study because they have recently been introduced to RLT. The second 
group of academics is based in a Cambodian university. These academics have little or no experience with aspects of RLT. Both groups give significance to this study.

Finally, there is rhetoric in HE policy document of research capacity building and teaching in the university. Thus, having understood different perceptions and practices of Cambodian and NZ academics on RLT as well as support and challenges for RLT, the study would provide some empirical evidence of how RLT is operated at the ground level. This can be significant for policy implications at the institutional level and the development of strategies to improve RLT on individual levels.

\subsection{Organisational structure of the study}

This study is presented in six chapters. Chapter One (this chapter) gives the introduction to the study. It provides an overall background of RLT in HE and a brief context of RLT in both settings. Furthermore, this chapter gives the rationale for this study, the research objectives, research questions, and the significance of the study.

Chapter Two presents the context of each study: detailed Cambodian and NZ context including general contextual information, HE system, its development and issues or any programs related to RLT.

Chapter Three is the literature review. This chapter discusses the conception of research, teaching and student learning; and the relationship between these three terms. It also describes the perceptions and opinions of international researchers on the topic and draws lessons that can be applied to the study. The conceptual framework of the study is also provided. Moreover, the chapter addresses the benefits and drawbacks of RLT on academics and students as well as the perceived useful support and challenges for the practice of RLT.

Chapter Four contains research methodology. This chapter describes the theoretical and methodological framework that underpins the study. It explains how the study was conducted and how the data was processed, analyzed, and presented. In addition, it illustrates the management and supervision of ethical requirements. This chapter includes ways in which research trustworthiness could be obtained.

Chapter Five is the description of the study findings. This chapter reports the four different conceptions and practices of RLT: teaching informed by academics, personal 
research, others' research, academics' teaching performance research and teaching encouraging students' engagement in research. In terms of the practices towards RLT, the study reveals academics' perceptions of RLT have an influence on their practice of RLT. The participants of this study perceived the positive impacts of RLT outweigh the negative ones. To make RLT possible physical support and accountability in institutional and individual commitment are perceived as useful and motivating.

Chapter Six contains discussion of the research findings and the conclusion. It discusses the research findings in broad themes and in relation to the literature. The chapter discusses the theoretical and applied contributions of this study. Limitations and implications for future research are explained. The chapter ends with a concluding statement.

\subsection{Chapter summary}

This study was inspired by reflections on the two different experiences of teaching and learning at university in Cambodia and NZ. Although many studies have been conducted to investigate the nexus between research and teaching, the understanding about this relationship is very complicated and limited. This study does not intend to report on the quality of the link between research and teaching but seeks to explore how RLT is perceived and practiced by academics via their experiences. This study hopes to provide empirical data of the conceptualization and practices of RLT from Cambodian and NZ academics' perspectives using single-case design through interviews and document analysis. 


\section{CHAPTER 2: \\ CONTEXT OF THE STUDY}

\subsection{Chapter overview}

This chapter gives an overview of the higher educational situation in relation to research in both settings: Cambodia and NZ. At first the chapter explains Cambodian contextual details such as geographical and physical features of the country, the HE system including its history, development, and issues related to RLT. Following this the chapter addresses NZ's context including geographical and physical features, the HE system and its' emphasis of RLT in HE through PBRF.

\subsection{The context of Cambodia}

\subsubsection{Geographical and physical features}

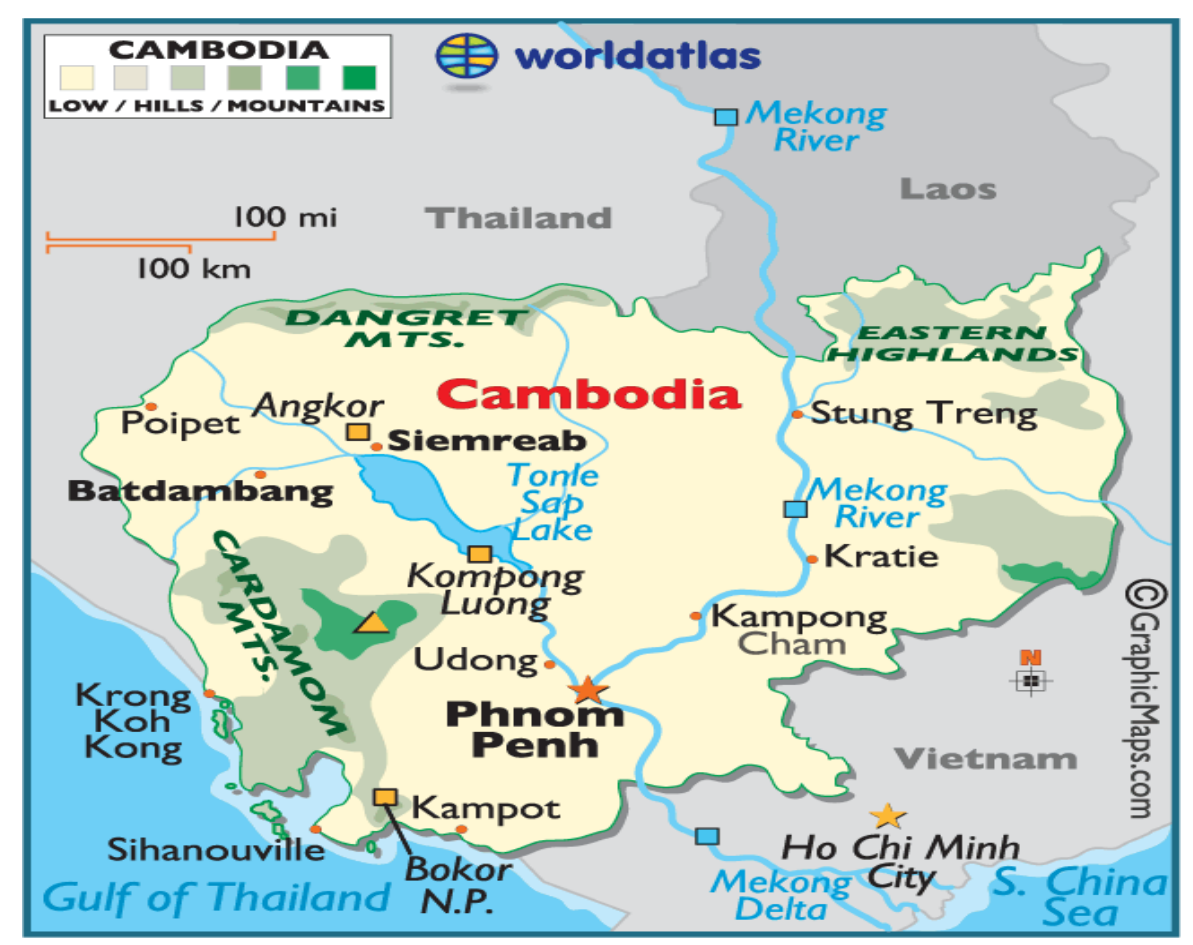

(Source: Retrieved from http://www.worldatlas.com/webimage/countrys/asia/kh2.htm\#.)

Figure 2.1. Map of Cambodia

Cambodia, or Khmer, is officially named the "Kingdom of Cambodia". Cambodia is a small South-east Asian country with a total landmass of 181,035 square kilometers and a population of almost 15 million people. The country has a 443 kilometres coastline on the Gulf of Thailand to the south-west and shares a 2,572 kilometre land border with 
three other countries: 1,228 kilometres with Vietnam to the east, 803 kilometres with Thailand to the north-west and 541 kilometres with the Lao People's Democratic Republic to the north-east (Figure 2.1). Cambodia's official language is Khmer. The majority of Cambodian people in regional areas may communicate amongst themselves with local dialects or regional languages. The main differences between these dialects are tone and some vocabulary.

\subsubsection{The history and development of $\mathbf{H E}$}

The history of Cambodian education can be seen to have a number of stages. This has left the education system, particularly HE, with a missing generation of scholars until now (Kwok, et al., 2010). To better understand the current situation of Cambodian HE, it is important to learn this history.

Before 1863, the vast majority of people were illiterate and Buddhist temples or Pagodas were the only places of formal education (Ayres, 2000). Monks taught children, mainly boys, how to read and write as well as carpentry skills (Ayres, 2000). HE (as we know it today) did not exist during that period. The French Colonization (1863-1953) was a turning point in the history of Cambodian education. Within this period Cambodian's went from learning at Pagodas to learning in schools with the introduction of western subjects such as arithmetic, history, and geography (Chandler, 2008). That said, HE during the French colonial period was not widely available although a secondary school and an institute (the National Institute of Juridical, Political and Economic Sciences) were established (Ayres, 2000). In 1953, Cambodia gained independence from the French state. During that time, King Norodom Sihanouk made significant improvements in primary, secondary and higher education. The number of primary and secondary schools increased dramatically throughout the country, along with the establishment of eight new universities (Chandler, 2008). The total student enrolment in HE rose from 347 in 1953 to 10,800 in 1967 (Sloper, 1999). This signified a significant development period in the history of Cambodian HE.

However, this growth did not last long. There was a coup against King Norodom Sihanouk by Lon Nol in 1970. The civil wars between 1970 and 1975 disrupted the education program, which resulted in poor quality of education and graduates (Chandler, 2008). After that, between 1975 and 1979 during the Khmer Rouge regime, education was one of the sectors most affected. Educational facilities and materials 
were demolished while $80 \%$ to $90 \%$ of educated people such as teachers and university professors were killed (Clayton 1998; Sloper, 1999). As a consequence, the education system established in the previous 20 years was totally destroyed during the Pol Pot regime.

After the collapse of the Khmer Rouge regime in 1979, the new regime was totally dependent on neighbouring communist countries and mainly the Soviet Union (Chandler, 2008). HE was highly influenced by these countries in terms of materials, trials and training assistance (Ayres, 2003). Overall, HE did not make much progress between 1979 and 1989 (Clayton \& Ngoy, 1997). However, Cambodia's political and economic liberalization in the early 1990s and an influx of foreign aid from Western countries significantly helped the restoration and growth of HE in Cambodia. While this may appear to be positive, it meant that HE was once again influenced by western ideologies (Pit \& Ford, 2004).

The early 1990s was a transition period in the chronology of Cambodian modern HE. The need for a skilled labour force and economic development has prompted realizations of the importance of $\mathrm{HE}$ and led the Cambodian government to reform $\mathrm{HE}$ (Ahrens \& Kemmerer, 2002). This led to the National Higher Education Action Plan (NHEAP) in 1995 with four main goals: "improvement in the quality of instruction, provision of relevance in academic programs, promotion of efficiency in operations, and development of effectiveness in institutional management" (Sloper, p. 279). This educational reform, along with the market economy, has led to another rapid expansion of the HE sector, with enrolment jumping from 2,357 in 1985 to 13,465 in 1996 (Minxuan, 1998).

Given this historical context, Cambodia has shown several issues and challenges in reform and development of HE in Cambodia. The challenges include the lack of financial resources and qualified human resources in all fields (Pit \& Ford, 2004).

\subsubsection{The current higher educational system}

Under education law, Cambodian HE sets out to promote scientific, technical, cultural and social research as well as reinforce the development of science and technology for education and support for research (Ministry of Education, Youth and Sports (MoEYS), 2010). HE in Cambodia is divided into two interrelated streams: an academic stream (supervised by MoEYS) and a vocational stream (supervised by the Ministry of Labour 
and Vocational Training) (Chet, 2009). All HEIs, including private institutions, are structured by 'registration' with the MoEYS and no Cambodian HEI has been attributed by an independent, external body (Innes-Brown, 2006). Moreover, HEIs are administered under a 'parent' ministry related to the principal fields or cluster of disciplines offered (Chet, 2009). Recently, there were 63 HEIs: 18 public universities and 45 private universities (MoEYS, 2010).

HEIs in Cambodia are further classified into three categories: the royal academies (undertaking research), universities (teaching and researching), and institutes or independent specialized schools (teaching-track institutions and undertaking no organized research). Theoretically, the function of the royal academy is more about research. However, due to the lack of human resources, the royal academy is working on training programs like other HEIs, leaving very little room for research activities and thus consultancy (Chet, 2009).

Under current regulations, the Royal Government has distinguished a university from other types of HEIs based on the following minimum characteristics:

- Offering multi-disciplinary fields of study from bachelor degrees onward, with several faculties;

- Offering a foundation studies programme;

- Offering teaching and research activities using modern methodologies;

- Having sufficient teaching staff with competency and experience;

- Having adequate library, laboratory, materials and other facilities to carry out teaching-learning and research;

- Having space and classrooms compliant with pedagogical norms;

- Having three mandatory faculties, namely: Arts, Humanities and Language; Mathematics and Science; and Social Science, and at least 2 additional faculties. (Chet, 2006, p.19)

\subsubsection{The status of research in $\mathrm{HE}$}

Within the knowledge-based economy, HE and especially universities should move beyond the concept of knowledge transmission - where teaching involves a direct transferring and receiving of knowledge - to knowledge advancement or creation, which is RLT (Kwok, et al., 2010). However, due to a shortage of human resources in the post-conflict society, Cambodian universities still focus mainly on knowledge 
transmission teaching (MoEYS, 2011) while research is not perceived as a core mission of universities (Kwok et al., 2010). Chet (2009, p.161) pointed out that "research is still in a dark stage". In other words, research has been an underdeveloped area in Cambodian HE, both public and private. Chet (2009) asserted that there is very limited research conducted by HEIs as the government budget for research activities is very small or completely neglected. Some leading public universities conduct research using funds from foreign donors or partners while research is almost completely unseen in private universities and not prioritized (Chet, 2009; Kwok et al., 2010). Chamnan and Ford (2004) argued that cultural tradition plays an important role in explaining the inadequate response to research facilitation. Traditionally in Cambodia, children are taught to memorize things and not to question parents, teachers, or any other elders as is not considered "polite". Thus, research in this sense, maybe considered impolite because it is fundamentally questioning already established literature. However, it should be noted that "this culturalist argument can be overstated in a deterministic or an essentialist way, especially when it is presented as an invidious contrast between Western and Eastern civilisations" (Kwok et al., 2010, p.29).

Despite the lack of research at university level, the MoEYS has shown some significant recognition for the importance of research by establishing two research departments at the ministerial level: the Scientific Research Department and the Pedagogical Research Department. However, research activity is still limited and needs much improvement (Chet, 2009). To increase the emphasis of research in HE an initiative on the policy of Research and Development (R\&D) has been approved by the Royal Government of Cambodia (RGC) on $1^{\text {st }}$ July, 2010 (MoEYS, 2010). The purposes of the policy include the following:

- To enhance the quality of HE in Cambodia by transforming the institutions into research centers for developing and creating new knowledge;

- To increase the opportunities for cooperation with national and international networks;

- To advance human resource capacity, creativity and innovation. (MoEYS, 2010)

Along with this policy, the following points are counted as core principles for the policy:

- To ensure that a wide range of research is conducted in all disciplines; 
- To improve the capacity of researchers and to develop the research capability of all HEIs;

- To promote respect for research ethics, protection of research achievements and dissemination of research results;

- To encourage the utilization of research results for producing new knowledge and development. (MoEYS, 2010)

To achieve the purpose of the policy, a five-year master plan (2011-2015) has been established with a number of strategic plans and actions to improve research capacity, research quality, cooperative research, research reports, research ethics and permission for research, international cooperation, and marketing R\&D (MoEYS, 2011). By 2015, the RGC expects the nine public HEIs supervised by MoEYs to increase the number of Cambodian academics publishing from 5\% in 2011 to $20 \%$ in 2015 and the percentage of academic staff with PhD from 5\% in 2011 to 9\% in 2015 (MoEYS, 2011).

\subsection{The context of New Zealand}

\subsubsection{Geographical and physical features}

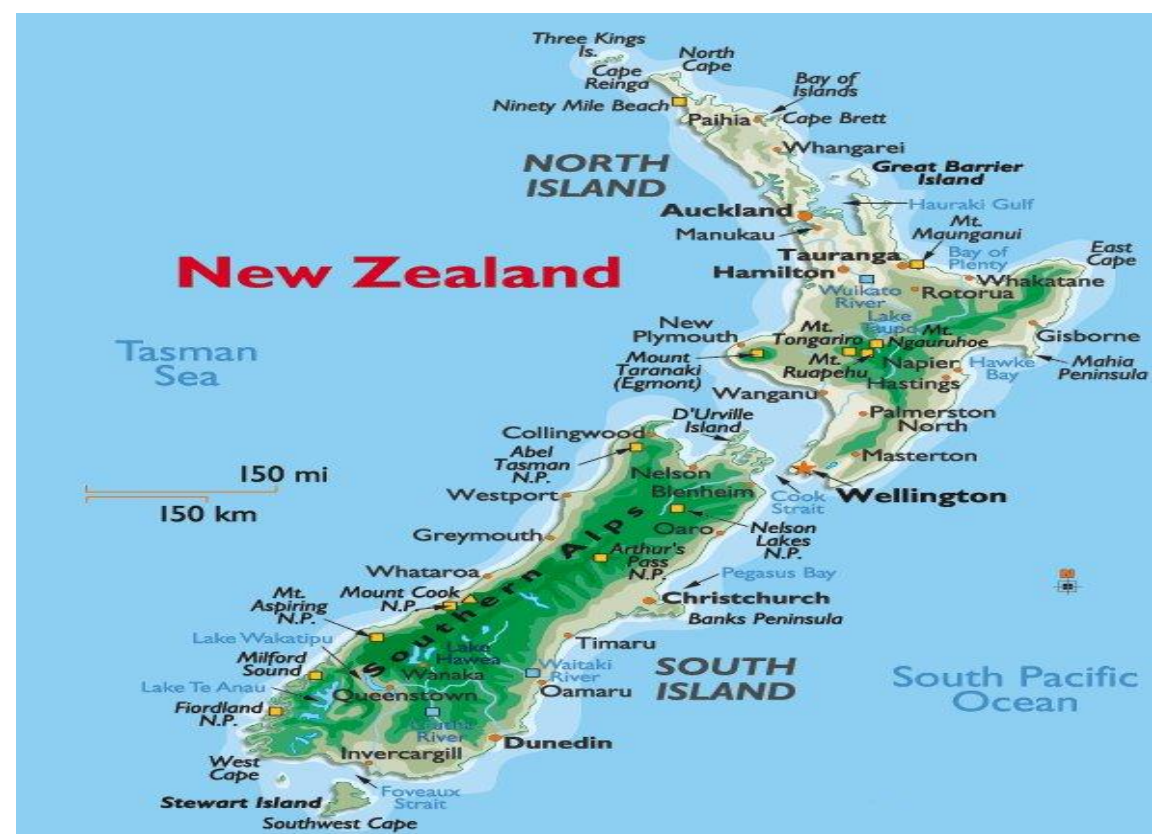

(Source: Retrieved from http://www.worldatlas.com/webimage/countrys/oceania/nzmaps.htm)

Figure 2.2. Map of New Zealand

New Zealand, also known as Aotearoa, is a small remote island country with a population of about four million people in the south-western Pacific Ocean. The country geographically consists of two beautiful main islands: North and South Islands. It is situated 1,500 kilometres to the east of Australia and about 1,000 kilometres south of 
the Pacific island nations of New Caledonia, Fiji, and Tonga (Figure 2.2). The official languages of NZ are English and Māori.

\subsubsection{Higher educational system}

In NZ, "Tertiary Education Organisations (TEO) can be grouped into six sub-sectors including universities, polytechnics, wānanga, private training establishments, industry training organisations and other tertiary education providers" (Ministry of Education (MoE), 2010, p. 18). Public tertiary education institutions include universities, polytechnics and wānanga. Universities are significantly concerned with advanced learning and research while polytechnics primarily focus on vocational training at certificate and diploma levels, offering applied degrees. Wānanga mainly provides programmes with an emphasis on the application of mātauranga Māori.

In NZ, there are eight universities which offer a wide range of tertiary education: Auckland University of Technology, Lincoln University, Massey University, University of Auckland, University of Canterbury, University of Otago, University of Waikato, and Victoria University of Wellington.

In the modern society universities are very crucial for teaching, research, and the development of society as a whole (Scott, 2002) because universities are involved in the basic skills needed in the profession. Universities are also crucial in cultivating what can be called basic life skills including analysis, flexible thinking, communication, adaptation and innovation. In fact, the NZ government under section 162 of the Education Act (1989) stated that all universities must possess characteristics as specified below:

- They are primarily concerned with more advanced learning, the principal aim being to develop intellectual independence.

- Their research and teaching are closely interdependent and most of their teaching is done by people who are active in advancing knowledge.

- They meet international standards of research and teaching.

- They are a repository of knowledge and expertise.

- They accept a role as critic and conscience of society. (p. 248)

In this sense, the NZ government expects universities to enable a wide range of students to successfully complete degrees and postgraduate qualifications; undertake 
international research; and create and share knowledge that contributes to NZ's economic and social development and environmental management (MoE, 2010). In accordance with high expectations, all universities have three core roles:

1. To undertake research that adds to the store of knowledge;

2. To provide a wide range or research-led degrees and postgraduate education that is of an international standard;

3. To act as sources of critical thinking and intellectual talent. (MoE, 2010, p.18)

As shown above, the NZ government devotes attention and action to support tertiary education. The government believes that "an effective tertiary education system will underpin NZ's ability to prosper economically and build a strong society into the future" (MoE, 2010, p.24). The government has increased the expenditure on tertiary education at an average rate of about $6 \%$ a year since 2000 . The expenditure increased to a total of 4 billion dollars in 2010 .

\subsubsection{The emphasis of research in $\mathrm{HE}$}

To align with the government's long-term investment in high quality of HE to meet the needs of students, the labour market and the economy, The Tertiary Education Commission (TEC) introduced and established the PBRF in 2002 and aims at enhancing the quality of research produced in HEIs. The government holds the view that researchdriven innovation at tertiary level will contribute to the development of NZ industries to become more productive (TEC, 2010). In addition, producing high-quality research is very useful for building on NZ's knowledge base; responding to the needs of the economy; and addressing environmental and social challenges (MoE, 2010, p.7).

\subsubsection{The PBRF}

The PBRF is a research-funding model that is based on an assessment of the quality and productivity of research at all universities and participating tertiary education institutions. This program provides a financial incentive to research-active institutions that earn the best rating in the assessment (TEC, 2010).

The main aims of the PBRF, as agreed by government, are to:

1. Increase the average quality of research;

2. Ensure that research continues to support degree and postgraduate teaching; 
3. Ensure that funding is available for postgraduate students and new researchers;

4. Improve the quality of public information on research output;

5. Prevent undue concentration of funding that would undermine research support for all degrees or prevent access to the system by new researchers;

6. Underpin the existing research strength in the tertiary education sector. (TEC, 2010, p.16)

To achieve the above aims the PBRF intends to focus on rewarding and encouraging excellence toward the production of high-quality research in any form such as journal articles and books. Beyond this, the PBRF also focuses on excellence of the following:

- The production and creation of leading-edge knowledge;

- The application of that knowledge;

- The dissemination of that knowledge to students and the wider community;

- Supporting current and potential researchers (eg. postgraduate students) in the creation, application and dissemination of knowledge. (TEC, 2010, p.16)

Since the main focus of the PBRF is placed on research, it is important to know what counts as research under the operation of the PBRF.

For the purposes of the PBRF, research is original investigation undertaken in order to contribute to knowledge and understanding and, in the case of some disciplines, cultural innovation or aesthetic refinement. It typically involves enquiry of an experimental or critical nature driven by hypotheses or intellectual positions capable of rigorous assessment by experts in a given discipline. (TEC, 2010, p.25)

\subsubsection{The PBRF funding formula}

According to TEC (2010), the PBRF is funded based on three measures. First, it assesses the quality of TEO individual staff members' research based on external peer review. Each TEO is then required to submit an evidence portfolio to the TEC board for the assessment. To assess the evidence portfolio the TEC Board seeks three key components including the outputs of an individual staff member's research; an indication of the quality of individual staff members' peer review research; and the staff member's contribution to a vital high-quality research environment, both within the TEO and beyond. In the total weights of $100 \%$ for the assessment, this first measure weighs $60 \%$ which is the most important measures among the three. Secondly, it measures the number of postgraduate research-based degree completions in the TEO. 
This second measure counts for $25 \%$. Thirdly, it calculates the amount of income for research purposes received by the TEO from external sources. This last measure contributes $15 \%$.

\subsection{The summary of the chapter}

HE in Cambodia at both institution and ministry levels has been affected by the country's traumatic history, different political ideologies, social and cultural issues, and various institutional influences. However, the RGC's aim of moving toward knowledge society through research and teaching has become visible in the last five years. Recently, RGC has created a new policy to strengthen the quality of HE through linking research with teaching in HEIs. Differently from Cambodia, NZ has had a very stable political environment during this century which allows the HE system to grow. Moving towards the conception of modern university during the $21^{\text {st }}$ century, NZ emphasizes the role of research in teaching in all universities. The NZ government has provided significant support for RLT through PBRF which aims at increasing research productivity among academics. 


\section{CHAPTER 3: \\ LITERATURE REVIEW}

\subsection{Chapter overview}

This chapter reviews the literature on the link between research and teaching/learning in HE and the conception of RLT. The chapter addresses conceptions of the term 'research', 'teaching' and 'student learning' to provide general understanding of the terms as these three key terms are used extensively in this thesis in relation to each other. It then provides a critical analysis of conceptions of RTN in various literatures and includes the different characteristics of RTN. The chapter also outlines the conceptual framework of the study and how RLT is operationalized for this study. Moreover, the benefits and drawbacks of RLT for academic staff and students are discussed. It also identifies what is considered useful support for RLT and its challenges before the summary of the chapter.

\subsection{Conceptions of 'research', 'teaching' and 'student learning'}

In HE, the relationship between research and teaching/learning has been the focus of much scholarly debate (Badley, 2002; Brew, 2003; Coate, Barnett \& Williams, 2001; Griffiths, 2004; Hattie \& Marsh, 1996; Healy, 2005; Lucas, Healy, Jenkins \& Short, 2008; Robertson, 2007; Robertson \& Bond, 2005;). Before proceeding further, it is important to address these terms individually to have a broader view and understanding of their relationship.

\subsubsection{Conceptions of "research"}

Research is a "complex phenomenon" (Brew, 2001, p.21) as it "does not have a single, generally accepted, meaning" and it takes many different forms of inquiry (Griffiths, 2004, p.714). There are numerous studies conducted to investigate the concepts of research amongst academics staff or students in research-led universities (Bill, 2004; Brew, 2001; Kiley \& Mullins, 2005; Meyer, Shanahan \& Laugksch, 2005; Prosser, Martin, Trigwell, Ramsden \& Middleton, 2007). The common themes about the conceptions of research coming through those studies include:

1. Gathering information and collecting data;

2. Being methodical and systematic in one's methods; 
3. Answering questions and solving problems;

4. Creating new knowledge; and

5. Achieving conceptual/theoretical insight and understanding.

(Akerlind, 2008, p. 22)

Similarly, Willison and O'Regan (2006) developed a research development framework that identified six facets of research to provide a broader picture of what counted as research for students. According to these authors, research is when students embark and clarify inquiry; find information; evaluate and manage information and research process; analyze and synthesize information; apply and communicate new knowledge.

Figure 3.1 provides detail of these six facets of research.

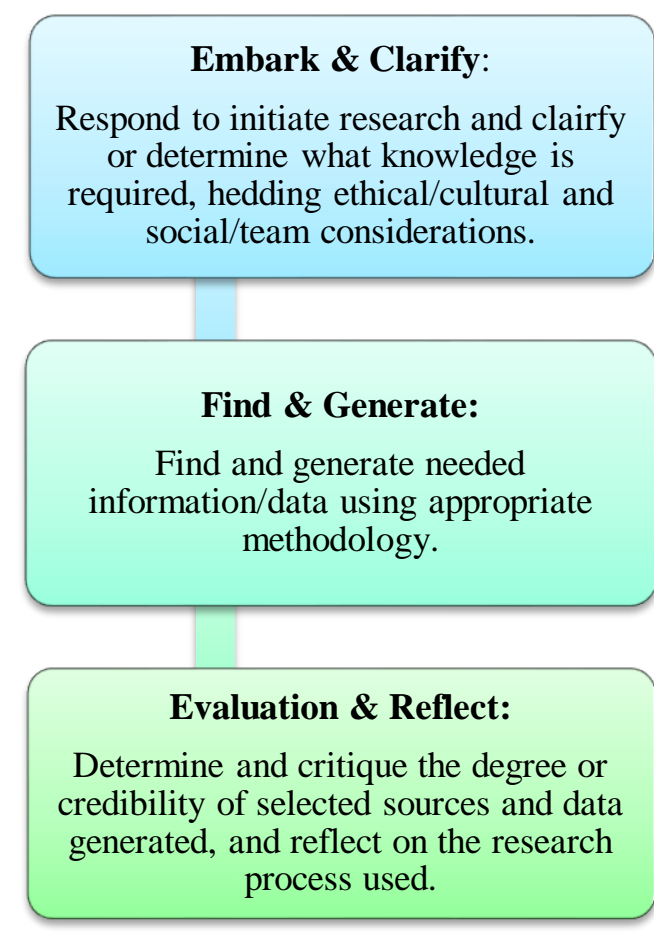

\section{Communicate and Apply:}

Write, present and perform the processes, understandings and applications of the research, and respond feedback, accounting for ethical, social and cultural issues.

\section{Analyse \& Synthesis:}

Analyse information/data critically and synthesis new knowledge to produce coherent individual/team understandings.

\section{Organise \& Manage:}

Orgainise information and data to reveal patterns and themes, and manage teams and research processes.

(Source: Willison \& O’Regan, 2006)

Figure 3.1. The six facets of research

The 'communicate and apply' facet suggests research is more than "an activity which is concerned with knowledge acquisition on the part of the researcher itself but also "with knowledge dissemination to academic peers and students" at the same time (Brown, 2005, p. 393). Therefore, the conception of 'research' used to discuss in this study is seen as a public, rather than private endeavour as it not only builds up knowledge by lecturers for lecturers but also for public dissemination through the teaching process. As 
Brown suggests one may assume that public dissemination of knowledge is via publications and also teaching.

\subsubsection{Conceptions of "teaching and student learning"}

Conceptions of teaching have two broad orientations: teacher-centered/ contentoriented and student-centered/learning-oriented (Kember, 1997). The former focuses more on teaching activities while the latter focuses on the student learning. Teaching in the conception of teacher-centered is "an activity which is primarily concerned with knowledge dissemination on the part of the lecturer and with knowledge acquisition on the part of students" (Brown, 2005, p. 393). In this sense, teachers present information through a transmission model (Prosser \& Trigwell, 1999) and students adopt surface approaches to learning (Marton \& Saljo, 1976) in which students are viewed as passive recipients of a body of content (Kember, 1997) as they concentrate on the surface feature of the study task and attempted to memorize material that is relevant to the exam question (Kember \& Gow, 1994). In contrast, in student-centered environments, students "developed a personal understanding of a phenomenon by interacting with conceptions within the literature, ideas presented by teachers and others and by personal experiences" (Brew \& Boud, 1995, p. 268) through deep approaches to learning (Marton \& Saljo, 1976). Deep learning was suggested as an effective way of learning in $\mathrm{HE}$ as it allowed students to become involved in active learning including learning by doing and inquiry-based learning (Biggs, 2003; Healy, 2005).
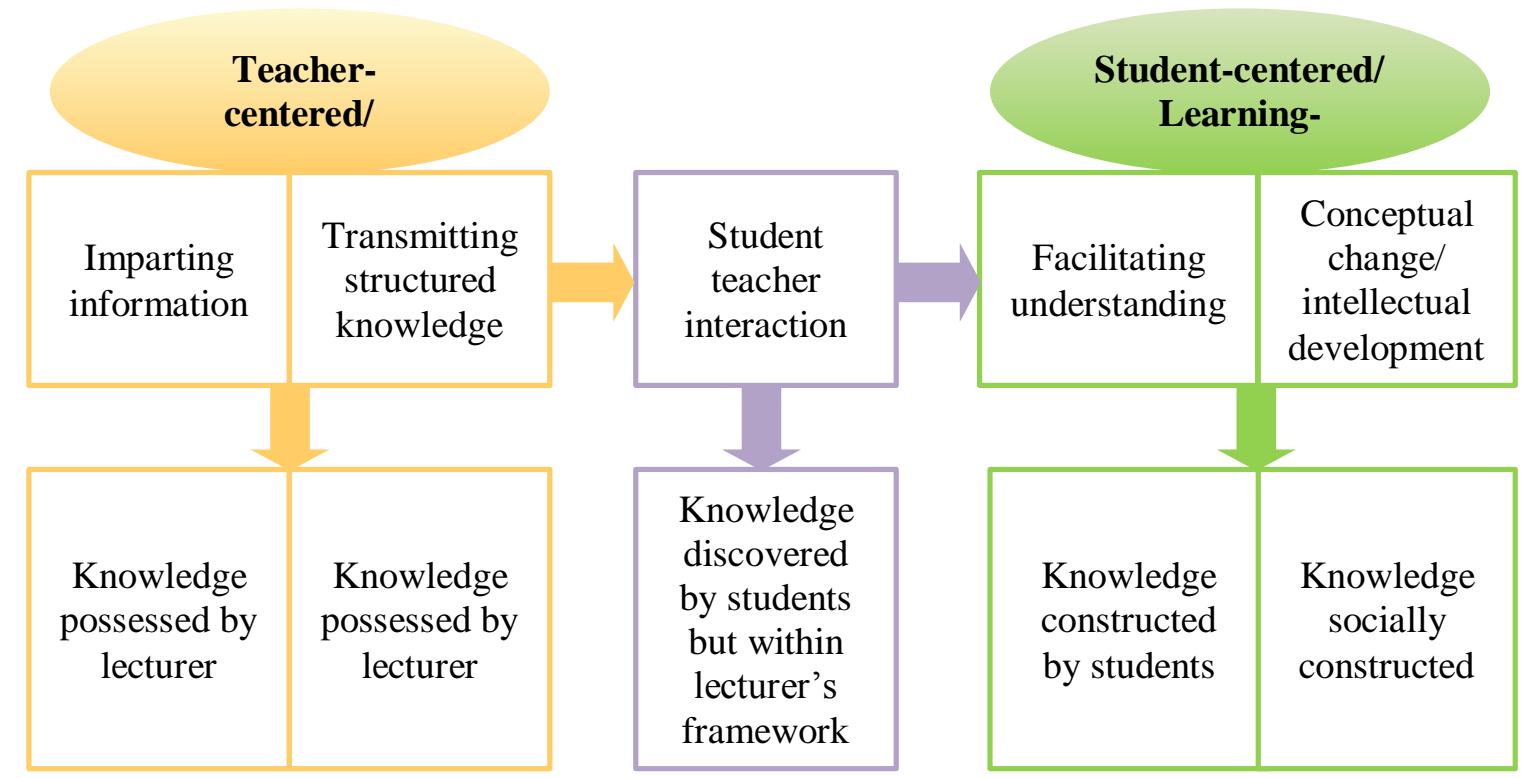

(Source: Adapted from Kember, 1997)

Figure 3.2. The conception of teaching and student learning 
Under these two orientations, Pratt (cited in Kember, 1997) divided the concept of teaching into five categories: imparting information, transmitting structured knowledge, teacher-student interaction, facilitating understanding and conceptual change (Figure 3.2).

According to this figure, student learning or knowledge creation could be obtained differently based on the approaches of teaching, content-oriented or learning-oriented, and learning approaches, surface or deep learning. Thus lecturers in the content-oriented approach potentially see their roles in disseminating research, whereas lecturers in the learning-oriented approach tend to get their students to engage in research or to conduct research as an active approach to learning.

\subsection{Conceptions of the link between research and teaching/learning}

The connection between research, teaching and learning has become a topic of international interest in recent decades. A number of articles, theoretical reviews and empirical studies have been conducted in Australia, Canada, the Netherlands, New Zealand, the UK and the United States to discuss and investigate the connection between teaching and research to enhance student learning (see Table 3.1). This study therefore reviews the literature based on the selection of the articles that are most relevant to this study and will help to understand the concept of this study well.

One of the main problems in the discussion about the relationship between research and teaching is that the idea is complex, disciplinary-based and university contextual (Brew, 2006; Healy, 2005; Schapper \& Mayson, 2010). There are many terms used to describe the processes, the activities or concepts of the link between research and teaching (Schapper \& Mayson, 2010). For instance, researchers have referred to either the teaching-research nexus (Neumann, 1992), the research-teaching nexus (Griffiths, 2004; Robertson, 2007), research-based teaching (Clark, 1997), or teaching-research relations (Brew 2007). Some authors have used the term research-teaching nexus (RTN) to describe how these terms are linked. This term has been used because it is a contested idea with no correlation, or cause and effect found within the link. It is interesting to note that different authors used this term to describe the different characteristics of the link between research and teaching and that these can be used interchangeably. 
Table 3.1. International literature scope for literature review

\begin{tabular}{|c|c|c|c|c|c|c|}
\hline \multirow[t]{2}{*}{ Topics } & \multirow[t]{2}{*}{ Authors \& Year } & \multirow{2}{*}{$\begin{array}{l}\text { Research } \\
\text { Design }\end{array}$} & \multirow[t]{2}{*}{ Context } & \multicolumn{2}{|c|}{ Participants } & \multirow[t]{2}{*}{ Key findings/themes } \\
\hline & & & & $\mathbf{A} *$ & $\mathbf{S} *$ & \\
\hline $\begin{array}{l}\text { Experiences of relation between } \\
\text { teaching and research }\end{array}$ & $\begin{array}{l}\text { Robertson \& Bond } \\
\text { (2001) }\end{array}$ & Interview & NZ & 7 & & $\begin{array}{l}\text { There is substantial variation in academics' } \\
\text { experiences of the meaning of this relation }\end{array}$ \\
\hline $\begin{array}{l}\text { Relationship between teaching and } \\
\text { research in higher education in England }\end{array}$ & $\begin{array}{l}\text { Coate, Barnett \& } \\
\text { Williams (2001) }\end{array}$ & $\begin{array}{l}\text { Interview \& } \\
\text { Focus group }\end{array}$ & UK & $\begin{array}{l}\text { Academics \& } \\
\text { Head of } \\
\text { department* }\end{array}$ & Students* & $\begin{array}{l}\text { There are a range of relationship, both positive and } \\
\text { negative, between teaching and research }\end{array}$ \\
\hline $\begin{array}{l}\text { Research-led teaching and learning in } \\
\text { higher education }\end{array}$ & Zamorski (2002) & Iinterview & UK & $\begin{array}{l}16 \text { including } \\
\text { senior } \\
\text { management } \\
\text { staffs }\end{array}$ & 12 & $\begin{array}{l}\text { The finding of the research covered a wider of range of } \\
\text { issues than had been originally and anticipated. } \\
\text { However, the study reported only one key point among } \\
\text { the four which is the academics and students' } \\
\text { understanding of RLT and learning }\end{array}$ \\
\hline $\begin{array}{l}\text { Research-led teaching: a review of two } \\
\text { initiatives in valuing the link between } \\
\text { teaching and research }\end{array}$ & Deakin (2006) & $\begin{array}{l}\text { Questionnaires } \\
\text { \& Interview }\end{array}$ & UK & Academics* & Students* & $\begin{array}{l}\text { Students value the link between teaching and research, } \\
\text { placing particular weight on RLT and the bearing } \\
\text { which it has on the quality of their learning experiences }\end{array}$ \\
\hline $\begin{array}{l}\text { Students' experiences of learning in a } \\
\text { research environment }\end{array}$ & $\begin{array}{l}\text { Robertson \& } \\
\text { Blackler (2006) }\end{array}$ & Interview & $\mathrm{NZ}$ & & 34 & $\begin{array}{l}\text { Students' relationship with research varies across } \\
\text { disciplines in both a spatial and temporal dimension } \\
\text { according to the ways in which knowledge is } \\
\text { conceived of and explored. }\end{array}$ \\
\hline $\begin{array}{l}\text { Beyond the 'research-teaching nexus': } \\
\text { exploring the complexity of academic } \\
\text { experience }\end{array}$ & Robertson (2007) & Interview & $\mathrm{NZ}$ & 17 & & $\begin{array}{l}\text { Academics' epistemologies are strongly influenced by } \\
\text { the way knowledge is conceived of and constructed } \\
\text { within their discipline which is important in shaping } \\
\text { experiences of research, teaching and learning. }\end{array}$ \\
\hline $\begin{array}{l}\text { International perspectives on student } \\
\text { awareness, experiences and perceptions } \\
\text { of research: Implications for academic } \\
\text { developers in implementing research- } \\
\text { based teaching and learning }\end{array}$ & $\begin{array}{l}\text { Turner, Wuetherick } \\
\text { \& Healy (2008) }\end{array}$ & Survey & $\begin{array}{c}\text { UK \& } \\
\text { Canada }\end{array}$ & & Over 500 & $\begin{array}{l}\text { The relationship between student perceptions and } \\
\text { experiences of research and the type of institution, as } \\
\text { well as the individual, institutional and national context } \\
\text { is very complex }\end{array}$ \\
\hline $\begin{array}{l}\text { Academics' experiences and perception } \\
\text { of research and teaching : developing the } \\
\text { relationship between these activities to } \\
\text { enhance student learning within different } \\
\text { disciplines and institutions }\end{array}$ & $\begin{array}{l}\text { Lucas, Healy, } \\
\text { Jenkins \& Short } \\
\text { (2008) }\end{array}$ & Interview & UK & $\begin{array}{l}\text { Academics \& } \\
\text { Senior } \\
\text { management } \\
\text { staff }\end{array}$ & & $\begin{array}{l}\text { Research and teaching links seemed strongest in those } \\
\text { departments which had cohesive and collaborative } \\
\text { culture. }\end{array}$ \\
\hline
\end{tabular}

*Number of participants is not provided / indicated in the study ( $\mathrm{A}=$ Academics, $\mathrm{S}=$ Students) 
Table 3.1. International literature scope for literature review (Continued)

\begin{tabular}{|c|c|c|c|c|c|c|}
\hline \multirow[t]{2}{*}{ Topics } & \multirow[t]{2}{*}{ Authors \& Year } & \multirow{2}{*}{$\begin{array}{l}\text { Research } \\
\text { Design }\end{array}$} & \multirow[t]{2}{*}{ Context } & \multicolumn{2}{|c|}{ Participants } & \multirow[t]{2}{*}{ Key findings/ themes } \\
\hline & & & & A* & $\mathbf{S}^{*}$ & \\
\hline $\begin{array}{l}\text { The balance between teaching and } \\
\text { research in Dutch and English } \\
\text { universities in the context of } \\
\text { university governance reforms }\end{array}$ & $\begin{array}{l}\text { Leisyte, Enders \& } \\
\text { Boer (2009) }\end{array}$ & $\begin{array}{l}\text { Interview \& } \\
\text { Document } \\
\text { analysis }\end{array}$ & $\begin{array}{l}\text { UK and The } \\
\text { Netherlands }\end{array}$ & 48 & & $\begin{array}{l}\text { Teaching and research are increasingly falling apart as two distinct } \\
\text { activities. Success or failure in research acquisition and performance } \\
\text { assessments has serious implications for the work portfolios in term of } \\
\text { teaching and research load of research units. }\end{array}$ \\
\hline $\begin{array}{l}\text { The idea research-teaching nexus in } \\
\text { the eyes of academics: building } \\
\text { profiles }\end{array}$ & $\begin{array}{l}\text { Visser-Wijnveen, } \\
\text { Van Driel, Van der } \\
\text { Jijst, Verloop \& } \\
\text { Visser (2010) }\end{array}$ & Interview & $\begin{array}{c}\text { The } \\
\text { Netherlands }\end{array}$ & 30 & & $\begin{array}{l}\text { Five profiles of the RTN could be distinguished: teaching results, make } \\
\text { research know, show what it means to be researcher, help conduct } \\
\text { research and provide research experience. }\end{array}$ \\
\hline $\begin{array}{l}\text { When academics integrate research } \\
\text { skill development in the curriculum }\end{array}$ & Willison (2012) & $\begin{array}{l}\text { Questionnaire } \\
\text { \& Interview }\end{array}$ & Australia & 17 & 46 & $\begin{array}{l}\text { Student developed a variety of discipline-specific research skills which } \\
\text { were very useful for subsequent studies and employment while } \\
\text { teaching is enhanced through making explicit development of student } \\
\text { research skills. }\end{array}$ \\
\hline $\begin{array}{l}\text { The relationship between research } \\
\text { and teaching: A meta-analysis }\end{array}$ & $\begin{array}{l}\text { Hattie \& Marsh } \\
\text { (1996) }\end{array}$ & $\begin{array}{c}\text { Theoretical } \\
\text { study }\end{array}$ & Australia & & & $\begin{array}{l}\text { A meta-analysis of } 58 \text { studies demonstrates that the relationship } \\
\text { between research and teaching is zero }\end{array}$ \\
\hline $\begin{array}{l}\text { Research-led teaching: moving from } \\
\text { a fractured engagement to a marriage } \\
\text { of convenience }\end{array}$ & $\begin{array}{l}\text { Schapper \& } \\
\text { Mayson (2010) }\end{array}$ & $\begin{array}{l}\text { Theoretical } \\
\text { study }\end{array}$ & Australia & & & $\begin{array}{l}\text { RLT cannot be just imposed or overlaid, on current research/teaching } \\
\text { practice. Supports such as time, money, energy, intellectual } \\
\text { engagement, motivation, commitment to change are needed during the } \\
\text { implementation. }\end{array}$ \\
\hline $\begin{array}{l}\text { The modern integration of research } \\
\text { activities with teaching and learning }\end{array}$ & Clark (1997) & $\begin{array}{l}\text { Theoretical } \\
\text { study }\end{array}$ & America & & & A culture of inquiry has important advantages in educational sites. \\
\hline $\begin{array}{l}\text { Teaching and research: New } \\
\text { relationships and their implications } \\
\text { for inquiry-based teaching and } \\
\text { learning in higher education }\end{array}$ & Brew (2003) & $\begin{array}{l}\text { Theoretical } \\
\text { study }\end{array}$ & Australia & & & $\begin{array}{l}\text { The paper suggests that if the relationship between teaching and } \\
\text { research is to be enhanced it is necessary to move towards a model } \\
\text { based on the notion of academic communities of practice. }\end{array}$ \\
\hline $\begin{array}{l}\text { Knowledge production and the } \\
\text { research-teaching nexus: the case of } \\
\text { the build environment disciplines }\end{array}$ & Griffiths (2004) & $\begin{array}{l}\text { Theoretical } \\
\text { study }\end{array}$ & UK & & & $\begin{array}{l}\text { The distinctions between research-led, research-oriented, research- } \\
\text { based, and research inform teaching have been found to be useful, and } \\
\text { might have application in other work on the RTN }\end{array}$ \\
\hline $\begin{array}{l}\text { Linking research and teaching to } \\
\text { benefit student learning }\end{array}$ & Healy (2005) & $\begin{array}{l}\text { Theoretical } \\
\text { study }\end{array}$ & UK & & & $\begin{array}{l}\text { Undergraduate are likely to gain most benefit from research in term of } \\
\text { depth of learning and understanding when they are actively involved in } \\
\text { various forms of inquiry-based learning. }\end{array}$ \\
\hline $\begin{array}{l}\text { Imperatives and challenges in } \\
\text { integrating teaching and research }\end{array}$ & $\operatorname{Brew}(2010)$ & $\begin{array}{l}\text { Theoretical } \\
\text { study }\end{array}$ & Australia & & & $\begin{array}{l}\text { The link of teaching and research cannot fully happen unless the } \\
\text { university becomes a partnership where all take part in it growth and } \\
\text { development through inquiries at different levels. }\end{array}$ \\
\hline
\end{tabular}


Those characteristics included how research is used to link, inform, support, enhance, promote or integrate (with) teaching in HE (Trowler \& Wareham, 2008). It is therefore often difficult to know whether authors are referring to the influence on teaching and learning of students doing research, staff doing research, staff practices being informed by research, the curriculum being informed by contemporary research, the "research culture of a particular context" and so on.

In addition, the nature of the connection and the nature of "research" also remain similarly unspecified in many cases. For instance, academics often asserted that there is a positive relationship between teaching and research (Brew, 2003; Brew \& Boud 1995; Rowland, 1996) while a meta-analysis of 58 empirical studies by Hattie and Marsh (1996) indicated that "the relationship between research and teaching is zero" (p.533).

In short, the whole concept of the research-teaching nexus is complex. For this reason, many researchers use this term in different ways to describe what is going on within the nexus, yet all of them make useful insight and contribution to the relationship between research and teaching. As mentioned earlier, the terminology reflects particular institutional contexts (Brew, 2006; Jenkins \& Healy, 2005). This study therefore, uses the term 'RLT' to talk about the link between research and teaching, especially how research is used to inform teaching and learning. This term is used predominantly to represent how research links to teaching and student learning in the setting where this study takes place. More explanation about the term is elaborated in Section 3.4.

\subsection{The characteristics of RTN}

The literature - empirical and non-empirical studies - identified different characteristics of the link between research and teaching.

Neumann (1992) conducted a qualitative study to explore the perception of the relationship between the research and teaching through semi-structured interviews with senior academic administrators including vice-chancellors, deputy and pro-vicechancellors, chairs of the academic board or senate, deans, heads of school and heads of department from different disciplines. The findings revealed a three-level nexus between teaching and research: the tangible nexus, the intangible nexus and, the global nexus. The tangible nexus refers to the transmission of the knowledge which is from the outcomes of the academic's research to the students. The intangible nexus refers to the 
development in students of an approach and attitude towards knowledge. The global nexus refers to the connection between teaching and research at the department level.

In contrast, Griffiths (2004) conducted a theory-based study to discuss knowledge production through RTN. The study described the relationship between research and teaching in three dimensions. First, the nexus can be specific (when academics in some ways use their research to incorporate with their teaching activities), or diffuse (when academics bring a more general way of thinking based on the academic's research experience). Second, the research can be embedded weakly in teaching activities (when research is referred in the lectures or include in reading list) or integrated strongly in teaching activities (when research is used intentionally to shape students learning activities). The direction of the relationship can be either unidirectional (flowing from research to teaching) or reciprocal (with research and teaching profiting from each other). Within this dimension, Griffiths (2004) divided the research-teaching nexus into four main models: (1) Research-led (teaching that is informed by the teacher's own or by others' research), (2) Research-oriented (teaching that emphasizes research skills and processes), (3) Research-based (teaching that involves the students in research and inquiry-based activities), (4) Research-informed (based on "systematic inquiry in the teaching and learning process).

Similarly, Healy (2005) conducted a theoretical review on the link between research and teaching to benefit student learning. Healy (2005) utilized Griffiths' first three models and adds the fourth one as "research-tutored" to describe teaching "focused on students writing and discussing papers or essays" (p.71). Healy (2005) emphasized that research-tutored and research-based are primarily student-focused while the other two (i.e., research-led and research-oriented) tend to be teacher-focused where students are audience. According to Healy (2005), research-tutored and research-led approaches emphasise research content while research-based and research-oriented approaches emphasise research process and problems.

In relation to her first article with Bond in 2001, Robertson (2007) extended her study by undertaking a qualitative study exploring the complexity of academics experiences. In her previous study, Robertson interviewed nine academics from different disciplines: engineering, economics, linguistics, mathematics, plant and microbial sciences and physics of the University of Canterbury in NZ. Those participants were academics who expressed their strong view about the relationship between research and teaching in a 
response to the meta-analysis of Hattie and Marsh (1996). Adding to this sample, in her later study in 2007; Robertson interviewed another 17 academics from the same university. The finding identified five categories of linkage between research and teaching based on academics' understanding. Category A is known as 'weak relation' which refers to a very little or non-existent relationship between research and teaching. For this category, the relationship is hardly seen or unseen due to the difficulties in incorporated research in undergraduate level. Category B is known as 'transmission relation' since research findings are transmitted to the students. In this category, academics tends to use their own research or other people's research to give examples to students or to put in the reading list. Category $\mathrm{C}$ is known as 'hybrid relation', which emphasises the importance of knowledge, and the students might be engaged in research inquiry. Category D is known as 'symbiotic relation' since research and teaching are strongly related, but can be identified independently. In this category, academics are getting students to think in a disciplinary way (ontological as well as epistemological) which is a way of thinking, being and living. Category $\mathrm{E}$ is known as 'integrated relation' in which research and teaching are inseparable. For this category, academics and students are conducting research to inform their teaching.

A strong theme that runs through these studies is that the relationship between research and teaching can be weak or strong based on the use of research in teaching process. For example, according to Griffiths' second dimension the link between research and teaching/learning is weak when research outcomes are used to deliver to the students in the passive way. This also can be identified from Neuman's (1992) tangible nexus, and Robertson's (2007) Category A and B. This relation Healy (2005) recognised as teacher-focused because students act as passive audiences. Moreover, Griffiths emphasis that the link can be strong when research is used in a way to encourage students to participate in research to help develop their skills and thought. This idea corresponds with Neuman's (1992) intangible nexus, and Robertson's (2007) Categories C, D and E. This relation is recognised as student-focused by Healy (2005) since knowledge is constructed by students.

Another common theme that runs through the study of Griffiths (2004) and Robertson (2007) is that Robertson (2007) is the only author to pay attention to Griffiths' (2004) third dimension, (i.e., the difference between a unidirectional relationship versus a reciprocal one). Her 'weak relation' is focused on the direction 'research towards 
teaching', while the more 'integrated relation' also includes the direction 'teaching towards research'. The other authors seem to focus on the unidirectional relationship.

In summary, several characteristics of the link between research and teaching are identified through the studies: tangible-intangible, specific-diffuse, unidirectionalreciprocal, output-process and audience-participant.

\subsection{Conceptual Framework of the study}

Although, there is an extensive literature on the relationship between research and teaching, most of this literature tends to focus on the nexus itself rather than to focus on how research is used to inform teaching and enhance student learning. According to Griffiths (2004) and Healy (2005), one aspect among the four aspects of RTN, is RLT. Actually, there are a lot of difficulties in use of the terms RTN and RLT in the literature review. However, the analysis has shown that RLT is described as teaching that is informed by academics' research. Thus, RTN is more about the relationship between research and teaching while RLT is more about an aspect of the relationship.

Zamorski (2002) conducted an "unusual and experimental" research (p. 413) on RLT and learning in HE. This study hoped to gain a clearer and deeper understanding of what university means by RLT and learning. In the study, 12 final year undergraduate students were recruited as researchers and were supposed to undertake a set of smallscale qualitative research tasks in the period of two months. The tasks included attending research workshops, interviewing eight fellow students from the undergraduate programme, keeping notes on interview and transcripts, maintaining a journal, writing about their own thoughts and experiences regarding RLT and learning, and capturing 12 images of research at the university along with the written commentary of the images. Besides, the data was also collected from 16 academics including the pro-vice chancellors for teaching and learning and for research, deans of schools, established lecturers and researchers, and newly appointed staff through interview. The study covered a greater range of issues than had been originally envisaged. However, the study reported only one part of the research: academics and students' understanding and experience of RLT and learning. The finding of the first part of the study showed that lecturers and students understood RLT and learning as: teaching that is heavily informed by lecturers' or other people's research, teaching 
where students' engagement in research formed part of pedagogy, and teaching where lecturers involved in investigating and reflecting on their own practice.

Moreover, according to The University of Auckland (2010), RLT refers to the teaching that "reflects and makes use of the teacher's disciplinary research to benefit student learning and outcomes"(p.2). It encompasses many elements and can take many different forms, as identified by Brew (2003).

\footnotetext{
We can also find differences in understandings of research-led teaching according to what is to be learnt and whether the teaching takes a student focused or a teacher-focused perspective. For example, if a teacher includes the content of their research in lectures and it is this content which students have to learn, we can say that this is research-led teaching focusing on content using a teacher-focused perspective. If the teacher gives a lecture (without active participation) on research methods, then we can say this is research-led teaching which again is teacher focused, but where the process of research is what is to be learnt. In both cases, the students are an audience for research (p.3)
}

To catch up with the educational trend in the knowledge society where research plays important role in HE, Angelo and Asmar (2005) introduce a new model which is known as 'Research-led Teaching and Learning' for their institution. This model focuses on three distinct approaches: RLT, inquiry-based learning and research on teaching and learning. RLT is also known as research-informed or research-based teaching (Angelo \& Asmar, 2005). Angelo and Asmar define RLT as teaching in which "academics share their own disciplinary research with students, and teach them disciplinary research methods" (p. 1). Moreover, Angelo and Asmar explain that this model is used to enhance teaching effectiveness, student learning, and graduate attributes; increase PBRF productivity and research degree enrolments and completion; and heighten university reputation.

To explore the perceptions of Cambodian and NZ academics concerning the relation between research and teaching to enhance student learning, I adapted Angelo and Asmar (2005) proposed model of Research-led Teaching and Learning. However, this study focuses only one approach of the model, RLT, and ignores the other two approaches: inquiry-based learning and research on teaching and learning.

The term RLT for this study is used to talk about the teaching that is informed by academics' own research, others' research, and student engagement in research (Figure 3.3). 


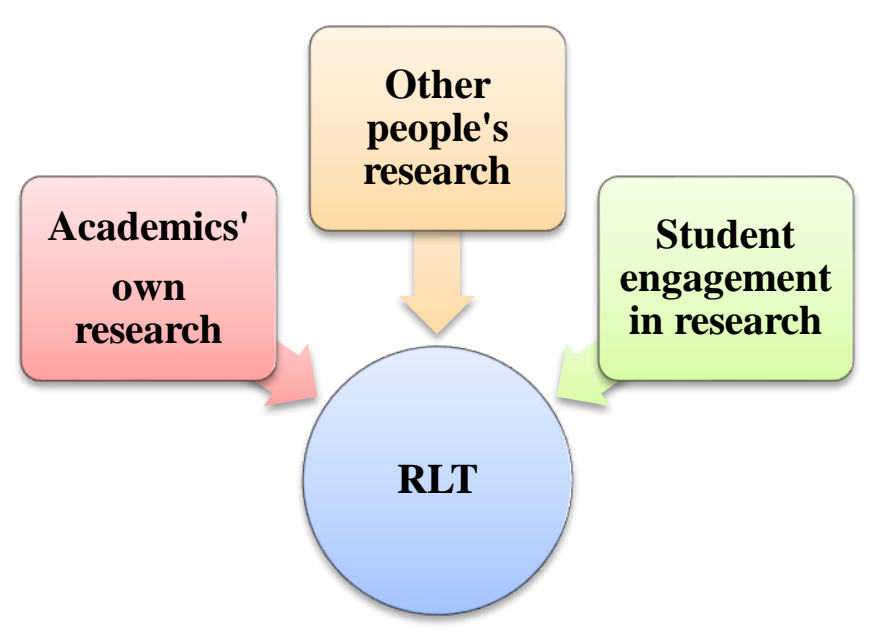

Figure 3.3. Conceptual Framework of RLT

From this framework, I intend to investigate the practice of RLT at ground level from the perceptions of academics who have the implementation role. Taking from the literature I review for this study, the following sections provide more explanation regarding the impact of RLT on teaching and student learning and as well as the opportunities and challenges of RLT.

\subsection{The benefits of RLT on student learning}

Literature indicates that the nexus between research and teaching can inform and enhance not only the teaching but also the learning environment, benefiting students during their degree studies and afterwards, when they move into the world of employment and (it is hoped) lifelong learning. Since RLT is one aspect of the nexus, I assume the benefit that students obtain from RLT is very similar to the RTN. According to Teaching-Research Nexus (2009), there are four key categories of benefits. Firstly, it helps deepen students' understanding of the knowledge bases of disciplines and professions, including their research methods and contemporary research challenges and issues. Secondly, it builds students' higher-order intellectual capabilities and enhances their skills for employment and lifelong learning. Thirdly, it develops students' capacity to conduct research and enquiry. Fourthly, it enhances students' engagement and develops their capacity for independent learning.

Moreover, students also benefit from the integration of academic's research and teaching activities. For instance, academics who teach using their personal research, or design courses and learning activities around contemporary research issues, bring 
research passion together with latest research in the field into the classroom teaching/learning context for evidence-based decisions. Through this, the value of the research findings is enhanced in the contextual teaching/learning environment, and in the same time students incrementally become familiar with a research based learning approach, and are unconsciously infused with the university research culture as they develop their research skills (Baldwin, 2005). Thus, the benefits students gained are that they become familiar with the nature of research and get to know the new knowledge created. Neumann (1994) found research having positive benefits to students by increasing the course's credibility and the perception that students were learning relevant and current course content. Additionally, the research interests of academic staff gave students the opportunity to view instructors as 'real people' and to relate on a level of interest and enthusiasm in the same area of study. Jenkins, Blackman, Lindsay, and Paton-Saltzberg (1998) reported that students' own motivation and interest in a subject area often stemmed from instructor enthusiasm which had roots in the academic's research interests. Healy (2005), in the summary of the literature examining student perceptions of research on their learning environment, has argued that students perceived clear benefits from staff research, including enthusiasm, credibility, and "the reflected glory of being taught by nationally and internationally known researchers" (p.193).

\subsection{The drawbacks of RLT on teaching and learning}

Despite the benefits of RLT, the contradictory effects have been identified due to the demand for the universities to meet performance outcomes, academics are encouraged to teach and research (Schapper \& Mayson, 2010). The drawback is somewhat different, however, depending on the institutional/departmental and disciplinary contexts.

Because of the essential role of research in the development of knowledge-based economy, more priority has been given to doing research nationally and internationally; national governments, and consequently higher education institutions put more emphasis on resources for research at university, essentially applied research (Jenkins \& Healey, 2005) that could quickly return revenue to the university. Gibbs (2002), based on his personal experience of a leading university, stressed that RLT can be seen as negative impacts where departmental policies were to focus on the achievement of research productivity by driving academic staff to preserve their time for research, and 
shortened time from teaching duties. Consequently, not only did academic staff suffer from having limited time to complete their duties, but students also experienced having too limited time with their teachers and having one exam instead of other coursework. This is due to the fact that students often perceived the research activities of a university as an 'extra' to what they believe is the primary requirement of a university, the provision of quality undergraduate teaching and learning. Jenkins et al. (1998) also reported that students place a higher priority on instructors who are available, able to communicate course content effectively, and engage the students in the subject matter.

Trowler and Wareham (2007) added that time and energy of academics have been devoted to research that sacrifices teachers' involvement in teaching and are replaced by teaching assistants; commonly, post-graduate students. Consequently, students are reluctant to receive lower level of expertise, feeling neglected by academic staff and the department.

Besides, students who did not view themselves as stakeholders in the research process, felt that they missed the research process and could only accessed to the final product of the research (Zamorski, 2002). This has left students with a poor understanding of the research process which could result in negative experiences and difficulties when took part in research process themselves (Zamorski, 2002). In addition, Robertson and Blacker (2006), argued that while some students have a sense of proximity to, and /or participation in research, others express frustration at how "research is hidden from them" (p.227). Drawing on Brew's notions of academic communities of practice, they argued that student frustration manifests when participation in the academic community is delayed and when they are unable to relate their current learning to their perception of that research community (Brew, 2003; Robertson \& Blacker, 2006).

\subsection{The opportunities and challenges for RLT implementation}

While research has been advantaged over teaching in some research-intensive or research-led universities, there is a demand for the universities to move beyond mass education to universal education (Coates, Dobson, Edwards, Friedman, Goedegebuure \& Meek, 2009). Due to this, literature indicates that HEIs are trying to establish policies and a number of strategies to support a research-led university. However, it is clear that there is a big gap in institutional rhetoric of RLT (Brew, 2006; Hattie \& Marsh, 1996). Schapper and Mayson (2010) argue, "the successful policy implementation requires 
commitment from all levels of the university and, in particular, academic staff" (p.642). To implement RLT for the improvement of learning outcomes for students, the faculties or departments have responsibilities to support, encourage and reward the practice of RLT (Schapper \& Mayson, 2010). Schapper and Mayson (2010) suggest four key principles to guide implementation of RLT (Table 3.2).

Table 3.2. Principles to guide implementation of RLT

\begin{tabular}{|l|l|}
\hline Principle & Actions by university \\
\hline Principle 1 & $\begin{array}{l}\text { The university acknowledges that despite the current research } \\
\text { findings that suggest a negligible relationship between } \\
\text { teaching outcomes and research outcomes that it nonetheless } \\
\text { supports strengthening the links between research and teaching } \\
\text { across the university. }\end{array}$ \\
\hline Principle 2 & $\begin{array}{l}\text { The university encourages and resources faculties and } \\
\text { discipline areas to develop an evidence base to provide } \\
\text { exemplars of RLT. }\end{array}$ \\
\hline Principle 3 & $\begin{array}{l}\text { The university accepts that the relationship between research } \\
\text { and teaching is complex and dependent upon disciplinary } \\
\text { approaches to knowledge creation and knowledge sharing. }\end{array}$ \\
\hline Principle 4 & $\begin{array}{l}\text { The university acknowledges there is no 'one best way' to } \\
\text { embed RLT across all faculties, departments and or } \\
\text { disciplines. (Schapper \& Mayson, 2010, p. 648) }\end{array}$ \\
\hline
\end{tabular}

Due to the complexity of the link between research and teaching, the implementation of RLT may take different forms based on individual discipline. Also, this implementation cannot be just imposed or overlaid; resources are needed along to make the process possible. Those resources include "time, money, energy, intellectual engagement, motivation, commitment to change" (Schapper \& Mayson, 2010). 


\subsection{Chapter Summary}

This chapter reviewed conceptualisations of the term 'research', 'teaching' and 'student learning' individually due to the fact that the different conceptions about the nature and meaning of these terms lead to different conceptions of RTN. It is obvious from literature that previous studies have been conducted in America, Australia, New Zealand, and the UK which are all in developed countries. However, there is no single study that has been done about the practices of RLT in HE in Cambodia. Therefore, investigating academics' perceptions and experiences in relation to the practices of RLT seems particularly relevant in the context of Cambodia. Moreover, although the relationship between research and teaching is a contested idea, many universities have included RLT as one of the core missions of the university as it is assumed that there is a positive link. A number of strategies have been initiated to support and promote RLT in university. 


\section{CHAPTER 4: \\ RESEARCH METHODOLOGY}

\subsection{Chapter overview}

The purpose of this chapter is to present the process of investigation used in this study. This chapter starts by highlighting the main objectives of the research as well as the research questions to provide an overview of how the study is connected to the choice

of research design. The next part elaborates the methodological framework with specific choices about the research design: philosophical worldview, strategies of inquiry, and research methods. The research methods deal with how participants were selected and how the research instruments were employed for data gathering and how the data was analyzed. Then, a description of the ways used to ensure the trustworthiness of the research and ethical considerations is explained.

\subsection{Research objectives and questions}

The purpose of this research is to explore Cambodian and NZ academics' perceptions, attitudes, and experiences of RLT in relation to student learning. To achieve these objectives, the following research questions were formulated:

1. What understanding do academics in Cambodia and NZ have of the term 'RLT'?

2. To what extent do the academics engage in RLT? Why or why not?

3. What are the academics' attitudes towards RLT?

4. How do the academics perceive RLT impacts on their teaching and student learning? Why?

5. What are the supports and challenges for RLT?

\subsection{Methodological framework}

I drew on Creswell's (2009) methodological framework in the design of this study. This framework suggested that research design involves three important components:

1. Philosophical Worldview/Research Paradigm - philosophical stance that lies behind the methodology and guides actions for research. 
2. Strategies of Inquiry - strategies or plans that provide specific direction for procedures in a research design.

3. Research Methods - techniques and procedures of data collection, data analysis and interpretation proposed for studies.

Creswell (2009) asserted that these three components show the interrelated levels of decisions in the process of designing research. The elements of the methodological framework for this study are presented below (see Figure 4.1). The following sections present and justify the choice of each element for this study.

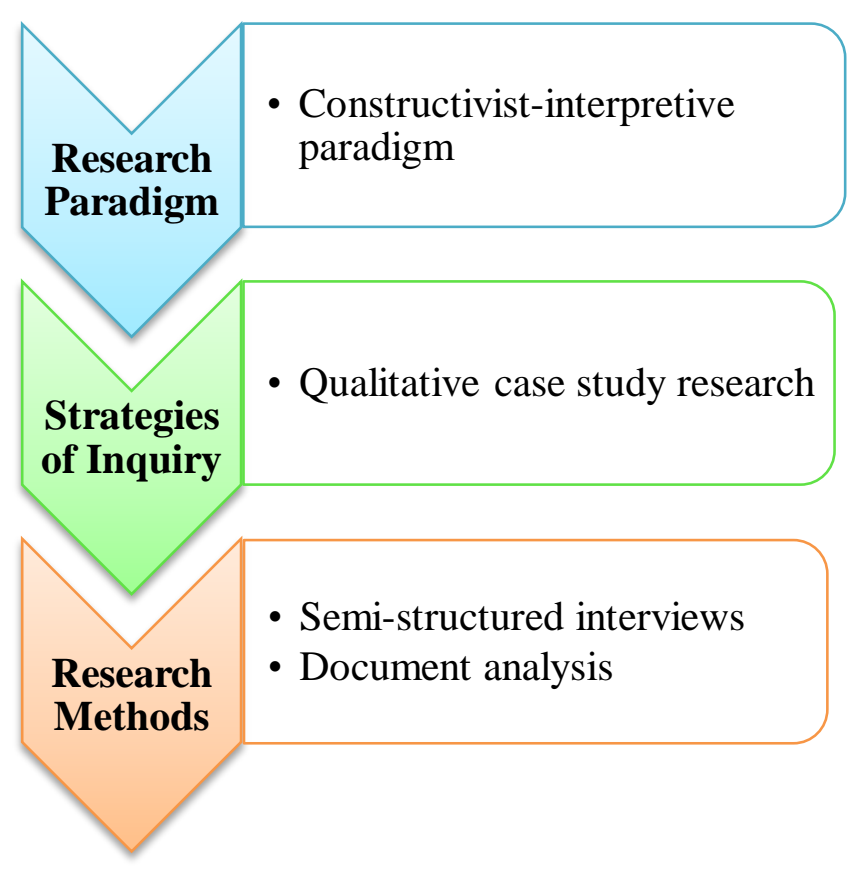

Figure 4.1. Methodological Framework

\subsection{Philosophical worldview/Research paradigm}

Research is described as a way of knowing (Bouma, 1996) and is about creating new knowledge based on evidence and making sense of evidence collected (Gillham, 2000). All research is interpretive; it is guided by the researcher's set of feelings and beliefs about the world and how it should be understood and studied which is known as research paradigm or worldview (Guba 1990, Denzin \& Lincoln, 2008, Creswell, 2009). Those beliefs may include ontology (the nature of reality), epistemology (what counts as knowledge and how knowledge claims are justified), axiology (the role of values in research) and methodology (the process of research) (Cresswell, 2013). The research paradigm not only determines how a study should be conducted, but also raises issues 
about the focus of a study and approaches employed to interpret the data (Hammersley, 2002). Thus, the choice of paradigm and methods for any research study should be consistent to what the researcher is trying to find out (Punch, 1998).

In seeking understanding of academics' perceptions of RLT, this study was grounded in a constructivist-interpretive paradigm. The constructivist-interpretive paradigm was chosen for this study as it endeavors to "understand and interpret the world in terms of its actors" (Cohen, Manion \& Morrison, 2000, p. 28). Such a perspective holds that "meaning is constructed by human beings as they engage in the world they are interpreting and make sense of based on their historical and social perspectives" (Creswell, 2003, p. 9). Thus, researchers for this type of research paradigm usually make an interpretation of what they find which is shaped by their own background and experience (Creswell, 2013). As an interpretivist, the researcher tries to explain why and how something is taking place and makes an interpretation of what she or he sees, hears and understands. This differs from, say, a positivist approach to research, which "is based on careful observation and measurement of the objective reality that exists out there in the world" (Creswell, 2009, p. 7).

Moreover, this paradigm is chosen as RLT is not an objective reality but a social construct which is made up by people (ontology). Thus, the constructivist-interpretive research paradigm enables me, for this study, to understand RLT from the different points of view of the academics within their natural settings (epistemology). Moreover, the openness of interpretivism will allow the researcher to gain deeper insight into the real practice, the importance and challenges of RLT in Cambodian and NZ (selected universities) through academics' perspectives, experiences and attitude towards RLT.

\subsection{Strategies of inquiry}

The strategy of inquiry is another major component of research design (Creswell, 2009). The "strategies of inquiry are types of qualitative, quantitative, and mixed methods designs or models that provide specific direction for procedures in a research design" (Creswell, 2009, p. 11). It can be called approaches to inquiry (Creswell, 2007) or research methodologies (Mertens, 1998).

This study employed qualitative research in the form of an exploratory single-case study approach to inquiry to seek in-depth understanding of the perceptions and practices of 
RLT in higher education and its relation to the benefits of teaching and student learning from Cambodian and NZ academics.

\subsubsection{Qualitative research}

Qualitative research was used extensively in this research after consideration of the consistency between the research topic, research questions and research methodology. As suggested by Punch (1998) and Johnson and Christensen (2008) it was the research topic and questions that determined the approach of inquiry. Denzin and Lincoln (2005) defined qualitative research as:

... a situated activity that locates the observer in the world. It consists of a set of interpretive material practices that make the world visible. This means that qualitative researchers study things in their natural settings, attempting to make sense of, or interpret, phenomena in terms of the meanings people bring to them. (p.3)

In this sense, the purpose of qualitative research is to achieve an understanding of how people make sense of their lives, explain the process of how meaning is being made and describe how people interpret what they experience (Merriam, 2009). Data and social phenomena are interpreted through the eyes of the researcher (Johnson \& Christensen, 2008) in a natural setting where the researcher is able to access sites and participants, using methods that are "interactive and humanistic in order to build rapport and credibility with the individuals in the study" (Creswell, 2003. p.8). Since the research aims to gain deep insight of how academics perceive RLT and also its relation to student learning, the qualitative approach is therefore appropriate for this study for three main reasons.

Firstly, the decision to use qualitative research is directly related to the nature of the research as it is well-matched with the constructivist-interpretive paradigm. The qualitative methods seek to represent perspectives and interpretations from academics of their natural settings: Cambodian and NZ universities. Secondly, the qualitative approach allows a variety of sources from interviews to documentation, for data analysis to help describe the phenomena being researched. Thirdly, compared to quantitative study the use of the qualitative approach is likely to encourage participants to share more detailed perceptions. Therefore, this approach enables me to obtain more in-depth information of how RLT has been viewed and practiced from the perceptions of the participants. 


\subsubsection{Case study}

Under the qualitative research framework, there are several strategies of inquiry that help researchers understand and explain the meaning of social phenomenon (Merriam, 1998). Those strategies include narrative study, phenomenology, grounded theory study, ethnography and case study. The case study approach has been selected for this study to investigate how RLT is being perceived and practised in two places, Cambodian and NZ universities. Yin (2009) described a case study as:

...an empirical inquiry that investigates a contemporary phenomenon in depth and within its real-life context, especially when the boundaries between phenomenon and context are not clearly evident. (p. 18)

Case study can be designed differently to fit the purpose of the study: collective, interpretive, or exploratory single/multiple case study design (Merriam, 1998; Stake, 2008; Yin, 2009). Since RLT is a contested concept among academics, but not much research has been conducted in Cambodia and NZ, this study was appropriate to use exploratory single-case study to investigate how RLT has been perceived and practised, and the reasons for the conception and practice among academics in Cambodia and NZ. Yin (2009) asserted that exploratory case study is appropriate for investigating research questions of a "how" or "why" nature, particularly where the researcher has little control over the actions of those involved in the study and where the focus is on contemporary rather than historical events.

Furthermore, using a single-case study will enable me to understand such a complex social phenomenon of RLT, as the use of a case study is intended to provide a detailed in-depth analysis of the case and is not intended to provide generalizations (Flyvberg, 2006; Yin, 2009). For this purpose the case study design was used to provide in-depth analysis of RLT. The case study design is also used in order to understand the different perceptions, attitudes, supports and challenges of academics using the practices of RLT in their universities.

In addition, a single-case study is appropriate for this type of qualitative study as it provides a clear framework for the case and what should be used to analyse the case. According to Stake (2008) and Merriam (2009), there are four important considerations in a case study design: unit of analysis, multiple perspectives, triangulation, and boundaries in each case. For this study, RLT was the case for investigation and 
academics were the unit of analysis. Academics from two different universities and different backgrounds allow me to obtain various perspectives of the case. However, this study is not intending to compare RLT in the two settings. Semi-structured interviews and documentation were utilized for the purpose of triangulation in this study. Selected universities with specific faculties and programs from Cambodia and NZ universities were set as the boundaries for this research study to explain the case from the contexts within which they exist. Based on these reasons, exploratory singlecase study appeared to be an appropriate research design for this study.

\subsection{Research Methods}

Research method is another crucial element in research design (Creswell, 2009). Research methods refer to the kinds of tools used to collect data in studies, whereas methodologies are the more comprehensive designs and frameworks used in investigations (Johnson \& Christensen, 2008). Research methods involve "the forms of data collection, analysis and interpretation that researchers propose for their studies" (Creswell, 2009, p. 15). The following sections describe and explain the choice of research methods for this study.

\subsubsection{Research sample}

The study was conducted in two different settings: a public university in Cambodia and another in NZ. For ethical reasons these universities are used under the pseudonym University A (Cambodia) and University B (NZ).

A master's program from the University A in Cambodia was selected while a faculty from the University B in New Zealand was recruited for another site of the study. The reason for selecting a master's program against a faculty was, while the organization of each institution differs both have very similar functions.

The reason for choosing Cambodia and NZ as the sites for the study was influenced by my own experiences and personal observation of how RLT is being viewed and practised in both universities. Recently, RLT has been a contested concept among academics but very little research had been conducted about RLT in these two settings. This encouraged me to further investigate how RLT is being viewed, implemented and strengthened among the academics in relation to student learning in both universities. 
Moreover, as research institutions, I strongly believe that I could get rich information from these two universities about the practices of RLT in either setting.

\subsubsection{Research participants and recruitment procedures}

Dornyei (2007) highlights that in a qualitative inquiry, the main goal of sampling is to find individuals who can provide "rich and varied insights into the phenomenon under investigation" (p. 126) to maximize what can be learned. In line with this thought, purposive and convenience samplings were used as the selection methods for participants of this study. The recruitment of both techniques was because purposive sampling allows the researcher to seek participants with specific characteristics for the study; whereas, convenience sampling allows an ease in recruiting the participants, particularly those who wish to participate in this study (Johnson \& Christensen, 2008) and is built upon selections which suit the convenience of the researcher and which are first to hand (Denscombe, 2007). Merriam (1998) noted that purposive sampling should be "based on the assumption that the researcher wants to discover, understand and gain insight and therefore must select a sample from which the most can be learned" (p.61). This enables me to identify people from whom I could learn the most for my research. In addition, it "allows the researcher to hone in on people or events which there are good grounds for believing will be critical for the research" (Denscombe, 2007, p. 17). The criteria for purposive sampling of this study were: six NZ academics who recently become research active and six academics who are currently teaching in Cambodia. The reason I employed convenience sampling is because I chose to interview Cambodian participants at my previous university. I found ease approaching these participants. In addition, the university was in close proximity to my home.

To sample six participants from each university, I initially browsed the university websites in search for lecturers contact list. Unfortunately, I only found the contact list for individual staff at University B. Consequently, I sent an email to a program director of the master's program in University A requesting the contact list of the academics teaching in the program.

The invitation email to participate in research (See Appendix A) was then sent to all lecturers on the lists (15 academics for University A and 45 academics for University B). The imbalanced size of participants between University A and B is due to the selection of a program against a faculty. I had planned to use random sampling as 
another sampling technique if there had been more than six volunteers from each university to select. There were, however, enough participants for this study: six participants from each university volunteered to participate which should suffice for the scope of a Master's Thesis.

The research information sheets (see Appendices B and C) and informed consent forms (see Appendices D, and E) were sent to the volunteers two weeks prior to conducting the interview. The consent forms were returned via email or handed to me before or during the scheduled interview. Table 4.1 summarizes the characteristics of the participants in this study.

Table 4.1. The summary of the characteristics of the participants

\begin{tabular}{|c|c|c|c|c|}
\hline Description & Range & $\begin{array}{c}\text { Number of } \\
\text { Participants in } \\
\text { Cambodia }\end{array}$ & $\begin{array}{c}\text { Number of } \\
\text { Participants } \\
\quad \text { in NZ }\end{array}$ & $\begin{array}{c}\text { Total } \\
\text { Number of } \\
\text { Participants }\end{array}$ \\
\hline \multirow{2}{*}{ Gender } & Female & 0 & 5 & 5 \\
\hline & Male & 6 & 1 & 7 \\
\hline \multirow{3}{*}{$\begin{array}{c}\text { Highest } \\
\text { qualification }\end{array}$} & Master & 3 & 0 & 3 \\
\hline & PhD Candidate & 0 & 2 & 2 \\
\hline & $\mathrm{PhD}$ & 3 & 4 & 7 \\
\hline \multirow{4}{*}{$\begin{array}{c}\text { Teaching } \\
\text { experiences }\end{array}$} & $20+$ years & 0 & 2 & 2 \\
\hline & 15 years & 0 & 1 & 1 \\
\hline & $10-14$ years & 2 & 1 & 3 \\
\hline & $5-9$ years & 4 & 2 & 6 \\
\hline \multirow{3}{*}{$\begin{array}{l}\text { Level of } \\
\text { teaching }\end{array}$} & Postgraduate & 3 & 2 & 5 \\
\hline & $\begin{array}{l}\text { Undergraduate } \\
\text { \&Postgraduate }\end{array}$ & 3 & 2 & 5 \\
\hline & Undergraduate & 0 & 2 & 2 \\
\hline
\end{tabular}

\subsubsection{Data collection tools and procedures}

In order to gain deep understanding of the 12 academics' perceptions, attitudes, and experiences towards RLT, the study utilized semi-structured interviews in the form of one-to-one interviews and documentation analysis (university guidelines/policy, course outlines/syllabi, academics' job descriptions) as data collection tools. 
Both methods of data collection were used as Yin (2003) suggested, in order to accomplish an accurate in-depth understanding of the case the researcher collects different forms of qualitative data, ranging from documents, to reports, to observations, to interviews, to archival records and to physical artefacts. Yin argued that no single source is advantaged over the other and each sources is highly complementary. From this, a good case study seems to use as many sources as possible since relying on one source of data does not typically develop in-depth understanding of the case (Creswell, 2013). However, due to time constraints I will limit data collection methods to two, semi-structured interviews and document analysis.

\section{Semi-structured interviews}

For this study, a one-on-one interview was conducted with 12 participants using a semi structured format of open-ended questions to gather in-depth understanding of the perceptions, experiences and attitudes of academics on RLT.

A semi-structured interview was a suitable method of data collection for this study as it captured how a person thinks or feels on a particular topic; it is flexible in terms of the order in which the topics are considered (Denscombe, 2007; Johnson \& Christensen, 2008 ). Furthermore, with such an interviewing strategy participants are able to express themselves freely without the interviewer controlling the discussion and develop connectedness with the interviewees (Johnson \& Christensen, 2008). In essence this allows the interviewees to go in-depth as they choose while the interviewer manages the broad discussion. Such interviewing enables the researcher to attain rich, personalized information (Mason, 2002). Moreover, the decision to use one-on-one interviews was because the technique is easier to arrange and control in comparison to focus groups. All in all, the participants of this study were lecturers and it was not easy to arrange one meeting time that suits them all. Also, I found it more manageable to locate specific ideas and to transcribe when the interviews stem from one interviewee (Denscombe, 2007).

Key themes for the interview (See Appendix F) were sent to participants before the interview. The reason for this is as follows: according to Hart and Bondas (cited in Bell, 2005) participants who speak a foreign language should be given time to read and reread the questions or key themes at his or her own pace. During the interviews I noticed the participants had a good understanding of the themes and questions being asked, thus 
reducing misinterpretation between interviewer and participants. This also helps the participants to think more deeply about the questions. The questions for the interview were developed based on the research objectives and questions. Also, an interview protocol (See Appendix G) was used during the interview by the researcher to keep track of the conversation and to note important answers, facial expressions and the feelings of the participants during the interview. The recording did not capture the latter.

The interviews were conducted in English for participants in New Zealand while the interviews in Cambodia were conducted in both English and Khmer based on the preference of the participants. There were five Cambodian participants who spoke English for the interview. The reason that most academics in Cambodia used English for the interview was because they acknowledged that this thesis would be written in English. It was a good idea to speak in English as it did not waste time translating and because it reduced misunderstanding or misinterpretations in Khmer or English. In order to avoid misunderstanding or misinterpreting, questions and answers were often repeated for clarification throughout the interview. Among the six participants in Cambodia one participant preferred to talk in Khmer despite being fluent in English. The participant wanted to ensure that accurate information was obtained during the interview because some expressions might be easily expressed in native language. To ensure the quality of information from this participant, double translations were made: from Khmer to English and from English to Khmer to cross-check and compare the information for the two languages in order to obtain accurate data.

Interviews were held in a place that was convenient and comfortable for both the researcher and participants and meeting time was arranged based on the agreement of both parties. Each interview lasted from 35 minutes to 60 minutes and was recorded with a digital voice recorder in order to capture the details of the interview. As suggested by Johnson and Christensen (2008), voice recording is the best method to capture all data mentioned by participants. In using the voice recorder I can refer to the original interview which note taking may not allow.

\section{Documentation}

Apart from the interview, another source of data collection used in this qualitative case study was the analysis of documentation. The documents used are official university 
documents including university guidelines, course outlines/course syllabi and academics' job description/employment contracts. Document analysis is a "systematic procedure for reviewing or evaluating documents" that can be either printed or electronic (Bowen, 2009, p.27). Denscombe (2007) pointed out, "documents can be treated as a source of data in their own right - in effect an alternative to questionnaire, interviews or observation" (p. 227). Yin (2003) asserted that "the most important use of documents is to corroborate and augment evidence from other sources" (p. 87). Documents gathered were analyzed alongside and integrated with the data collected from semi-structured interview providing another source of triangulation (see Section 4.6.4).

Conducting document searches through the internet enabled me to identify the policy of the university, any research initiatives at the universities and the practices of RLT among the participants in my study. Such internet searches offered documents such as university guidelines, academics' job description, academics' employment contract and course outlines/syllabus. This helped me reflect upon the culture of the academics who worked in the universities. The analysis of the documentation revealed university policy related to the teaching and role of RLT in the university.

\subsubsection{Data Analysis Process and Methods}

Data analysis in qualitative research involves transforming raw data from interview or documentation into findings by making meaning of text or images (Creswell, 2009; Patton, 2002). However, there is no single correct way of analyzing qualitative data but one of the important factors in making effective data analysis is the need to be systematic (Koshy, 2010). For this study, data was analyzed using a deductive approach. A deductive approach was considered the most suitable method for analysis of the data for this study as data from the interview was coded based on the predetermined themes generated from literature review. According to Menter, Elliot, Hulme, Lewin and Lowden (2011) if a researcher "seeks to explore and test theories (deductive), the initial codes will reflect research objectives, questions and related concepts" (p. 145). Thus, by using deductive approach the answer to the research questions could be obtained.

For deductive analysis the coding process is very important as themes and concepts in the data are identified through comparisons, categorisations, interpretations, 
descriptions and synthesis (Ezzy, 2002; Copper, 1998). Such a process creates meaning out of the text data; examining codes for overlaps as well as reducing and collapsing codes into broad themes (Creswell, 2008) and consequently narrowing data into fewer and more precise themes (Creswell, 2003). In this case the deductive approach was used to code each interview transcript and collected documents based on the research questions or key themes with the facilitation of Nvivo 9 qualitative analysis software for the process of coding.

For this study I used guidelines provided by Densombe (2007). The steps to coding and analyzing interview data and documents are described as follows.

Preparation of data: At this stage, in order for the raw data to be amenable to analysis I imported all interview transcripts and collected documents into two different files of Nvivo software.

Familiarity with the data: In this phase, I was familiarizing with data by reading through all the 12 transcripts and collected documents several times to gain an overall sense of the information and to consider its general meaning. I also corroborate those transcripts with the notes I made in the interview to make sure I obtained accurate data and transcripts.

Interpreting the data: For this step, I coded the themes in Nvivo9 by creating tree nodes with hierarchical structures from the interview transcripts. First, I developed initial codes themes based on themes derived from the broad concepts of RLT identified in the literature review and research questions of the study as it is a deductive analysis. Then, I picked one transcript of choice, considered its meaning and coded according to the initial codes. I also added new codes emerging from transcripts which related to research focus. At this point, I was open to any possibility that was potentially relevant to answer the research questions. Recurrent patterns of particular instances, whether a word, a phrase or a sentence, were examined and coded and added to the tree node by creating another level of node for sub-theme. The process of coding by identifying text segments and assigning a code word was used the same ways for the 12 transcripts and all collected documents. The codes were then grouped together into patterns to provide an answer to the theme questions. This involved the identification of data and the production of codes from data that related to the research questions. 
Verifying the data: For the purpose of data coding verification, I cross-checked coding with my supervisor for four transcripts (See Section 3.7.2). Moreover, to obtain the credibility of the study, I have put a lot of considerations on research truthworthiness (See Section 3.7).

Representing the data: I based an analysis of data on the interviews, and synthesized this with a document analysis for concise and convincing report findings.

\subsection{Research Trustworthiness}

The validity and reliability of data from qualitative research studies are often judged against the concepts of trustworthiness (Lincoln \& Guba, 1985 cited in Merriam 2009). To establish the trustworthiness of a study, Lincoln and Guba (1985), suggested four confirmability. These criteria acknowledge the irreducible complexity of the case study context, the perspectives and meanings drawn from the inquiry by individuals which must be reflected in the research design and methods. Since this study involved investigating people's perceptions there is a need to ensure that the report and its findings are as authentic as possible by applying the four criteria to this research at the design phase.

\subsubsection{Credibility}

In qualitative research, credibility refers to the extent to which the research account is believable and appropriate (Gibbs, 2007). In this sense, it is based on determining whether the findings are accurate from the standpoint of the researcher, the participant, or the readers of an account (Creswell \& Miller, 2000). The strategies adopted to ensure this degree of credibility were: use of triangulation and member checking.

Triangulation: Triangulation is a powerful way of demonstrating concurrent credibility, particularly in qualitative research (Johnson \& Christensen, 2008). There are many types of triangulation: triangulated by source of data, research methods, researcher, theory (Miles \& Huberman, 1994). For this study, I triangulated the data through two different methods of data collection: interview and documentation. This helped to overcome the weaknesses of a single method and helps to gain more evidence of the area being studied (Johnson \& Christensen, 2008; Yin, 2003). I utilised different 
sources of data (different perspectives from participants in Cambodia and NZ) to build coherent justification for themes.

Member checking: Member checking or respondent validation is "the process of a researcher sharing preliminary data analysis and interpretation with study participants to determine whether they agree or disagree with the researcher's analysis" (Hinchey, 2008, p. 97). In assuring the credibility of this study, member-checking was conducted. I used member checking to ensure there was no discrepancy between my understanding of the academics' responses and the meaning they intended in their responses by returning the transcripts of the interviews to participants so that they could review the data for necessary amendment. Due to my tough research time frame, I could not manage to share my initial analysis with participants for feedback.

\subsubsection{Dependability}

Dependability in qualitative studies indicates that the researcher's approach is consistent across different researchers and different projects (Gibbs, 2007). In qualitative research dependability can be addressed in several ways. According to Creswell (2013), dependability can be enhanced through detailed field notes (by using a good recorder to record the interview), the transcription of interviews and the cross-checking of code by different researchers to establish inter-rater reliability. For this study I tried to achieve dependability by conducting pilot interview and cross-checking the transcription, translation and coding.

Pilot interviews: Before the actual interviews with participants I carried out two pilot interviews. First of all, it was done with one of my supervisors while another supervisor acted as an observer to give feedback. After having feedback on the first trial, I changed the way I posed the questions. I conducted the second trial with a postgraduate student. The purpose of the pilot interviews was to ensure the reliability by practising the conversation method of interviewing (ie., giving probes and avoiding leading questions). The interview trial was very beneficial as this allowed me to practise better listening, clarifying and garner interview skills based on my supervisors' comments. Moreover, I was aware of linguistic variability that could arise during the interview. For that reason I sought to understand the words and meanings as participants wanted them to mean, irrespective of how participants said them. This awareness enabled me to use the findings in a valid and fair manner and not to interpret data 
exploitatively. Both trial and actual interviews were recorded using a digital voice recorder. Using a good voice recorder allowed me to obtain detailed information from the interview which made my data more reliable.

Transcription and translation: The data from the Cambodian interview were transcribed (and translated) from Khmer to English by a local translation company in Cambodia. To ensure the quality of transcription and translation, the transcripts were rechecked by the researcher. Then, copies of the written transcripts were sent back to participants through email to check and comment. Some transcripts were accepted as a true and correct record with no changes while some participants made some comments and small amendments. Generally, participants did not change a viewpoint they shared after their interviews but rather added comments on the way they saw them and made small amendments on language use.

For the accuracy and reliability of translation, the researcher played an important role in rechecking the translation by re-reading the raw data in Khmer language and adopting the process of "cross-language interpretation" suggested by Esposito (2001, p. 571). He suggested that to develop a reliable translation, the translator should conceptualize and understand the meaning of the raw data in participants' language and be able to reexpress the meaning before translating into target language.

Inter-rater reliability: According to Johnson and Christensen (2008) two types of inter-rater reliability are inter-coder reliability and intra-coder reliability. Inter-coder reliability refers to the consistency obtaining between or across different coders while intra-coder reliability refers to the consistency achieving within a single individual (Jonhson \& Christensen, 2008). To obtain intra-coder reliability for my coding I used the same process and the same main and sub-themes to analyze data of the 12 transcripts. Moreover, to reduce errors due to inconsistencies for my coding, inter-coder agreement was used to measure the reliability of the coding. Inter-coder agreement is another term using by Creswell (2009) to refer to two or more coders agreeing on codes used for the same passage in the text. In line with this, my supervisor and I did the coding from the same two transcripts. At first we did the coding individually based on research questions. After we got it done, we compared our coding. We agreed on 43 out of 56 code decisions. The result of our coding comparison was approximately $75 \%$ agreement on the coding. It is recommended that the consistency of the coding be in agreement at least $80 \%$ of the time for good qualitative reliability (Mile \& Hurberman, 
1994). Since our coding did not achieve the level of a good reliability, we did two more coding from two other different transcripts. The second time we discussed and agreed with each other on the description of the code we were going to make before we started our next coding. In comparison, we agreed on 53 out of 59 code decisions for both transcripts which was approximately $95 \%$ agreement on the coding. This process was very useful for me as I can improve the quality of my coding for the subsequent coding.

\subsubsection{Transferability}

Transferability refers to "the extent to which the findings of one study can be applied to other situations" (Merriam, 2009, p. 223). Schwandt (2007) asserted that transferability deals with issues of generalizing the findings from case-to-case. However, the transferability for a single case study is limited (Flyvberg, 2006). A case study cannot offer transferability other than that by which the reader recognizes as applicable to their situation. Thus, to enable the readers to assess the transferability of this study, I conducted in-depth interviews with 12 participants which aimed at providing detailed description of themes that are central to my findings so the reader can determine the degree to which the conclusions in this case study can inform the practices in their setting.

\subsubsection{Confirmability}

According to Denscombe (2007), confirmability or objectivity refers to the degree to which the findings of a research study are created by the participants and not by the researcher's bias, motivation, or interest. To reduce the effect of my bias in the present study I have encountered this by reflexivity (See section 4.8 for more explanation), triangulation of data using multiple data collection methods and sharing my initial findings with my supervisors. Schwandt (2007) suggested that having other persons besides the researcher examining the data and interpretations could be a strategy to promote confirmability.

\subsection{My role as the researcher}

For the purpose of the axiology of the study, it is important that I undertake an interpretive-constructivist approach to acknowledge the background and perspectives that I bring into this research. Smith (2008) pointed out that "it is important to 
acknowledge the perspective one brings; however the goal is not to overcome or change this perspective, but later make known how it has affected the research" (p.18).

Throughout this research I tried to be aware of the personal and professional biases I bring to the study as I am a teacher at a private institute in Cambodia and also a postgraduate student in both Cambodia and NZ. These experiences might influence my worldview of the understanding and the practice of RLT in higher education for both countries. Moreover, it can be assumed that my role as a researcher for this study was also partly that of a participant in this study. It is acknowledged that this role was conducted for and with participants as I am also a teacher in a private institution in Cambodia. According to this, I entered fieldwork with assumptions that may have influenced how I gathered and analyzed data during this research. For instance, prior to the fieldwork taking place I had the impression that RLT was very useful for both teachers and students. I was also under the impression that not many teachers in Cambodia conducted RLT as they did not have enough support while teachers in NZ were expected to conduct research for their teaching and provided support.

Although I might bring my biases into the research, my biases are minimized through reflexivity and the acknowledgement of each participant's influence. Through reflexivity I monitored and attempted to control my biases by actively involving myself in critical self-reflection on my potential biases and predispositions.

\subsection{Ethical considerations}

Any research study involving human beings should be characterised by protection of the human rights, dignity, health and safety of the participants and researchers (Johnson \& Christensen, 2008). Prior to undertaking the study ethical approval was obtained from the Victoria University of Wellington Faculty of Education Human Ethics Committee (see Appendix H).

\subsubsection{Consent form}

While ethical considerations are central to all research, it does not follow that the same approach is appropriate for all. As Blaxter (cited in Bell, 2005) makes clear, "ethical research involves getting the consent form of those you are going to question" (p.46). The premise of consent form, according to Denscombe (2007), is that people's "participation must always be voluntary, and they should have sufficient information 
about the research to arrive at a reasonable judgment about whether or not they want to participate" (p.145).

To gain consent (see Appendices D and E) for this study all participants were provided an information sheet explaining the background and purpose of the study and what was required of them. This was to ensure that all participants had a chance to read and gain a clear understanding about what, how and why the research was being conducted before they agreed to participate in this study and sign the consent form.

\subsubsection{Confidentiality and Anonymity}

Special care was taken to ensure that participants' confidentiality and professional integrity is not compromised by anything they contribute to this study. The participants' names and the names of the universities were not mentioned in report findings. The confidentiality for selected universities and participants were maintained by using pseudonyms.

Explicit assurances were given regarding all information gathered, data storage and use. The transcripts and recordings were stored in the researcher's personal laptop and protected by password. Furthermore, access to all research data was restricted to my supervisors and me. All written data and voice recording used in the research are to be destroyed in three years after the completion of this research.

A confidentiality contract (see Appendix I) was agreed by the translation/coding company to maintain the confidentiality of all information contained on the files, including the names of participants as well as any other identifying information (such as university, etc.). Furthermore, it was agreed not to make any copies of the data or keep any record of them other than those required for the project and requested in writing by the investigator/researcher.

\subsection{Chapter summary}

This chapter has presented the constructivist-interpretive paradigm and the qualitative case study research underpinning this thesis. These theoretical perspectives are important for understanding the nature of the research, its assumptions about methodology, how the study was carried out and the framework for conducting the research. Furthermore, the methods used to collect the empirical materials to answer 
the research questions were semi-structured interview and documentation for the purpose of triangulation. The analysis of data was conducted through a deductive approach whereby coding was based on key themes or research questions. Also, the research trustworthiness was judged against four main criteria: creditability (through triangulation and member-checking), dependability (through pilot interview, transcription/translation, inter-rater reliability), transferability (through thick description of the themes), and confirmability (through researcher's reflexivity, triangulation and sharing initial findings with supervisors). To reduce bias for this study, the researcher's role was also pointed out. Finally, ethical considerations such as informed consent and the confidentiality and anonymity of the participants and universities were discussed. 


\section{CHAPTER 5: \\ RESEARCH FINDINGS}

\subsection{Chapter overview}

This chapter reports the findings that have been drawn from the five main research questions below:

1. What understanding do academics in Cambodia and NZ have of the term 'RLT'?

2. To what extent do the academics engage in RLT? Why or why not?

3. What are the academics' attitudes towards RLT?

4. How do the academics perceive RLT impacts on their teaching and student learning? Why?

5. What are the supports and challenges for RLT?

The findings are organised into three main themes. The first theme addresses the first, second and third research questions which are about academics' perceptions, attitudes and practices of RLT. The second theme is the academics' reflections on how RLT impacts on and contributes to teaching and student learning. The third theme is the useful supports for RLT and the challenges of the academics in practising RLT. The chapter concludes with a brief summary of the key findings of the study.

\subsection{Academics' perceptions, attitudes, and practices of RLT}

\subsubsection{Conceptualising 'RLT'}

Participants of the study perceived RLT in four different ways (see Table 5.1). First, the majority of the participants (10 out of 12) conceptualised RLT as teaching that was informed by academics' personal research. In other words, while teaching academics were using their own research either in the form of an example for their class discussion and other class activities or as course reading materials. For example, Cambodian Lecturer (CL) \#12 commented that RLT involved bringing the findings or results from one's own research to relate to the course being taught or to use for other class activities. Similarly, NZ Lecturer (NZL) \#4 added that if she was carrying out research into an aspect of teaching, then when she is teaching her students she is able to give them examples from her own research. Meanwhile, NZL\# 2 thought RLT was informed 
by the research that she had done, so that she primarily taught based on research. With that, RLT lecturers emphasised the relationship between teaching and academics' own research for relating to the class activities or lessons.

Table 5. 1: The summary of how academics defined RLT

\begin{tabular}{|c|c|c|c|c|}
\hline Participants & $\begin{array}{c}\text { Teaching } \\
\text { informed by } \\
\text { academics' } \\
\text { own research }\end{array}$ & $\begin{array}{c}\text { Teaching } \\
\text { informed by } \\
\text { other peoples } \\
\text { research }\end{array}$ & $\begin{array}{l}\text { Teaching that } \\
\text { promotes } \\
\text { students' } \\
\text { engagement in } \\
\text { research }\end{array}$ & $\begin{array}{c}\text { Teaching } \\
\text { informed by } \\
\text { academics } \\
\text { performance } \\
\text { research }\end{array}$ \\
\hline NZL\#1 & $\checkmark$ & $\checkmark$ & & \\
\hline NZL\#2 & $\checkmark$ & $\checkmark$ & $\checkmark$ & \\
\hline NZL\#3 & $\checkmark$ & $\checkmark$ & $\checkmark$ & $\checkmark$ \\
\hline NZL\#4 & $\checkmark$ & $\checkmark$ & & $\checkmark$ \\
\hline NZL\#5 & $\checkmark$ & $\checkmark$ & & $\checkmark$ \\
\hline NZL\#6 & $\checkmark$ & $\checkmark$ & $\checkmark$ & $\checkmark$ \\
\hline CL\#7 & & & $\checkmark$ & \\
\hline CL\#8 & $\checkmark$ & $\checkmark$ & $\checkmark$ & \\
\hline CL\#9 & $\checkmark$ & $\checkmark$ & $\checkmark$ & \\
\hline CL\#10 & $\checkmark$ & $\checkmark$ & $\checkmark$ & \\
\hline CL\#11 & $\checkmark$ & $\checkmark$ & & \\
\hline CL\#12 & & $\checkmark$ & $\checkmark$ & $\checkmark$ \\
\hline
\end{tabular}

Secondly, all participants viewed RLT as a kind of teaching that can be informed by reading or using other peoples' recent research. In this sense research refers to official publication of journal articles, research projects, working papers, books or book chapters. Academics used these types of research articles to link to their teaching course in order to inform their teaching. For instance, NZL\# 3 and NZL\#5 argued that they rely on their own research, and the literature and research of others to inform their teaching. Similarly, CL\#11 emphasised, "teachers have to be active consumers of research products, meaning that they have to read many research pieces in order to inform their current teaching practices in the classroom". NZL\#2 and NZL\#5 justified the need for others' research as a component of RLT because their own research areas were less broad and alone, could not possibly inform everything that they taught. As summarized by NZL\#5, it seems that "RLT involves reading and using other peoples' research and helping students to unpack by relating the research into their teaching". 
Thirdly, eight participants explained RLT as teaching that promotes or enhances students' engagement in conducting research or using existing research publication in their study. The academics reported that for this conception of RLT the students' engagement included: learning research methods, analyzing the results of published research, engaging at any stage of the academics' research such as helping collect data for the purpose of degree fulfillment or interest. Some instances of such conception can be seen in the following statements by the participants:

If I was using RLT, I was trying to get my students to reflect on research and the application of that research. (NZL\#2)

It is also around the students having opportunities to engage with research themselves either in term of looking at research findings really closely. (NZL\#3)

RLT can be seen when I allow my students to engage in any stage of my own research such as data collection. (CL\#12)

Fourthly, five participants acknowledged RLT as the kind of teaching in which academics were researching their own teaching practices or student learning to improve their performance or the quality of their teaching. In other words, RLT is an approach for academics to conduct evaluations of their own practices and the quality of their teaching is informed or improved through findings of their research:

The other aspect of RLT was that I researched my students and what my students were learning from the courses to improve my teaching. (NZL\#4)

RLT was teaching and doing an experimental or action research on my own practices at the same time in order to improve my teaching and experiences. (CL\# 12)

In summary, RLT can be seen through four major conceptions: (1) teaching informed by academics' own research, (2) teaching informed by reading or using other people's research; (3) teaching enhanced by the promotion of students' participation in either academics' actual research or reflecting on ready published research; (4) teaching informed by academics conducting research to improve their teaching performances. Although these four main conceptions of RLT were perceived by the participants of this study, not all academics held all four perceptions. Some participants held broader ideas 
about RLT while other participants viewed the conceptions of RLT with a narrow understanding.

\subsubsection{Academics' practices of RLT and attitudes towards RLT}

The previous section illustrated a wide range of academics' understanding about RLT. Although the majority of academics shared similar conceptions of RLT, there were some differences in terms of emphasis and actual practices of RLT in the institutions and classrooms.

\subsubsection{The practices of RLT at institutional level}

All participants from NZ indicated that RLT has become very common in practice, but this was not a view articulated by Cambodian participants for reasons explained later in Section 5.4.2. As some participants explained:

Lecturers were moving into research-led culture that was not what we came for at first. (NZL\#1)

Lecturers have been encouraged to become research active and to bring their research into their teaching which then became the culture of RLT definitely. (NZL\#2)

RLT was not common in this institution as lecturers didn't have the culture of doing it. (CL\#8)

The majority of the participants in NZ noted that one of the most influential reasons for the culture of RLT was the institutional expectation which encouraged academics to become active researchers. As a result of institutional pressure most academics were expected to practise research to keep their job. This could be inferred from the following statements:

I think the original trigger that made it happen was the compulsion. (NZL\#1)

To show that we are research active is to keep our job.... it's a big motivation. (NZL\#5)

Although the culture of RLT originally arose from the demand of the institution most $\mathrm{NZ}$ academics showed very positive attitudes towards this practice. As reported, they 
found it was difficult and were resentful in the beginning but enjoyed doing it at the end. To quote some words of the participants:

It now becomes I do it not because I have to do, but it becomes something I do because I enjoy doing it. (NZL\#1)

I think I'm getting better at it and it's like when you're learning new things, it takes time to be good at it. (NZL\# 4)

From the analysis of academics' position description/ employment contracts and information about university policies, there is support for what the NZ academics said about the practice of RLT at their university: RLT was a common practice for NZ academics as they were expected to be research active and the university's mission was to promote RLT. Also, RLT was one of the performance indicators for University B's academics. The following is an excerpt from University B:

...plays a leading role in shaping NZ's future by adding significantly to the knowledge and understanding of natural phenomena, society, culture and technology through research, teaching, and interdisciplinary perspectives (University B's mission)

To professionally develop ones' self through research that complements the standard of teaching ... (Academics' position description for University B)

The document analysis indicated that RLT is emphasised for all levels in university B ranging from institution levels to personal levels. The emphasis at the institutional level can be seen through university policies, missions/vision, and academics' position description. The emphasis on an individual level can be seen through course syllabi and outlines.

However, document analysis on employment contracts for University A showed that there was no attention given to RLT as the duties for academics, the university and program mission however stated:

To foster high-quality research which will assist the development of new knowledge and create paths for national development; to provide research and service to the public [my emphasis] and private sectors for the advancement of national self-reliance. (University A's mission) 
To conduct scholarly research and train scholars who can conduct academic research [my emphasis] that address critical national and regional educational issues. (Program mission)

According to the latter, it could be assumed that there was a rhetoric-reality gap into implementing RLT in University A as it was emphasized in high level documentation but it was not visible or practiced among academics. This explains why Cambodian participants reported that RLT was not common practice in their workplace.

\subsubsection{The practices of RLT at personal level}

This section reports four main ways academics put RLT into practise based on the four conceptions defined by participants. The summary of academics' practices of RLT is shown in Table 5.2.

Table 5.2. The summary of academics' practices of RLT

\begin{tabular}{|c|c|c|c|c|}
\hline Participants & $\begin{array}{c}\text { Teaching } \\
\text { informed by } \\
\text { academics' } \\
\text { own research }\end{array}$ & $\begin{array}{c}\text { Teaching } \\
\text { informed by } \\
\text { other peoples' } \\
\text { research }\end{array}$ & $\begin{array}{c}\text { Teaching that } \\
\text { promotes } \\
\text { students' } \\
\text { engagement in } \\
\text { research }\end{array}$ & $\begin{array}{c}\text { Teaching } \\
\text { informed by } \\
\text { academics' } \\
\text { performance } \\
\text { research }\end{array}$ \\
\hline NZL\#1 & $\checkmark$ & $\checkmark$ & $\checkmark$ & $\checkmark$ \\
\hline NZL\#2 & $\checkmark$ & $\checkmark$ & $\checkmark$ & $\checkmark$ \\
\hline NZL\#3 & $\checkmark$ & $\checkmark$ & $\checkmark$ & $\checkmark$ \\
\hline NZL\#4 & $\checkmark$ & $\checkmark$ & $\checkmark$ & $\checkmark$ \\
\hline NZL\#5 & $\checkmark$ & $\checkmark$ & $\checkmark$ & \\
\hline NZL\#6 & $\checkmark$ & $\checkmark$ & $\checkmark$ & \\
\hline CL\#7 & & $\checkmark$ & $\checkmark$ & $\checkmark$ \\
\hline CL\#8 & & $\checkmark$ & $\checkmark$ & \\
\hline CL\#9 & & $\checkmark$ & $\checkmark$ & \\
\hline CL\#10 & $\checkmark$ & $\checkmark$ & $\checkmark$ & \\
\hline CL\#11 & & $\checkmark$ & $\checkmark$ & $\checkmark$ \\
\hline CL\#12 & & $\checkmark$ & $\checkmark$ & $\checkmark$ \\
\hline
\end{tabular}

First, the analysis shows that all participants had the opportunities to conduct their own research. Of these, seven were researching to inform their teaching. More importantly, 
the participants who conducted research to inform their teaching emphasised that quite often they conducted research which related to their area of teaching expertise as they discovered that it was useful for their teaching and students when their research and teaching were related. This enabled them to use their research in a more effective way, to inform their teaching. For example, NZL\#1 made a comment that he would not conduct research unless his research was actually going to lead into helping the students that he was teaching or helping his profession more widely. Similarly, CL\#10 suggested that when conducting research to inform teaching, academics should focus on the areas of expertise rather than covering other areas that do not fall within their expertise.

In addition, the participants who conducted research to inform their teaching asserted that they tried to use their research during class activities because they acknowledged the course benefits. Academics could relay research findings by incorporating it into course readings, thus permitting in depth lectures and discussions. As CL\#12 indicated conducting one's own research and using it in the teaching was more effective as the ability to deliver the message from the research to students was more in-depth, more reliable and clearer because he/she undertook the research.

Many academics conducted research for other purposes rather than to inform their teaching. Those purposes were to broaden their knowledge:

... teachers did research in order to strengthen their capacity and then to transfer that knowledge and experiences to the students. (CL\#10)

I have done a few researches for a few organisations so far, but most of my research is not to inform my teaching. I do it for other purposes such as to broaden my knowledge of the other field of my interest, but not in the field of teaching and I haven't used much of those research in my teaching as well (CL\#12)

For these reasons, research topics were not likely to link to the academics' fields of interest or teaching. This made it very hard to make connections to their teaching expertise.

Besides personal research, all of the participants used wide ranges of literature and colleagues' research to inform their teaching and broaden the field of their teaching. However, the ways they use other people's research varied. Some academics used other 
people's research as either course reading or extra reading materials for class discussion or lectures while other academics used it for course preparation. Moreover, instead of using other people's research immediately, some academics simply invited the researcher of the journal articles as a guest lecturer. The participants described their own experiences as follows:

I am using other people work either by getting them to come in to talk to the students or by including some of their work in the reading list. (NZL\#2)

I need to prepare my course syllabus on my own before I teach ... To do this, I need to search and read a lot of existing publications such as journal articles, research and so on. (CL\#12)

I asked my students to read some parts of other people research. Then I will ask those students to write their own objectives or research problems and discuss in a relation to the articles I gave. (CL\#10)

I am able to summarize the journal concept or something that I've read to spread to the class. (CL\#7)

Documents (i.e. course syllabus) that I collected confirm that all participants used extra readings such as journal articles and book chapters to inform their teaching. The majority of the participants used articles alongside course books for lectures, class discussion, assignments and exams. Some participants invited guest speakers to talk about their research for their class.

Almost all of the academics found that reading and using other people's research was to enrich their class activities. However, NZL\#6 suggest that academics should not totally rely on literature or other peoples research to inform their teaching. She stressed that the academics also needed to think about the context of the research and whether it would fit their context of teaching. Therefore, when reading or using other people's research to inform teaching, lecturers needed to make sure that those researching had a connection that could be used within the same context of their teaching.

Third, all participants reported that to some extent they had engaged their students in RLT. They tried to encourage their students through: taking the students along during data collection, assigning students some assignments which included processes of 
research, and reflecting the existing research publication. The participants described their own experiences as followed:

When I conduct research myself, I helped about ten students who were studying with me by providing the opportunities for them to engage in my research by going to the field to collect data with me. (CL\#10)

I gave students some raw data from my research and I asked them to look at the key themes of the data so they were actually engaging in data analysis as part of the task. (NZL\#3)

However, these engagements differed depending on whether students were undergraduate or postgraduate. It has been reported that engaging postgraduate students in research was easier to conduct than undergraduate students. This is because postgraduate students were learning more specific things and possess more time for research:

I think in the postgraduate environment, it is easy to engage the students in RLT. (NZL\#2)

For undergraduate course, it tends to be more formal learning environment to the lecture towards the course I am teaching. (NZL\#2)

For most of undergraduate students, we don't have them for long enough to engage in any worthwhile research. (NZL\#1)

Thus, it appeared that it was not easy to get students to conduct research themselves. It is manageable to engage them in some parts of the research but not in conducting research themselves.

Five academics conducted research on their teaching to inform and to improve their teaching performance. Most participants tended to research their students and what their students were learning from their course in order to improve the course syllabus and teaching performance for the next cohort. NZL\#6 did this through getting feedback from students on her teaching and by filming herself while teaching as a reference point for making changes for the next class. In this way, RLT was more to do with researching teachers' own performance to improve the quality of their teaching. In short, conceptions of RLT were reflected by the practices of RLT. 


\subsection{Perceived impacts of RLT on academics and students}

This section reported the second major theme of the findings which explained how RLT teaching was perceived to impact on the teaching profession and student learning. The participants of the study reported that RLT had more positive impacts than negative impacts for both academics and students. Each form of RLT - teacher research, using other people's research, student and teacher research into their teaching practice- had slightly different benefits and impacts on students and teachers. For instance, teacher research or teacher action research and using other people's research may mostly impact students and teachers while student research mainly benefits students.

The majority of the participants reported that in all forms RLT had many benefits for teachers and students. Teachers grew more expertise in teaching, gained more prestige through publication and felt more excited and enthusiastic about the teaching profession. Meanwhile, students had opportunities to learn up-to-date knowledge based on research evidence. NZL\#2 stressed that teacher research could help academics to develop an area of expertise to become more efficient as teachers. In summary, NZL\#2 can speak more enthusiastically and can engage students more often. NZ\#1 elaborated on the same point. NZL\#1 shared that when the students see the lectures they not only see the ideas but they also see the evidence the idea is based on. CL\#12 added to this point sharing that these sorts of things help situate the students in a bigger picture. This then helps students learn better as research is empirical and grounded in real-life experience. More importantly, students are learning current information from someone who has conducted research and is interested and passionate about the subject area (NZL\#2). Moreover, by conducting their own research academics earned practical experience, gained new information, a better image in publications, and meet their institution's promotion criteria (NZL\#2, NZL\#4 \& CL\#12). Furthermore, since RLT is an expectation for NZ participants three participants mentioned that one of the benefits of RLT was to keep their job. For instance, NZL\#4 noted, "the benefit is I still have this job".

Also, the participants of this study pointed out that research on teaching performance was very useful for both teachers and students. This form of RLT was perceived to enhance the quality of teaching and learning simultaneously. As NZL\#6 asserted, it was really important to have that kind of action research approach within one's own teaching practices, within each course because each course was very different. NZL\#6 
shared that researching academic's teaching led to adjustments to better meet student needs.

Reading and using literature or other people's research was considered very beneficial for both teachers and students. For example, one NZ lecturer (NZL\#1) believed that while conducting his research, he suddenly became aware of what people around the world were doing and this often provided reassurance in his practices that they have worked well. Also, academics were able to introduce certain things, certain concepts in practical ways from the research they read. The students also had great opportunities to learn more diverse things from different journal articles or research which were more tangible than only focusing on textbooks (CL\#10).

The participants of the study reported that encouraging students to conduct research themselves or engaging students in some parts of their research allowed students to learn more independently and become more in-depth in the area of their interest. In some participants' words:

By allowing my students to involve in collecting data for my research, this might help them to have better understanding of the theories they have learnt in term of research methodology in the course book in a relation with the reality.... (CL\#12)

By developing a strong research interest among students, I was encouraging my students to develop an expertise in that area and publish research. (NZL\#2)

It was a very useful way to really promote student learning autonomy or to promote a culture of inquiry learning to enhance student learning when they were doing research. (CL\#9)

For these reasons, CL\#8 claimed that although RLT might have good impact on students; students are not getting the most benefit out of RLT if they do not become involved in research-led learning. In this sense, no matter the extent of teacher's efforts in encouraging RLT in classrooms; students can only benefit from RLT if they practice research-led learning. Without research-led learning there were no benefits of RLT.

Although five participants reported that they could not imagine any bad impacts of RLT on teachers or students, the rest of the participants perceived some negative impacts that 
may affect both teachers and students. First, some participants explained that they had less time with students because most of the time was spent on research. Also, excessive focus on self-research created the feeling for the students that they were being used for someone's professional interests. The following statements illustrate these negative impacts:

In order to make lecturers become research active, courses had been shortened so students didn't get much time for face-to-face interaction with their lecturers. (NZL\#5)

If academics only taught what they researched, there would be huge gaps, as some research topics were so narrow and could not only be drawn on to inform their teaching. (NZL\#1)

RLT could sound like "self-centred or egocentric" things to students as they hear their lecturers talking about their own research. (NZL\#6)

Teacher may spend more time in class to test their theories rather than working on the contents itself which causes students to be just a guinea pig. (CL\#12)

Secondly, regarding the use of other people's research, lecturers might experience risks when the research is not applicable into the context of their teaching. As CL\#11 asserted sometimes the implication of the findings for a particular research study was not conclusive enough to be draw on when teaching.

Thirdly, some participants thought that RLT could be challenging for students as conducting research was time-consuming and demanded high critical thinking, active engagement and good preparation on each stage of research. NZL\#2 claimed for this point that it was very challenging for students as they need critical thinking to conduct their own research.

\subsection{The supports and challenges in conducting RLT}

This section reports the third main theme of the study: the supports needed in conducting RLT and academics' challenges in conducting RLT.

It is important to note that all participants in NZ reported that there was a lot of support for academics who are research active. Those supports include funding for conducting 
research and pursuing $\mathrm{PhD}$; time off from teaching to focus on research; facilities convenient for conducting research; research skills through workshops or training courses; incentives through recognition or promotion; advices from other colleagues. In contrast, Cambodian participants reported that they were having very little support for conducting research and some types of supports do not exist for them at all.

\subsubsection{Useful supports for RLT}

The participants for this study perceived: providing funding, balancing time, building research skills, promoting collegial support, providing infrastructure and giving incentive as useful supports for enhancing the practice of RLT across the institution as shown in Figure 5.1.

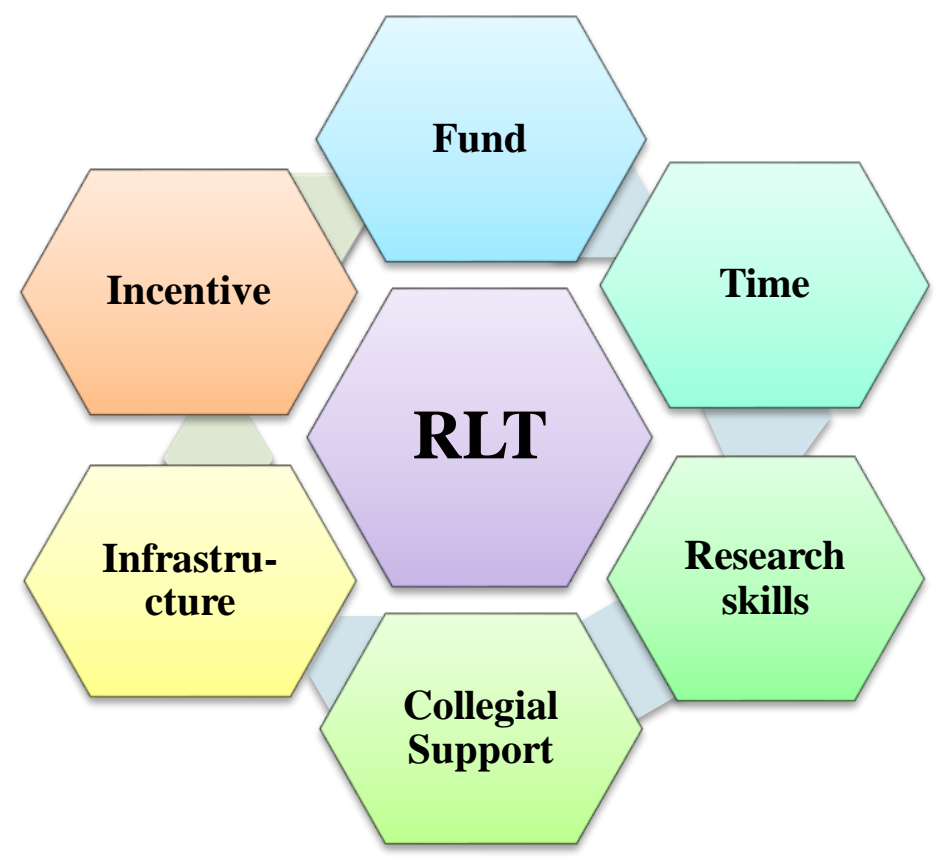

Figure 5.1. Useful support for RLT

The majority of the participants reported that financial support and the balance between teaching time and conducting research time were very important for them as they could use that budget to spend on the cost of research, production, and buy time off from teaching or marking to allow time for research. This can be seen through the following statements:

I can get some funds to go and present my research at conferences. (NZL\#2) 
I could use funding predominantly to pay a research assistant who helped doing a lot of research for me. (NZL\#3)

I sometimes use some budget from research grants to buy some time to release me from teaching or marking. (NZL\#5)

The institution should encourage teachers to conduct more research by allocating some time for teachers to do research and spend less time teaching... should establish some funding annually for teachers to conduct research related to their focus of teaching. (CL\#12)

Another important support was building on research skills. Most participants mentioned that research skills training or workshops were considered very useful for them to conduct research. Also, research involved academic writing which was not easy without a research background. As asserted by some participants:

A writing retreat was really useful for me and other academics because many academics including me have never written academic papers for most of our lives so by having that was very supportive. (NZL\#1)

I could go to various courses to familiarize myself with research skills which was very helpful for research actives. (NZL\#2)

Collegial support was reported to be another crucial support for research-led teachers as this could be the source of motivation to conduct research. Research was "a long way to run" so the person who conducted research needs ample mental and physical support to do better research (NZL\#1). All participants valued team work as one of the key successes for RLT. NZL\#2 asserted that collaborative research was very good for her. She added that working with someone else tends to motivate her because she is meeting with others and talking about it; this keeps it more alive than just doing something in her own time:

I can talk to people... I can ask for reading from my colleague and take courses to fill those knowledge gaps. (NZL\#1)

I had senior colleagues who were very encouraging, available to give advice and guidance which was supportive" (NZL\#6) 
I think teaming up is more possible for us to conduct research while teaching. (CL\#7)

In addition, infrastructure including proper facilities and technical support are very helpful for academics to conduct time-consuming research while teaching. It is very helpful if there are enough resources and facilities available for use. Some participants asserted:

It was very helpful to have staff members who would read, edit and check referencing and so on. (NZL\#4)

There was a research office... that supported academics with research processes such as transcription, publishing. This was really helpful. (NZL\#3)

The majority of participants, Cambodian academics in particular, reported that incentive was another powerful source of motivation and support to encourage teachers to conduct research. Incentives included recognition for doing research, value of publication and promotion criteria for being research active. CL\#10 asserted that with incentive, academics might become more involved in conducting research to inform their teaching despite minimal financial support. CL\#11 explained that this was because the recognition had made lecturers who are research active appear different from lecturers who are not research active. Some other academics mentioned:

The publication or presentation of the research results should be more welcome though the results of the study are more negative about the institute. (CL\#10)

If possible, the institution should think about the promotion for lecturers who published their research on a formal basis. (CL\#12)

\subsubsection{The challenges for RLT}

All participants of this study stated that time was the biggest challenge for them. Time was not only the challenge for participants who were conducting research but also a challenge for participants lacking opportunities to conduct research. For academics who were currently conducting research, balancing time between teaching, marking, and researching are enduring hardship as they are overloaded with responsibilities. For example, NZL\#2 shared her own experiences that doing research did not seem to be that hard, but having time to actually analyse the data and write it up into some forms of 
publication was probably the biggest challenge for her. She added that duties were exasperated by marking and other tasks, thus requiring her to be well-organised. NZL\#4 also shared her challenges. She shared that there were times when she felt very challenged because she had to juggle many commitments. Academics who did not conduct research explained that one of the reasons for this is that they were seen as merely part-time lecturers and did not have enough time for research. Meanwhile, fulltime lecturers thought that they were paid based on teaching time not time for research. Thus, they ended up not conducting research. To quote some participants words:

In my case, I was a part-time teacher so I don't have time to conduct any research. (CL\#7)

Teachers are not paid for time spending on research; they were paid based on teaching hours so all time was spent on teaching and no time for research. (CL\#10)

I don't really have luxurious time to design and spend on research although I knew it was very useful. (CL\#9)

Another challenge for most participants was the lack of research capacity. This included skills for conducting research. For example, one NZ participant pointed out that when he started doing his research it was a qualitative research which was "a whole new game" for him as he had not done any before he was "learning on the run" (NZL\#1). NZL\#6 gave a further explanation that it was challenging for an early career academic like her who came from the school teaching profession and who did not yet have an established research background. CL\#7 added that many teachers including himself, were not clear about research methods or research skills in conducting research as this was not taught properly in class during his studies. Thus, for him, a culture of doing research at the same time as teaching was lacking.

One more challenge for participants in NZ was the implementation of the Performance Based Research Fund (PBRF). Two participants reported that the requirement for academics to present an evidence portfolio of their research activities and publications for a PBRF assessment has led to an imbalance between teaching and research. This can be inferred from the following statements: 
There has been an external challenge which had been around the PBRF pushing all staff to be research active. (NZL\#3)

The suspicion was that, last year, the PBRF would not care if academics did not teach as long as academics got research projects done for the university. (NZL\#1)

The other important challenges for the participants of this study, the Cambodian participants in particular, was the lack of support in conducting research and the lack of value of research. The majority of the participants noted that there were not enough support for academics to conduct research and research was not valued by the society. For example, CL\#10 was conducting a research project and found the MoEYS unhappy with the findings. As the result, he fell under increased scrutiny by the MoEYS. He reported that "the MoEYS mentioned one thing that there are a lot of good things, you don't write. You write only about bad things". From this statement, one can assume that it is not the quality of research that is unsatisfactory rather, the findings that trouble the MoEYS. Further, CL\#10 explained that in this sense, research was not recognised or valued. He added that some topics were banned from researching. CL\#11 added that there were no differences in terms of recognition or promotion. Academics who conducted research and academics who did not were treated equally. However, some participants argued that having prime support is not enough for establishing and promoting RLT. In order to make RLT possible and successful among academics, individual responsibility and the institutional role in developing a culture of research must privilege accountability across the institution. This is because the institution is perceived as the powerful mechanism promoting the culture of RLT. The need for personal commitment can be inferred from the following quotes:

At the personal level, although money is always an issue...it is something more than money...It depends on individual commitment. I think personal commitment plays a critical role in term of practising in RLT. As far as you have commitment, you can sacrifice some time to do it. (CL\#8)

I think support is an external thing.... we need to change ourselves first...start from ourselves... don't complain about having no support. (CL\#10)

I would say it likely depends on the interest or motivation for each faculty member. (CL\#11) 
Regarding the importance of university encouragement of the practice of RLT, NZL\#1 commented that "if universities, as opposed to the technical institution or whatever, I would have thought that the universities themselves, the managerial side would be the ones to start the ball rolling". NZL\#2 added that the practice of RLT will happen if it is an expectation from the university. NZL\#3 argued, make RLT a requirement as sometimes accountability makes people work harder and is more convincing.

In synopsis, it seems that these three components: support, expectation from the institution (with attendant accountability) and individual commitment must coincide to establish a successful research-led university (Figure 5.2). NZL\#5 shared her belief that it would be terrible to make academics practice RLT without putting support in place. Furthermore, it is still impossible if the academic is without strong commitment.

\section{Accountatbility}

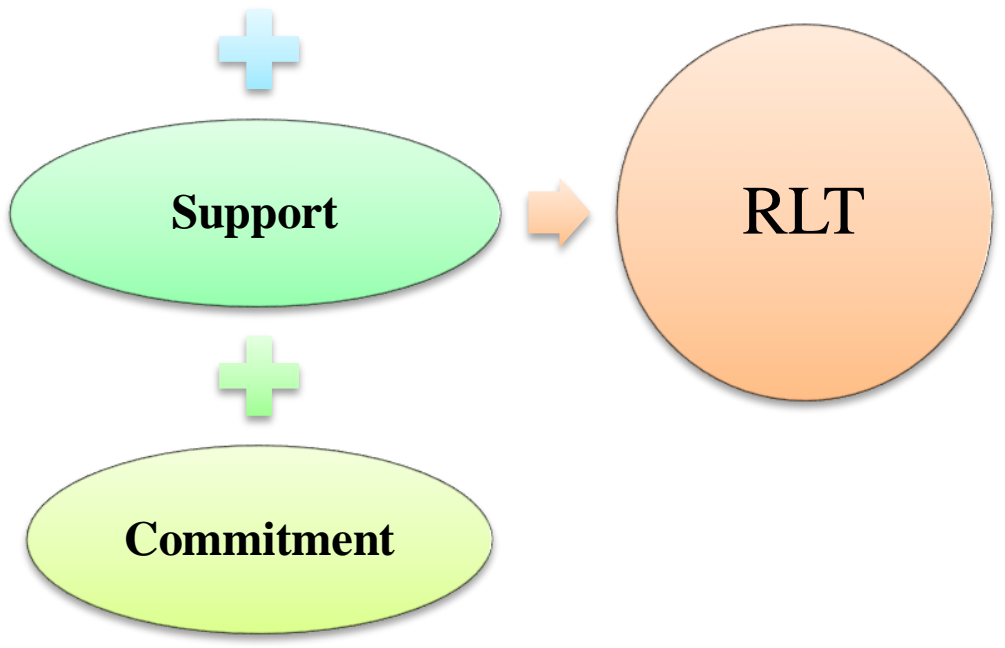

Figure 5.2. Useful components in promoting RLT across the institution

\subsection{Chapter summary}

RLT was conceptualised into four main points: (1) teaching informed by teacher research, (2) teaching informed by reading or using other people's research; (3) teaching that enhances student research; (4) teaching informed by teacher action research. The first and second conceptions were the most common understanding among the participants. In terms of practice, the use of other peoples' research to inform teaching was very popular for all participants. Meanwhile the rest are less common due 
to reasons such as time constraint, lack of research background and lack of financial support for conducting research. Although, the participants thought that RLT was very challenging for them, the majority of the participants still showed a very positive attitude towards the practice of RLT as they thought that RLT had many benefits for both teachers and students. Benefits include enhancing teaching and learning in a way that increases academics expertise in teaching. This exposes students to up-to-date knowledge and reliable information on the basis of research evidence. Some participants also pointed out the importance of individual commitment and the university role in pushing the culture of RLT into practice. 


\section{CHAPTER 6: \\ DISCUSSION AND CONCLUSION}

\subsection{Chapter overview}

This chapter is the overall summary of the thesis. First, the chapter summarizes key findings for the five main research questions below:

1. What understanding do academics in Cambodia and NZ have of the term 'RLT'?

2. To what extent do the academics engage in RLT? Why or why not?

3. What are the academics' attitudes towards RLT?

4. How do the academics perceive RLT impacts on their teaching and student learning? Why?

5. What are the supports and challenges for RLT?

Second, the key findings will be further discussed and explained with reference to the conceptual framework of the study, and previous studies. Third, it examines the implications of the study for academics, and research-led universities. Fourth, it outlines the limitations of the study. Fifth, it provides recommendations for further research. Finally, a brief conclusion statement finishes the chapter.

\subsection{Summary of the research findings}

This section summarizes the key findings of the research through the five main research questions.

The first question sought academics' understanding or conceptualisation of the term 'RLT'. A significant finding for this first question revealed four main conceptions of RLT. The conceptions included teaching that was informed by academics' personal research (research that is either directly related to the area of teaching expertise or around the discipline of their teaching); teaching that was informed by colleagues' or other people's research; teaching that was informed and enhanced by academics' research on their teaching or student learning (some participants called this action research); and teaching that promoted students' engagement in research to enhance student learning. Although, these four conceptions were perceived among the 
participants of this study, only one participant held all the four conceptions while others might have one, two or three conceptions (see Table 5.1.).

The second question examined the practice of RLT at institutional and personal levels. An important finding was that the institution's expectation for academics to become research active was a key source of motivation for the practice of RLT at both levels. Also, there was a rhetoric-reality gap between institutional policy and the implementation of RLT in Cambodia. The condition of RLT in NZ was reported as a common practice at the time of this study, while it was seen as a new idea for Cambodian academics. Also, academics' practice of RLT at a personal level was diversified based on meanings attached to the term 'RLT'. The RLT implementation comprised of academics using their own research to link to their lectures, assignments, class discussions or to include in the course reading lists. In addition, the use of other's people research was recognized in many different forms such as for course preparation, course reading, class discussions and guest speaker. However, the engagement of students in research was not common for undergraduate levels due to the time constraint and little emphasis of research skills. For postgraduate students, academics encouraged participation in data collection of their own research and assigned students some tasks, including the process of research or analysis of data from existing research publication. Some academics conducted research on their own teaching or student learning to improve their teaching quality and performance.

The third question recognized academics' attitudes towards the practice of RLT. The study revealed that most academics showed very positive attitudes towards the practice of RLT although it was considered difficult at the start. Another important finding from this study was the ambivalence many academics had towards the practice of RLT as it was both beneficial and challenging for them.

The fourth question explored academics' perceptions on the impacts of RLT on academics themselves and students. Both Cambodian and NZ academics perceived the benefits of RLT outweighed the drawbacks. For academics whose teaching was research-led in any forms, expressed themselves had greater knowledge of the field of teaching, and were more motivated and enthusiastic about teaching profession which, they believed, then led to better teaching. Also, they gained more prestige in publications and were promoted, while students learnt very up-to-date and diverse evidence-based material from research or journal articles which was more contemporary 
than just focusing on textbooks. Moreover, academics thought that learning through RLT made students became more independent, more critical in their learning and more passionate about further education. However, according to some academics in this study, the greater focus on research might result in less teaching time with students, and created the feeling for the students that they only studied from a narrow focus of individual professional interest.

The fifth question identified what considered useful supports for the implementation of RLT and challenges that might impede or inhibit implementation of RLT. Academics pointed out providing research funding, balancing time between teaching and researching, building research capacity, promoting collegial support, equipping enough infrastructure and giving incentives were useful and helpful for RLT implementation. Without these supports, it becomes a challenge for academics to practice RLT. The academics in this study concluded that besides all supports mentioned above, academics who were research active or wish to become research active needed to have high personal commitment and that making research accountability visible across the institution led to the implementation of RLT at both personal and institutional levels.

\subsection{Discussion of research findings}

For this section, I will discuss the findings with the conceptual framework of the study and in relation to the literature. The discussion is divided to five main parts: academics' perceptions of RLT, academics' experiences of RLT, academics' attitudes toward RLT, the impact of RLT on academics and students, and the support and challenges for academics.

\subsubsection{Academics' conceptions of RLT}

As indicated in the review of the literature, the conception of RLT is very complex (Brew, 2006; Healy, 2005). It varies from individual context of how university, academics understood the term 'research' (Brew, 2003; Zamorski, 2002), and how research is embedded in curriculum or pedagogy (Zamorski, 2002). For example, if academics have the notion that research usually focus on the external environment (Brew, 2001), they may conceptualise RLT as types of activities that involve students in a wide range of social activities such as "mirroring research conferences, journal publication, presenting posters, engaging in teamwork or networking" (Brew, 2003, p. 
2). However, if academics hold the notion that research normally focus on the analysis of empirical evidence to build their understanding or create knowledge, they may see RLT is "more a process of engaging students in a course on methodology, interpretation of data" (Brew, 2003, p. 2). Due to this, RLT has no single definition.

The research finding for this study indicates that it is RLT when academics used their personal research and other people's research to link into their teaching as well as to engage students in research. With this respect, the research findings informed the conceptual framework adapted from Angelo and Asmar (2005) for my study. More importantly, the findings revealed one conception of RLT that I had not originally included in the conceptual framework of my study. That element was 'teaching informed by academics' research on teaching and learning'. However, this conception can be grouped in the conception of teaching informed by academics' personal research. According to this, the conceptual framework of my study is reconceptualised as below:

\section{Other People's Research}

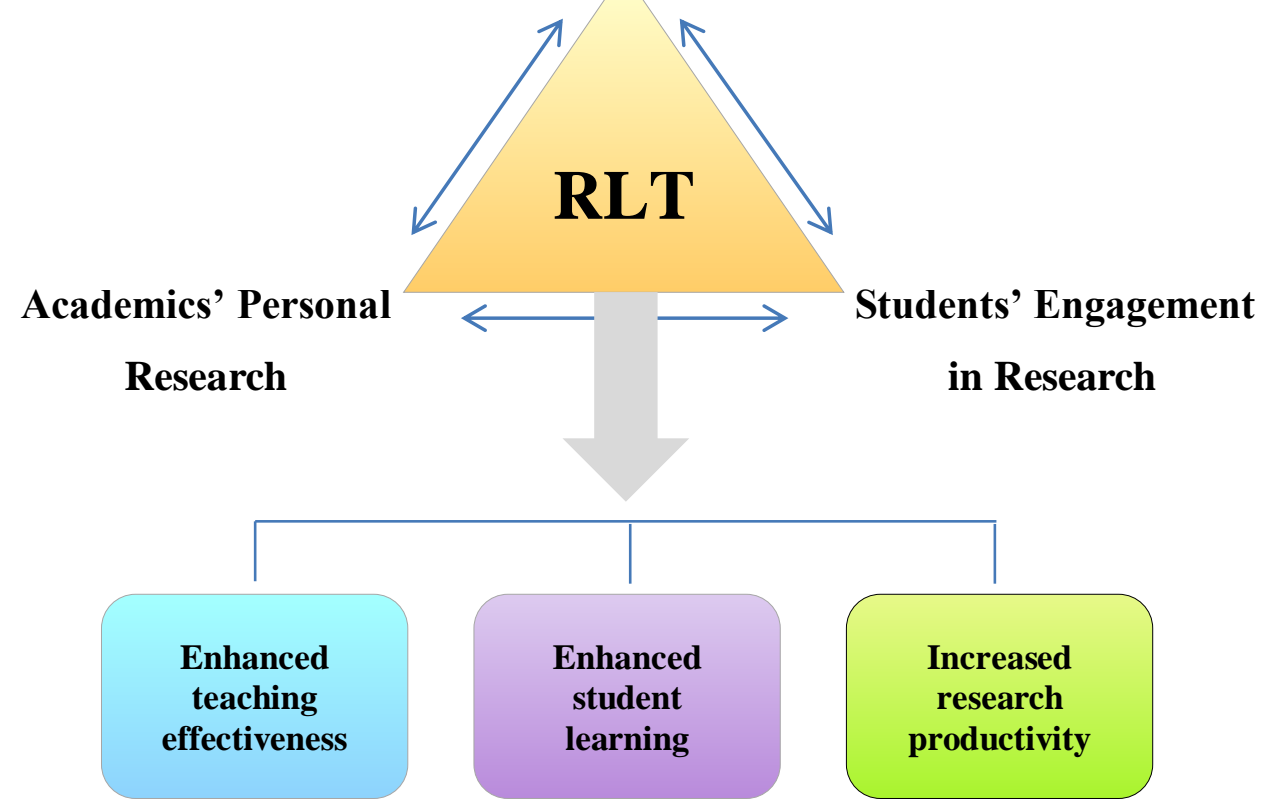

Figure 6.1. Reconceptualization of RLT

In addition to the consistency of the finding with the original conceptual framework of the study, it also supports Zamorski's (2002) study in which RLT were typically viewed by academics and students as "teaching that is heavily informed by their or others' recent research, or where research with or by students forms parts of the pedagogy or content of the course" (p.415). Zamorski (2002) also identified another less common 
understanding of RLT as the idea that academics investigated and reflected on their own practice. In this sense, it can be inferred that this notion of RLT is linked to my study as 'teaching that is informed by academics' personal research'. Such a conception includes research that is directly linked to the course teaching, research that is around the discipline of teaching, as well as research on the teaching performance or student learning.

\subsubsection{Academics' experiences of RLT}

Enhancing student learning through the engagement of research in teaching is very important for research-led education. In this respect, RLT is implemented through several ways based on an institution's or academics' understanding of the term itself. The literature indicates that this can be done through sharing academics' or other people's research findings with students and the engagement of student in research itself (Zamorski, 2002). Healy (2005) suggests RLT can be developed along three dimensions according to: 1) whether the emphasis is on research content or research process; 2) students as the audience or participant; and 3) whether the teaching is teacher-focused or student-focused.

The key theme running through the research finding is that the participants for this study articulated a transmission model of teaching to implement RLT while the enquiry based learning appeared to recieve less attention. The academics in this study usually transfered research findings to the students during class lectures or class discussion. By the omission of enquiry based approaches, RLT in this respect seems to be more teacher-focused rather than student- focused. According to Kember (1997), when academics impart information or transfer structured knowledge in the process of their teaching, students are very passive and the knowledge is possessed by academics. Thus, in these cases, the relationship between research and teaching is seen as transmission related (Robertson, 2007). RLT, in this sense, has a very small impact on the enhancement of student learning as learners gain most benefit from RLT when they are actively involved in part or in whole of undertaking research project (Healy, 2005). To gain more advance knowledge, literature suggests RLT needs to move beyond the transmission model. Universities have responsibilities to prepare students for the complex and challenging world that they will face as professionals (Brew, 2010). To do this, Robertson suggests further practice of RLT which emphasizes the engagement of students in research inquiry. For this kind of implementation, instead of transfer 
knowledge of research finding to their own student, academics are getting students to critically think in disciplinary ways, regarding the ontology and epistemology of the research with which they are engaging.

Since participants of this study are relative new to RLT and some are not research active, most of their practices towards RLT were more about the transmission model especially at undergraduate level. It is quite likely that a more experienced sample of academics, for whom higher levels of postgraduate teaching is their main focus, would have quite different approaches towards RLT.

\subsubsection{Academics' attitudes towards RLT}

Literature indicates that the national and institutional policy on RLT is the main drive for the beginning of a research culture. For example, in New Zealand, the establishment of PBRF has intensified research output, which may have led to greater implementation of RLT in the NZ university in this study. The academics found it hard and frustrating at the start of the practice of RLT, but the support through PBRF make them feel better at the end. A nation wide accountability mechansism such as the PBRF may be a source of motivation as well as a constraint for NZ academics at the same time. It is motivational as it is an expectation from the university, which has provided supports for academic staff. The challenge of such a system is that the teaching component of academics' workload is not overcome by the expectation for quality research.

\subsubsection{The impacts of RLT on academics and students}

Although, empirical studies reveal little relation between research and teaching (Hattie \& Marsh, 1996) and the benefit of RLT is still questioned (Robertson, 2007), academics assert that the link between research and teaching is beneficial for teaching and learning. Regarding this, participants in my study claimed that RLT benefits both teaching and learning. While academics become more expert in the field of teaching, students studied up-to-date information and became more independent in learning. This is aligned with a few studies by Neumann, (1994) and Zamorski (2002) which found that benefits that students gain from academics" research included "staff enthusiasm, the credibility of the staff and the reflected glory of being taught by nationally and internationally known researchers" (p. 193). However, Hattie and Marsh (1996) argue that academics who conducted good research may not be the most able to communicate research findings through their teaching. The implication here, is that the research that 
academics use to link with their teaching must be carefully chosen or conducted to reflect the real situation which then helps prepare students' research capability.

\subsubsection{The supports and challenges of RLT for academics}

Literature indicates that each HEI has different policies and priorities in promoting RLT. The study identifies different supports and challenges academics experience in the implementation of RLT in the Cambodian and NZ context. Surprisingly, there is very little literature addressing what support is needed to promote RLT. In term of support, the participants for this study, Cambodian in particular, concluded that support is considered a very useful mechanism in making RLT possible in the institution. The supports included funding, research capacity building, team work, incentive, and infrastructures. With the support from the institutions in a high stakes accountability environment, NZ participants seem to face fewer difficulties in conducting research to inform their teaching. However, participants in Cambodia found it very challenging to implement RLT. Shamai and Kfir (2010) asserted that budgetary difficulties and lack of expertise is the main obstacle for academics to conduct research to inform their teaching. In contrast, while having enough support from the PBRF program, NZ participants found it a challenge for them as this program tend to focus too much on research but not teaching or learning. Also, so much time was spent on conducting research that it restricted academics from having much teaching time with students.

\subsection{Implications for policy and practices}

This study specifically provides recommendations for the emphasis and the implementation of RLT at national, institutional and individual levels that enhance the quality of teaching and student learning, and increase research productivities. Also, the study fosters critical thinking and problem analysis in Cambodian university in particular as the study recognized very little emphasis and practice of RLT. Having identified the issues from the literature and study findings about Cambodian university, I will highlight some important issues that need to be taken into consideration in order for RLT to be implemented.

\subsubsection{Implications for national level}

An implication for the national level is that there is a need to review what has been contributed and affected based on the policy on the strengthening of RLT. In NZ, PBRF 
is an accountability mechanism for the culture of RLT in the universities. While the PBRF has undoubtedly been successful in the intensification of research, exactly to what extent this has had on RLT is less clear. The NZ academics seemd to speak of RLT as a by product of their research focus. Perhaps a future review of the PBRF takes into account the teaching of universities? Meanwhile, Cambodian Universities, if in a similar situation to the one I used as a sample in this study, may also need to establish some accountability mechanism (i.e. an equivalent of the PBRF) to shape the research output of Universities. Indirectly, this may help develop a more sustained practice of RLT across universities in Cambodia. This can help increase both research productivity and the quality of teaching and learning.

\subsubsection{Implications for institutional level}

Since there is a rhetoric gap between the policy and the implementation level in developing and strengthening the practice of RLT, an implication for the tertiary institutions is to review what is already in place or perceived to be in place. For instance, Cambodia has a lot of issues in regards to this. Strong emphasis on RLT in the institution is needed to develop the culture of RLT. This can be done through the inclusion of the implementation of RLT in university mission, position description and elsewhere in the university official documents. Also, the institution needs to encourage policy into practice by having enough supports in place. Through this, the culture of RLT can be developed and seen. The institutional drive to encourage RLT in the NZ University in this study was clearly backed by financial and human resources, that seem to be far less developed in the Cambodian setting. An increase in investment towards RLT at the institutional level in Cambodia may help Universities market themselves to students who want to be taught by academics at the 'cutting edge' of knowledge.

\subsubsection{Implications for individual level}

An implication of this study for teaching practice is for academics to move one step further of RLT from being teacher-centred to student-centred by explicitly engaging students in research to enhance their learning. This could be addressed by increasing class activities that embed research skills, especially for late undergraduate level, and encouraging students to undertake or be involved in research process. Due to the missing generation of academics in Cambodian HE, the enhancement of this potential should be initiated in teaching practices in order to ensure the wider population of 
students are introduced to this important skill. This conception of RLT is very useful in making connection between new and older academics by encouraging, inspiring, and motivating the next generation of academics. Even for most students who will not wish to become part of academia, such an introduction to RLT will develop the skills of critical and analytical thinking that will serve them well for whatever employment they decide to enter.

\subsection{Limitations of the study}

In order to achieve the purpose of the study, I used a constructivist-interpretive paradigm with the qualitative single case study approach. Also, semi-structured interviews and documents were conducted and collected among twelve participants for the purpose of data analysis. This research design was carefully chosen and prepared to provide trustworthy research finding as discussed in Chapter 4. However, due to the fact for having no perfect research design for a specific study (Guba \& Lincoln, 1994), it is worth acknowledging the limitations of this study.

First, since the recruitment of the participants fell on semester break for university in NZ, the confirmation of participation process was quite slow. There were just six participants out of 45 to confirm their participation. The selection of six participants in Cambodia was a challenge since the program had only 15 teaching staff.

Second, in qualitative study, having smaller number of participants through interviews provided more depth of the case than having larger number of participants as in quantitative study. However, the finding obtained from six academics of each country cannot represent the perceptions of all Cambodian and New Zealand academics in all universities across the countries. Moreover, due to the limited scope of this study, the findings of this study relied mainly on the perceptions and experiences of the academics while students' perceptions were ignored. Thus, the findings on the contributions and impacts of RLT to/on students may be problematic.

Third, the concept of RLT is quite new to Cambodian participants. For this reason, some participants may have little experience in real practices of RLT in teaching to respond to the questions being asked. Thus, it is not easy to obtain accurate information about the link between their perceptions and practices of RLT. 
Finally, this study is conducted and written in English which is not my native language; therefore, to some extent, this can be a challenge for me to get in-depth information during the interview as well as report the research findings. To deal with this, I had planned to use member checking which aimed to check the accuracy of the transcripts and the reliability of my interpretation on each participant's transcript by returning the transcript and initial coding/interpretation of the transcript to all participants. Unfortunately, I could manage to only check the accuracy of the transcript because I had an accident and broke my ankle. This incident has distorted the flow of my study and has left me a lot of concerns with research time frame. Consequently, the finding from the interview was reported based on my interpretation of the transcripts, without follow up member checking by participants.

\subsection{Recommendations for further research}

Initially, the findings from this study suggest that the application of RLT in HE has the potential benefits for student learning and teaching performance. It is therefore recommended that further research is undertaken to collect empirical evidence that validates these findings. Empirical studies on the practice of RLT in Cambodian or New Zealand universities would be particularly valuable due to the lack of research in this field, Cambodia in particular. A more thorough investigation into higher educational context and its cultural, social and political features is also recommended in order to generate a more detailed proposal for the application of RLT in Cambodia.

Moreover, adding to interview and document analysis, observation would be a useful method in data collection in further studies to examine academics' and students' actual practices of RLT. This will validate participants' reported perceptions, and reported practices in this study.

Additionally, further research should expand the scope of this study by recruiting a greater number of participants from different faculties or programs. This will provide a better and diverse insight into the area RLT and allow for better generalization that can represent a wider population. Besides, the recruitment of the participants of this study should be expanded from academics to students and top management staff such as program director, dean and vice-chancellor instead of just focusing on the academics' perceptions alone.

More importantly, data for this study was collected from two different settings, a post conflict society, Cambodia and a politically stable country. The findings for the study 
can be a bit contradicted from Cambodian context to NZ context due to the emphasis of RLT in the university context. Future research in this area should limit the scope of the study to just one setting, but from different universities in order to gain a more thorough insight into their experiences of RLT in that setting. Or future research might conduct a comparative study by selecting two settings which are broadly economically and socially comparable to make a comparison of the similarities and differences in the academic experience of these two groups in order to identify specific strategies for each group.

It would be beneficial if future research explored the strategies to enhance the practice of RLT as this finding reveals that there is rhetoric in policy regarding to the implementation of RLT at the 'ground level'. It would also be helpful if strategies were identified that would help Cambodian universities where RLT is almost unseen to overcome other kinds of challenges that have been explored in this study.

\subsection{Conclusion}

This study has made a practical contribution to educational research, particularly in the field of research and teaching in $\mathrm{HE}$ by providing empirical evidence to explore academics' meanings attached to RLT, as well as their reflections on RLT implementation. The findings of my study reveal that RLT is commonly practiced among NZ participants, although with different emphasis. RLT is less of a focus for Cambodian academics, a result of quite different expectations and supports at national, institutional and individual levels. 


\section{REFERENCES}

Ahrens, L., \& Kemmerer, F. (2002). Higher education development. Cambodia Development Review, 6(1), 8-11. Retrieved from

http://www.cdri.org.kh/webdata/cdr/2002/cdr03-1.pdf

Akerlind, G. S. (2008). An academic perspective on research and being a researcher: An integration of the literature. Studies in Higher Education, 33(1), 17-31.

Angelo, T. \& Asmar, C. (2005). Towards a new definition of research-led teaching and learning at VUW. Unpublished discussion paper. Retrieved from http://utdc.vuw.ac.nz/research/rlt.pdf

Ayres, D. (1999). The Khmer Rouge and education: Beyond the discourse of destruction. Historical of Education, 28(2), 205-218.

Ayres, D. (2003). Education and the localization of structural adjustment in Cambodia. In K. Mok \& A. Welch (Eds.), Globalization and educational restructuring in the Asia Pacific region (pp.232-261). New York: Palgrave Macmillan.

Ayres, D. (2000). Anatomy of crisis: Education and Scientific Cooperation: Strategy. Vienna: Australia Development Agency.

Badley, G. (2002). A really useful link between teaching and research. Teaching in Higher Education, 7 (4), 443-455.

Baldwin, G. (2005) The teaching-research nexus: How research informs and enhances learning and teaching in the University of Melbourne. Melbourne: The University of Melbourne.

Bell, J. (2005). Doing your research project: A guide for first-time researchers in education, health and social science. Maidenhead: Open University Press.

Biggs, J. (2003). Teaching for quality learning at university. Maidenhead: SRHE.

Bills, D. (2004). Supervisors' conceptions of research and the implications for supervisor development. International Journal for Academic Development, 9 (1), 85-97.

Bouma, D. G. (1996). The research process. Australia: Oxford University Press.

Bowen, G. A. (2009). Document analysis as a qualitative research method. Qualitative Research Journal, 9 (2), 27-40.

Brew, A. \& Boud, D. (1995). Teaching and research: Establish the vital link with learning, Higher Education, 29(3), 261-273.

Brew, A. (2001). The nature of research: inquiry in academic contexts. London: Routledge Falmer. 
Brew, A. (2002). Enhancing the quality of Learning Through Research-led Teaching. Workshop presented at Annual Conference of the Higher Education Research and Development Society of Australasia: Quality Conversations, Perth, WA.

Brew, A. (2003). Teaching and Research: New relationships and their implications for inquiry-based teaching and learning in higher education. Higher Education Research \& Development, 22 (1), 3-18.

Brew, A. (2006). Research and teaching: Beyond the divide. Hampshire, UK: Palgrave Macmillan.

Brown, B. R. (2005). Why link personal research and teaching? Educational \& Training, 47(6/7), 393-405.

Chandler, D. (2008). A history of Cambodia (4th ed.). Boulder, Colo.: Westview Press.

Chet, C. (2006). Cambodia. In UNESCO. Higher education in South-East Asia (pp.1333). Bangkok: UNESCO Bangkok.

Chet, C. (2009). Higher education in Cambodia. In Y. Hirosato and Y. Kitamura (Eds), The political economy of educational reforms and capacity development in Southeast Asia: Cases of Cambodia, Laos, and Vietnam (pp. 153-165). Dordrecht \& London: Springer.

Clark, B. R. (1994). The Research-Teaching-Study Nexus in Modern System of Higher Education. Higher Education Policy, 7(1), 11-17.

Clark, B. R. (1997). The modern integration of research activities with teaching and learning. Journal of Higher Education, 68(3), 241-255.

Clayton, T. (1998). Building the New Cambodia: Educational Destruction and Construction under the Khmer Rouge, 1975-1979. Retrieved from http://www.jstor.org/stable/369662

Clayton, T., \& Ngoy, Y. (1997). Cambodia. In G. A. Postiglione, \& G.C. L. Mak (Eds.), Asian higher education (pp. 21-36). Westport,Conn.: Greenwood Press.

Clayton, T., \& Yuok, N. (1997). Cambodia. In G. A. Postiglione \& G. C. Mak (Eds.), Asian higher education: An international handbook and reference guide (pp. 2136). Westport: Greenwood Publishing Group, Inc.

Coate, K., Barnett, R., \& Williams, G. (2001). Relationship between teaching and research in higher education in England. Higher Education Quarterly, 55(2), 158-174.

Coates, H., Dobson, I., Edwards, D., Friedman, T., Goedegebuure, L., \&Meek, L. (2009). The attractiveness of the Australian academic profession: A comparative analysis: Melbourne: ACER.

Cohen, L., Manion, L., \& Morrison, K. (2000). Research methods in education. London: Routedge Falmer. 
Copper, H. (1998). Synthesizing research: A guide for literature reviews (3rd ed.). Thousand Oaks, London: Sage Publications.

Creswell, J. W. (2003). Research design: Qualitative and quantitative, and mixed method approach. Thousand Oaks, California: Sage Publication.

Creswell, J. W. (2007). Qualitative inquiry and research design: choosing among five traditions. Thousand Oaks, California: Sage Publication.

Creswell, J. W. (2008). Educational research: Planning and evaluating quantitative and qualitative research. New Jersey: Pearson Education.

Creswell, J. W. (2009). Research design: qualitative, quantitative and mixed methods approach. Thousand Oaks, California: Sage Publication.

Creswell, J. W. (2013). Qualitative inquiry research design. Choosing among the five approaches. Thousand Oaks, California: Sage Publication.

Creswell, J. W., \& Miller, D. (2000). Determining validity in qualitative inquiry. Theory into Practice, 39(3), 124-130.

Deakin, M. (2006). Research led teaching: A review of two initiatives in valuing the link between teaching and research. Journal for Education in the Built Environment, 1 (1), 73-93.

Denscombe, M. (2007). The good research guide for small-scale social research Projects $\left(3^{\text {rd }}\right.$ ed.). Maidenhead: Open University Press.

Denzin, K. N., \& Lincoln, S. Y. (2005). The handbook of qualitative research ( $3^{\text {rd }}$ ed.). Thousand Oaks: Sage Publication.

Denzin, K. N., \& Lincoln, S. Y. (2008). The landscape of qualitative research. California: Sage Publication.

Dornyei, Z. (2007). Research method in applied linguistics. Oxford: Oxford University Press.

Elliot, D., Menter, I., Hulme, M., Lewin, J., \& Lowden, K. (2011). A Guide to practitioner research in education. London: Sage Publication.

Elton, L. (2001). Research and teaching: Conditions for a positive link. Teaching in Higher Education, 6 (1), 43-56.

Esposito, N. (2001). From meaning to meaning: The influence of translation techniques on non-English focus group research. Qualitative Health Research, 11(4), 568579 .

Ezzy, D. (2002). Qualitative analysis. New South Wales: Allen \& Unwin.

Flyvberg, B. (2006). Five Misunderstandings about case-study research. Qualitative Inquiry. 12 (2), 219-245. 
Freire, P. (1972). Pedagogy of the oppressed. Harmondsworth, UK: Penguin.

Gibbs, G. R. (2002). Institutional strategies for linking research and teaching. Exchange, Issue 3, 8-12.

Gibbs, G. R. (2007). Analysing qualitative data. London: Sage Publication.

Gilham, B. (2000). Case study research method. London: The Tower Building.

Griffiths, R. (2004). Knowledge production and the research-teaching nexus: The case of the built environment disciplines. Studies in Higher Education, 29 (6), 709726

Guba, E. G. (1990). The alternative paradigm dialog. In E. G. Guba (Ed.), The paradigm dialog (pp. 17-30). Newbury Park: Sage Publication.

Hammersley, M. (2002). The relationship between qualitative and quantitative research: Paradigm loyalty versus methodological eclecticism. In J. T. E. Richardson (Ed.), Handbook of qualitative research methods for psychology and the social sciences (pp. 159-174). Oxford: BPS Blackwell.

Hattie, J. \& Marsh, H.W. (1996). The relationship between research and teaching: A meta-analysis. Review of Educational Research, 66 (4), 507-542

Healey, M. (2005). Linking research and teaching to benefit student learning. Journal of Geography in Higher Education, 29(2), 183-201.

Hinchey, P. H. (2008). Action research primer. Peter Lang Inc Publication.

Innes-Brown, M. (2006). Higher Education, Cambodia. Australian Education International. Canberra: National Office of Overseas Skills Recognition.

Jenkins, A., \& Healey, M. (2005). Institutional strategies to link teaching and research. Heslington, UK: The Higher Education Academy.

Jenkins, A., Blackman, T., Lindsay, R., \& Paton-Saltzberg, R. (1998). Teaching and research: Student perspectives and policy implications. Studies in Higher Education, 23(2), 127-141.

Johnson, B., \& Christensen, L. (2008). Educational research: Quantitative, qualitative, and mixed approaches $\left(3^{\text {rd }}\right.$ ed.). Thousand Oaks, CA: Sage Publications.

Kember, D. (1997). A reconceptualization of the research in to university academics' conceptions of teaching. Learning and Instruction, 7(3), 255-275.

Kember, D., \& Gow, L. (1994). Orientations to teaching and their effect on the quality of student learning. Journal of Higher Education, 65(1), 58-74.

Kiley, M., and G. Mullins, (2005). Supervisors' conceptions of research: What are they? Scandinavian Journal of Education Research, 49, 245-62. 
Koshy, V. (2010). Action research for improving educational practice: A step-by-step guide. Sage Publications Ltd.

Kwok, K.W., Chan, S., Heng, C., Kim, S., Neth, B. \& Thon, V. (2010). Scoping study: Research capacities of Cambodia's universities. Phnom Penh: T \& S Printing.

Lucas, L., Healey, M., Jenkins, A. \& Short, C. (2008). Academics' experiences and perceptions of 'research' and 'teaching': developing the relationship between these activities to enhance student learning within different disciplines and institutions. York: Higher Education Academy

Marton, F., \& Saljo, R. (1976). 'On qualitative differences in learning 1. 'Outcome and process', British Journalof Educational Psychology, 46, 4-11.

Mason, B. (2002). Researching your own practice: The discipline of noticing. London: Routledge Falmer.

Merriam, S. B. (1998). Qualitative research and case study applications in education $\left(2^{\text {nd }}\right.$ ed.) California: Jossey-Bass.

Merriam, S. B. (2009). Qualitative research: a guide to design and implementation. San Fransisco, California: Jossey-Bass.

Mertens, D. M. (1998). Research methods in education and psychology: Integrating diversity with quantitative and qualitative approaches. Thousand Oaks, California: Sage Publication.

Miles, M. \& Huberman, A. (1994). Qualitative data analysis ( $2^{\text {nd }}$ ed.). Thousand Oaks, California: Sage Publication.

Ministry of Education. (2010). Tertiary education strategy 2010-15. Wellington: Author.

Minxuan, Z. (1998). Cambodian reforms in higher education finance. International Higher Education, 11, (p.8). Retrieved from

http://www.bc.edu/bc org/avp/soe/cihe/newsletter/ihe pdf/ihe11.pdf

MoEYS. (2010). Policy on Research Development in the Education Sector. Phnom Penh: Author.

MoEYS. (2011). Master Plan for Research Development in the Education Sector 20112015. Phnom Penh: Author.

Neumann, R. (1992). Perceptions of the teaching-research nexus: A framework for analysis. Higher Education, 23 (2), 159-171.

Neumann, R. (1994). The teaching-research nexus: applying a framework to university students' learning experiences. European Journal of Education, 29(2), 323-339.

Patton, M. Q. (2002). Qualitative research \& evaluation methods (3rd ed.). London: Sage Publication. 
Pit, C., \& Ford, D. (2004). Cambodian higher education: Mixed visions. In P. G. Altbach and T. Umakoshi (Eds), Asian universities: Historical perspective and contemporary challenges (pp. 333-362). Baltimore and London: The Johns Hopkins University Press.

Prosser, M., \& Trigwell, K. (1999). Understanding learning and teaching: The experience in higher education. Buckingham: Society for Research in Higher Education and the Open University Press.

Prosser, M., Martin, E., Trigwell, K., \& Ramsden, P. (2008). University academics' experience of research and its relationship to their experience of teaching. Instructional Science, 36(1), 3-16.

Punch, K. F. (1998). Introduction to social research: Quantitative and qualitative approaches. Thousand Oaks, London: Sage Publication.

Ramsden, P., \& Moses, I. (1992). Associations between research and teaching in Australia higher education. Higher Education, 23 (3), 273-295.

Robertson, J. (2007). Beyond the 'research/teaching nexus': Exploring the complexity of academic experience. Studies in Higher Education, 32 (5), 541-556.

Robertson, J., \& Blackler, G. (2006). Students' experiences of learning in a research environment. Higher Education Research \& Development, 25(3), 215-229.

Robertson, J., \& Bond, C. (2001). Experiences of the relation between teaching and research: What do academics value? Higher Education Research and Development, 20(1), 5-19.

Robertson, J., \& Bond, C. (2005). The research/teaching relation: A view from the 'edge'. Higher Education, 50(3), 509-535.

Rowland, S. (1996). Relationship between teaching and research. Teaching in Higher Education, 1(1), 7-20.

Schapper, J. \& Mayson, S. E. (2010). Research-led teaching: moving from a fractured engagement to a marriage of convenience. Higher Education Research and Development, 29 (6), 641-651.

Schwandt, T. (2007). The sage dictionary of qualitative inquiry. Los Angeles: Sage Publication.

Scott, P. (2002). Let's stop trying to separate the inseparable. Exchange, Issue 3, 27-29.

Shamai, S. \& Kfir, D. (2010). Research activity and research culture in academic teachers' colleges of Israel. Teaching in Higher Education, 7 (4), 398-410.

Sloper, D. (1999). Higher education in Cambodia: The social and educational context for reconstruction. Bangkok: UNESCO PROAP. 
Smart, W. (2009). The impact of the performance-based research fund on the research productivity of New Zealand universities. Social Policy Journal of New Zealand. Issue 34, 136-151.

Smith, L. (2008). Ethical principles in practice: evidence from participatory. KAIRARANGA, Volume 9, Special Edition: 2008. Retrieved from http://www.eric.ed.gov/PDFS/EJ908179.pdf

Stake, R. (2008). Qualitative case studies. In N. Denzin \& Y. Lincoln (Eds.), Strategies of qualitative inquiry ( ${ }^{\text {rd }}$ ed.). (pp.119-150). Los Angeles: Sage Publication.

Teaching-Research Nexus, (2009). Benefits for Students. Retrieved from http://trnexus.edu.au/index.php?page=benefits-for-students.

Tertiary Education Commission. (2010). Performance-Based Research Fund Quality Evaluation Guidelines 2012. Wellington: Crown

The University of Auckland. (2010). Commentary on issue of higher education and research. The Publication of the Office of Vice-chancellor, Issue 3, 1-4.

Trowler, P., \& Wareham, T. (2008). Tribes, territories, research and teaching: Enhancing the teaching-research nexus. York: The Higher Education Academy.

Willison, J., \& O’ Regan, K. (2006). Research skill development framework. Retrieved from http://www.adelaide.edu.au/clpd/rsd

Yin, R. K. (2009). Case study research: Design and methods (4 ${ }^{\text {th }}$ ed.). Los Angeles: Sage Publication.

Yin, R. K. (2003). Case study research: Design and methods. California: Sage Publication.

Zamorski, B. (2002). Research-led teaching and learning in higher education: a case. Teaching in Higher Education, 7 (4), 411-427.

Zetter, R. (2002). Teaching-research: Making the department link. In M., Healy and A. Jerkins (Eds). Exchange. Issue 3. 


\section{Appendix A: Invitation Email to Participate in Research}

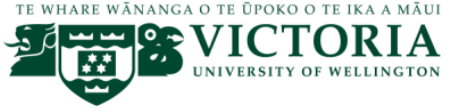

\section{Faculty of Education}

\section{Invitation Email to Participate in Research}

Dear [insert program/ faculty] Lecturers

I am Sovannden Moeung, a Master of Education student at Victoria University of Wellington, New Zealand. I am conducting a research focusing on research-led teaching in Cambodian and New Zealand higher education. This research aims to offer some valuable insights on the importance of the roles of research in informing teaching and student learning; and would be significant in contributing to the literature on researchled teaching in higher education in Cambodia and New Zealand. If you have any queries about the research or the way the research is being conducted, please feel free to contact me or my supervisors: Mike Taylor (mike.taylor@vuw.ac.nz) and Dr. Liz Jones (liz.jones@vuw.ac.nz). This research has been approved by the Victoria University of Wellington Human Ethics Committee.

To this end, I would like to request your participation in this research study. Your participation would involve a semi-structured interview on the topic which includes your perspective, attitude and experiences of research-led teaching in relation to student learning. Each interview will last up to 60 minutes and will be scheduled at a time and place convenient to your working day.

Finally, it would be very helpful if you could drop me an email to confirm your participation in this study. It is important to note that I am looking for 6 lecturers to participate in this study. However, if there are more than 6 lecturers interested to participate in this study, I would random select the six lecturers from the volunteers. You will be given information sheet and will be asked to sign a consent form once your participant has been confirmed. You can choose to return your consent form by email me or return at scheduled interview.

Yours sincerely

Sovannden Moeung

Email: moeung sovannden@yahoo.com

Mobile Phone: [supplied] 


\section{Appendix B: Research Information Sheet for Cambodia}

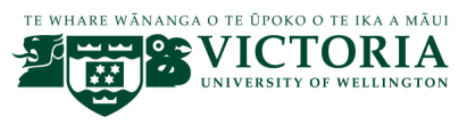

Faculty of Education

\section{Research Information Sheet for Cambodia}

\section{Research-led teaching in higher education: Perspectives of Cambodian and New Zealand Academics}

Dear [insert Name]

I am Sovannden Moeung, a Master of Education student at Victoria University of Wellington, New Zealand. I am conducting a research focusing on research-led teaching in Cambodian and New Zealand higher education. This research aims to offer some valuable insights on the importance of the roles of research in informing teaching and student learning; and would be significant in contributing to the literature on researchled teaching in higher education in Cambodia and New Zealand.

To this end, I would like to request your participation in this research study. Your participation would involve an interview on the topic which includes your perspective, attitude and experiences of research-led teaching in relation to student learning. Each interview will last up to 60 minutes and will be scheduled at a time and place convenient to your working day. The interview can be conducted in English or Khmer based upon your preferred choice. A copy of the interview key themes will be forwarded to you before the interview takes place. The interview will be recorded using a digital audio recording device and will be transcribed by researcher and a transcription company. The company will be asked to sign a confidentiality agreement. Moreover, a copy of the interview transcript will be sent to you for review before analysis begins.

Your participation is voluntary. You are free to refuse to take part in the study at any time after the interview before the process of data analysis, without giving a reason for doing so, and all relevant data and/or information will be destroyed if you decide to withdraw from this research. A notice about the time for data analysis will be given to the participants one week before the actual process of data analysis. If you do decide to participate, you will be given this information sheet to keep and be asked to sign a consent form.

Your identity, or that of your employer, will not be disclosed on any report findings and any information provided will be kept confidential to the researcher and my supervisors. All electronic data or information will be stored in a password-protected file in my personal laptop and will be restricted to the researcher and my supervisors. Also, all data or information obtained from this research will be retained confidentially, and will be destroyed three years after the research is completed by 31 May 2013. The findings of this research will be presented as a thesis in fulfilment of a Master of Education qualification. To this end the thesis will be deposited in the WJ Scott Library, Victoria University of Wellington, New Zealand. In addition, the findings maybe 
submitted for publication in peer reviewed conference proceedings or academic journals. A summary of research findings will be available on request upon the completion of this study.

This research project has been approved by the Victoria University of Wellington Faculty of Education Research Committee and Human Ethics Committee. If you have any queries about the research or the way the research is being conducted, please feel free to contact me or my supervisors: Mike Taylor (mike.taylor@vuw.ac.nz) and Dr. Liz Jones (liz.jones@vuw.ac.nz).

Yours sincerely

Sovannden Moeung

Email: moeung_sovannden@yahoo.com

Mobile Phone: [supplied] 


\title{
Appendix C: Research Information Sheet for New Zealand
}

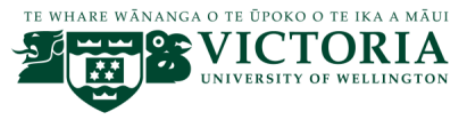

Faculty of Education

\section{Research Information Sheet for New Zealand}

\author{
Research-led teaching in higher education: Perspectives of Cambodian and New \\ Zealand Academics
}

\section{Dear [insert Name]}

I am Sovannden Moeung, a Master of Education student at Victoria University of Wellington, New Zealand. I am conducting a research focusing on research-led teaching in Cambodian and New Zealand higher education. This research aims to offer some valuable insights on the importance of the roles of research in informing teaching and student learning; and would be significant in contributing to the literature on researchled teaching in higher education in Cambodia and New Zealand.

To this end, I would like to request your participation in this research study. Your participation would involve an interview on the topic which includes your perspective, attitude and experiences of research-led teaching in relation to student learning. Each interview will last up to 60 minutes and will be scheduled at a time and place convenient to your working day. A copy of the interview key themes will be forwarded to you before the interview takes place. The interview will be recorded using a digital audio recording device and will be transcribed by researcher and a transcription company. The company will be asked to sign a confidentiality agreement. Moreover, a copy of the interview transcript will be sent to you for review before analysis begins.

Your participation is voluntary. You are free to refuse to take part in the study at any time after the interview before the process of data analysis, without giving a reason for doing so, and all relevant data and/or information will be destroyed if you decide to withdraw from this research. A notice about the time for data analysis will be given to the participants one week before the actual process of data analysis. If you do decide to participate, you will be given this information sheet to keep and be asked to sign a consent form.

Your identity, or that of your employer, will not be disclosed on any report findings and any information provided will be kept confidential to the researcher and my supervisors. All electronic data or information will be stored in a password-protected file in my personal laptop and will be restricted to the researcher and my supervisors. Also, all data or information obtained from this research will be retained confidentially, and will be destroyed three years after the research is completed by 31 May 2013.

The findings of this research will be presented as a thesis in fulfilment of a Master of Education qualification. To this end the thesis will be deposited in the WJ Scott Library, Victoria University of Wellington, New Zealand. In addition, the findings may be submitted for publication in peer reviewed conference proceedings or academic journals. A summary of research findings will be available on request upon the 
completion of this study.

This research project has been approved by the Victoria University of Wellington Faculty of Education Research Committee and Human Ethics Committee. If you have any queries about the research or the way the research is being conducted, please feel free to contact me or my supervisors: Mike Taylor (mike.taylor@vuw.ac.nz) and Dr. Liz Jones (liz.jones@vuw.ac.nz).

Yours sincerely

Sovannden Moeung

Email: moeung_sovannden@yahoo.com

Mobile Phone: [supplied] 


\section{Appendix D: Consent form for Cambodian Participants}

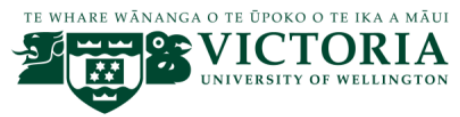

Faculty of Education

\section{Consent form for Cambodian Participants}

Research Title: Research-led teaching in higher education: Perspectives of Cambodian and New Zealand Academics

(This research has been approved by the Victoria University of Wellington Human Ethics Committee)

Please confirm your consent to participate in this research by placing a tick in the relevant boxes below:

I have read the information sheet and will keep it for my records. I have been given an opportunity to ask further questions related to this research and have them answered to my satisfaction.

I agree to participate in a semi-structured interview for this study, which last for 60 minutes and I understand that I can choose to speak English or Khmer during the interview.

I understand that my participation in this research is voluntary and that I am free to decline to answer any particular questions or to withdraw from the interview during or after data collection period.

I agree that my conversation will be audio-recorded and this recorded data will be kept in a password secured laptop and destroyed three years after the completion of the research.

I understand that I will receive a copy of the interview key themes one week before the interview take place.

I understand that my identity and my institution identity will not be disclosed in any report of this study.

I understand that I will have an opportunity to review a transcript of the interview.

I would like a copy of summary findings when research is completed. Yes / No (please circle)

Please sign and return the consent form to the researcher at the scheduled interview or through this email: moeung_sovannden@yahoo.com

\section{Participant}

Name:

Signature:

Date: 


\title{
Appendix E: Consent form for New Zealand Participants
}

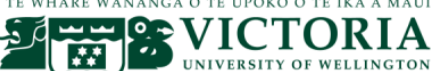

\section{Faculty of Education}

\author{
Consent form for New Zealand Participants \\ Research Title: Research-led teaching in higher education: Perspectives of Cambodian \\ and New Zealand Academics
}

(This research has been approved by the Victoria University of Wellington Human Ethics

Committee)

Please confirm your consent to participate in this research by placing a tick in the relevant boxes below:

I have read the information sheet and will keep it for my records. I have been given an opportunity to ask further questions related to this research and have them answered to my satisfaction.

I agree to participate in a semi-structured interview for this study, which last for 60 minutes.

I understand that my participation in this research is voluntary and that I am free to decline to answer any particular questions or to withdraw from the interview during or after data collection period.

I agree that my conversation will be audio-recorded and this recorded data will be kept in a password secured laptop and destroyed three years after the completion of the research.

I understand that I will receive a copy of the interview key themes one week before the interview take place.

I understand that my identity and my institution identity will not be disclosed in any report of this study.

I understand that I will have an opportunity to review a transcript of the interview.

I would like a copy of summary findings when research is completed. Yes / No (please circle)

Please sign and return the consent form to the researcher at the scheduled interview or through this email: moeung_sovannden@yahoo.com.

\section{Participant}

Name:

Signature:

Date: 


\section{Appendix F: Key Themes for Interview}

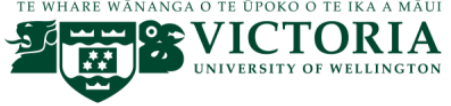

\section{Faculty of Education}

\section{Key Themes for Interview}

The following key themes will be the focus of the interview. The questions for the interview will be developed based on these key themes. The interview will last up to an hour.

1. Introductory questions that seeks demographic detail

2. Lecturers' understanding of the key term " research-led teaching"

3. Lecturers' perceptions, attitudes and experiences towards research-led teaching

4. Lecturers' perceptions of the impacts and benefits of research-led teaching to/ for student learning

5. Lecturers' perceptions of the supports and challenges of research-led teaching in their institution

6. Lecturers' suggestions/recommendations about successful research-led teaching. 


\section{Appendix G: Interview Protocol}

\section{Faculty of Education}

\section{Interview Protocol}

\section{Starting}

- Greeting

- Researcher introduces herself, the purpose of research, collects signed consent form from the participants, reminds about voice recording

\section{Background information}

- Could you tell me about your job here?

- How long have you worked here?

- Is this your first job as a university academic?

\section{Lecturers' understanding about the term "research-led teaching"}

- What do you understand about research led teaching?

- What sort of things and who should involve in research-led teaching?

- Do you think reading other people research to inform our teaching is also called research-led teaching?

- Do you think it is a research led teaching or not when the academic try to engage his or her students in the research to inform his or her teaching?

- Do you think academic engage themselves in research is research-led teaching?

\section{Lecturers' attitude and practices towards research-led teaching}

- Do you conduct research to inform your teaching? (Why / Why not?)

- If yes, could you tell me about a recent or current research project that informs your teaching?

- How/ In what ways do you use your research to inform your teaching?

- To what extent do you read other people research to inform your teaching? (Why/ Why not?)

- How/ In what ways do you use other people's research to inform your teaching?

- To what extent do you encourage your student to participate in your research to inform your teaching? (Why/ Why not?)

- How/ In what ways do you engage yours student in research to inform your teaching? 
- What do you think about the practice of research-led teaching in your institution?

- Is research-led teaching common practice in your discipline or a new idea for your discipline? (Could you tell me more about it please?)

- Is it the requirement for you or this discipline towards research-led teaching? (Could you tell me more detail about this requirement? / Could you give me an example of this requirement?)

- Is research-led teaching an essential required part of the university? How important it is?

\section{The impacts of research-led teaching on teachers and students}

- In your opinion, what are the positive impacts of research-led teaching on teaching (teachers) and learning (students) in higher education?

- Are there any negative impacts on teachers and students? If yes, could you tell me a bit about the negative impacts of research-led teaching on students and teachers?

\section{The personal or institutional challenges for research-led teachers}

- What are your personal challenges that you come across in regards to researchled teaching?

- Are there any institutional challenges? (What are they?)

\section{The support for teachers in doing research to inform teaching}

- Are there any supports for teachers to conduct research while teaching?

- If yes, what are those supports?

- How do you feel/ what do you think about those supports?

- For example, if there are no support available, do you wish to do research to inform your teaching?

\section{Suggestion/ recommendations about successful research-led teaching}

- What suggestions/ recommendation would you give to a colleague who just start in research-led teaching or who wants to become a successful research-led teacher?

- What would you suggest/recommend to improve research-led teaching in your discipline?

\section{Closing}

- Would you like to add anything we have mentioned earlier?

- Do you have any other comments?

- Many thanks for your time and useful information. 


\section{Appendix H: Letter of Ethic Approval}

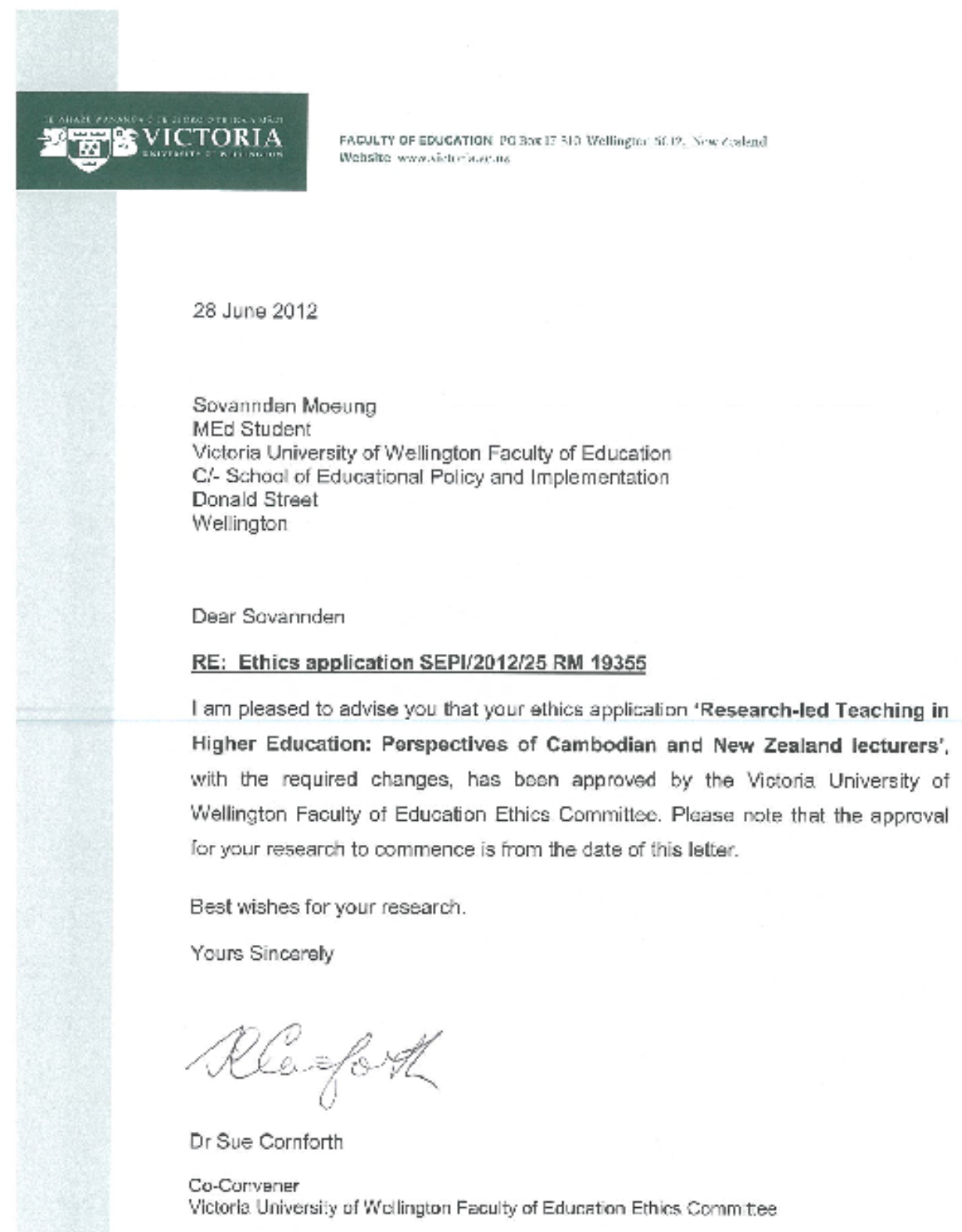




\section{Appendix I: Confidentiality Agreement}

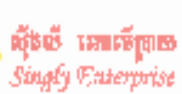

Address: \#1358, Strect 286. Samgkal Toul Svay Prcy 2,

Chamcamon. Phnom Penh, Cambodia

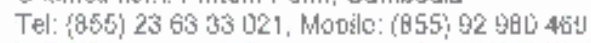

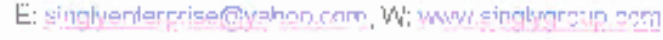

\section{CONFIDENTIALITY AGREEMIE.YT}

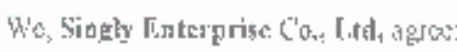

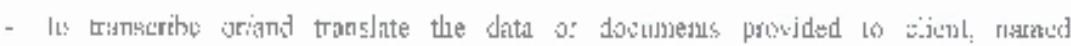

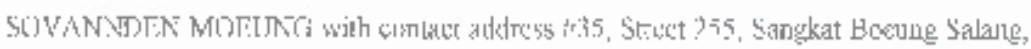

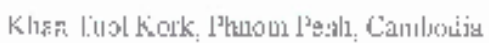

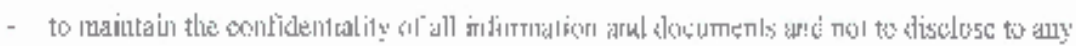

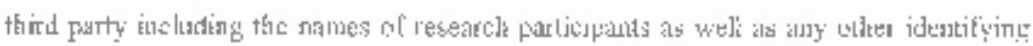

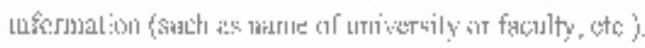

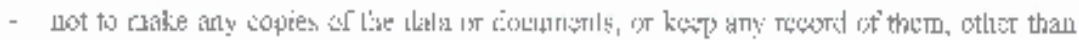

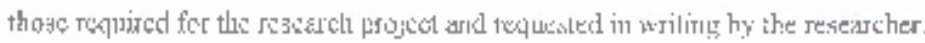

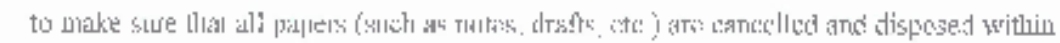

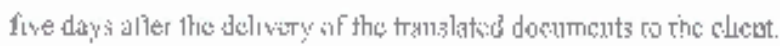

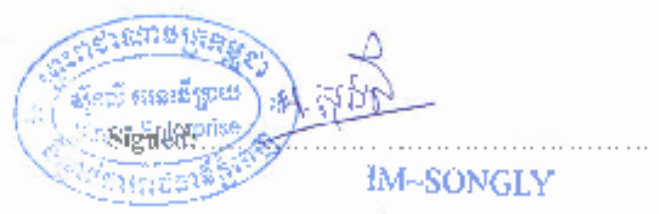

Dute: 30 A AmIs! 2012 